\title{
SARS-CoV-2 mechanisms of action and impact on human organism, risk factors and potential treatments. An exhaustive survey.
}

\author{
Belén Carro ${ }^{1}$.
}

\begin{abstract}
Novel COVID-19 is the most considerable health threat the humanity has faced in decades, with global impact also in the social and economic scopes. Moreover, SARS-CoV-2 involves an unprecedented exciting scientific challenge that has focused all efforts on defeating the new coronavirus. Research results are continuously increasing and updating knowledge about the virus and the disease, and understanding the virus characteristics proves essential in order to identify and attack its weak points, as well as uncovering the host reactions to search for treatments. Through this survey we will offer the reader a thorough exposition on how SARS-CoV-2 infects and affects the human organism, the wide set of risk factors that impact the susceptibility to and the course of the disease, related biomarkers, and potential drugs and treatments against the virus host entry, the infection and its consequences. What has been learned over one and a half year is expected to help in facing future global health threats.
\end{abstract}

Keywords-SARS-CoV-2, COVID-19, infectious disease, pandemic, treatment.

\section{INTRODUCTION}

If you were an external observer of the Earth, you would perceive that the power of nature and the human mind rule the world. The current COVID-19 pandemic implies a fascinating time and health pressing complex challenge for both and some kind of imbalance that favors nature. At least up to now.

SARS-CoV-2 is a novel Betacoronavirus (1) from the Coronaviridae family, responsible of the COVID19 disease, that was first informed by the WHO in early 2020 and is currently active representing a global health threat in the form of pandemic. The sudden appearance of SARS-CoV-2, its incredibly fast spread across the planet, and the lack of specific treatments for COVID-19 or vaccines to prevent the disease along 2020 has originated a huge worldwide impact (2) in terms of human lives loss -which by June 2021 is approaching a dreadful four million-, of people affected by the disease, and, consequently, of an unprecedented international economic crisis that is shaking the foundation of our civilization in the $21^{\text {st }}$ century.

Only several months after the COVID-19 pandemic appearance, there are some issues that we certainly know, many that are continuously being discovered, but still others yet to be uncovered that prevent us from definitely knocking down this nightmare. We know for sure we are facing a virus which is a close relative of former severe acute respiratory syndrome coronavirus (SARS-CoV), that infects us through our respiratory tract, entering the organism via our mouth or nose, and that spreads quick and easily with a relatively low lethality rate. We also know that many infected never develop any symptom (asymptomatic), that elderly people are more severely affected, males to a large extent, and that rarely children are seriously impacted. We have discovered that SARS-CoV-2 is able to infect through the air, by droplets but also aerosols expelled when breathing, talking and principally shouting and singing, mainly in poorly ventilated indoor environments. That some previous pathologies are associated with worst prognosis, such as cardiovascular diseases (mostly hypertension), obesity or diabetes, as well as some biomarkers and genetic factors. That the majority of deaths are caused by an inadequate overreacted immune response to the pathogen. And not only the lungs but many other organs are affected and suffer from inflammation and severe vascular problems, not to mention COVID-19 persistent symptoms. That old well-known elementary physical measures like hands washing, face masks and social distance do help in avoiding infection or spreading of the virus when strictly implemented. That though diagnostic tests are rapidly evolving, they have room for improvement in sensitivity, in auto diagnosis capabilities and price, so that they can constitute a pivotal role in early isolating the infected and stopping the spread of the disease. That the nonadoption of security measures pursuing to reach a herd or population immunity, at the cost of many lives

${ }^{1}$ Author is with the Department of Signal Theory and Communications. Universidad de Valladolid. Campus Miguel Delibes, 47011, Valladolid, Spain (email: belen.carro@uva.es).

(C) 2021 by the Author. Distributed under a CC-BY 4.0 International license. 
in some kind of natural selection process is not scientifically supported and has proven to be a resounding failure in countries like Sweden.

And... and there is still no silver bullet treatment against COVID-19, but the long awaited vaccine is here (3) (4) (5) (6) (7) (8) (9) (10). Early in the pandemic several possible antiviral treatments were expected to avoid severe COVID-19 complications and even fatal outcomes in the short term, what could have saved thousands of lives. Nevertheless, none of them has demonstrated significant efficacy up to now, moreover, they would have not been able to stop the course of the pandemic (contagions) nor avoid the unexpected subsequent complications that may appear even in mild or asymptomatic patients. Therefore, the vaccine against COVID-19 is indispensable. As of December 2020, several pharmaceutical companies had already developed their vaccines in record time of less than one year. This is a really impressive achievement and will surely constitute a scientific milestone, that will trigger a new era for the development of vaccines to fight other critical diseases. However, the end is near but not so straightforward (aside from phase IV clinical trial results): most of the world population needs to be vaccinated -with a percentage that depends on the contagiousness of the dominant variants- to theoretically reach the herd immunity and successfully finish the pandemic (with all the broad implications this requirement poses), but also to avoid potentially dangerous SARS-CoV-2 mutations that may arise if the virus is widely spread, and that could even affect the effectivity of the vaccine; this herd immunity would only be achieved with sterilizing vaccines, that protect the vaccinated from infection and therefore also the non-vaccinated: transmission of the infection might not be avoided with an intramuscular vaccine since mucosal immunity is not ensured in all cases (3); moreover, sterilization may be jeopardized due to decreased immune response and viral evolution over time. Reinfected vaccinated (with a non-sterilizing solution) individuals could still transmit the infection but to a lower extent, during a narrow transmission window that spans from infection until neutralization by a quick immune response that has previously faced the antigen. In the end, it is a matter of probability: of contagion, of transmission, of severity, of vaccine side effects, of vaccine effectiveness, of virus mutations... and this game of probabilities has a direct impact on people's behavior and in turn again on the pandemic evolution.

Knowledge about the virus and the disease is continuously growing and evolving, with some studies and trials even offering contradictory results, so our vision of the problem should not be strict but open to new hypothesis, suggestions, and heterodox discussion. In this paper, we will try to dissect the challenging problem that SARS-CoV-2 constitutes from a scientific point of view, offering an extensive and referenced review with the aim of shedding light over questions we all have in mind, and also over some deeper queries. With the hope that what we are learning during this extreme situation helps to better confront future global health problems.

\section{THE PROBLEM STATEMENT}

Elderly affected by a more severe COVID-19 fall within what could be expected. But why do male patients present higher rates of critical illness and lethality than females? Why do children providentially barely suffer severe COVID-19 unlike what happens with other common cold coronaviruses or even influenza? What triggers the cytokine storm? What is the cross-reactivity and how can it affect the disease? What kind of drugs are being tested against the viral infection and the overreacted immune response? Are virus mutations and their effects predictable? Is there a reason for the counterintuitive low rate of asthmatic patients, or smokers? Do host genetics have any influence on the course of the disease? And our microbiota? Are antibodies essential for fighting the infection, or could they even act against the organism? Do food supplements like vitamin D or zinc show any benefit?... Many questions arise, and we will try to approach valid answers keeping in mind that biology is not (yet) infallible mathematics.

The paper is structured as follows. We can contain the SARS-CoV-2 threat in several ways, first of all, by avoiding infection and consequently, spreading of the disease. This is an essential strategy and involves hygienic, social and pharmacological measures to tackle the problem at source. Second, by treating the disease when already infected. Many factors may intervene and influence the course of the infection and therefore multiple treatment candidates arise. We will mark several lines of defense for reaching both objectives. Following, we will analyze relevant COVID-19 risk factors including biomarkers, patient's sex and age, genetic factors, autoimmunity and influence of the microbiota. Next, implications of SARS-CoV2 mutations will be analyzed, and finally, emergent potential treatments will be exposed. A conclusions section will summarize what we have learned and will identify open issues. 


\section{AVOIDING THE INFECTION}

\section{A. First line of defense: physical barriers}

Though SARS-CoV-2 is a novel virus, it presents several characteristics shared with other known coronaviruses like SARS(-CoV) or MERS. Also, the understanding of the virus has grown quickly since its appearance. However, as knowledge expands it becomes more evident that too many aspects related to the SARS-CoV-2 biology and impact in human health still remain unknown. Here we can humbly adopt Socrates saying, "I know that I know nothing".

The main entry of the SARS-CoV-2 in our organism is via the respiratory airways through our nose and/or mouth. Probably, the eye mucous membrane is another point of entry, however there is currently no strong evidence but the intuitive logical affection when droplets directly impact the eye. Also, it is already proven that, apart from droplets and fomites, aerosols are one, if not the most relevant SARS-CoV-2 transmission factor (11) (12). We could even think of this way of contagion as fortunate since protective measures are possible and even straightforward. Therefore, a physical barrier covering nose and mouth is the first solution to think of, and this is not new: this was already the case early in the 20th century when the erroneously called Spanish influenza in 1918 devastated the world causing millions of deaths. Hands washing and social distance complement the current-old measures to keep the virus away. However, face masks used by general population are not perfect due to loose fit, overuse and fabrics with variable permeability to virus penetration. Only respirators or personal protective equipment prevent the wearer from inhaling aerosols (including the aerosol transported SARS-CoV-2) and gases. In Europe, they must meet the European standard EN 149: 2001 that consists of three classes of disposable particulate respirators: FFP1, FFP2 and FFP3, depending on the percentage of filtration. FFP3, with a minimum filtration percentage of 99, is not usually available for consumers and is restricted to sanitary personnel dealing with patients. Since a physical barrier is the easiest and safest solution, we believe effort should have been put on providing FFP3-like protective face masks to the population at an affordable price. New generation electronic masks are beginning to appear. Think that if every person in the world wore a really protective face mask for several weeks each time out of home or in any potentially infectable situation, SARS-CoV2 would have soon been history (skipping other issues like social eating or even pets possibility of transmission (13) (14)).

\section{B. Second line of defense: preventing the virus from entering the cells}

Viruses need the (transcription and) translation host cell machinery to replicate. SARS-CoV-2 would not cause infection in humans if binding to the ACE2 receptor was avoided. Several choices co-opt to reach this aim.

\section{$i$. The human innate immune system}

Even tiny bacteria have an immune system. The human immune system exhibits a very high complexity and is still not fully understood. The immune system consists of innate and adaptive branches, that interact together. The innate part attacks first and may handle up to $99 \%$ of infections. It consists mainly of physical and chemical barriers, phagocytic cells like neutrophils and macrophages, dendritic cells, natural killer cells, and the complement system. If it fails, the adaptive branch is called, and specific T lymphocytes (or $\mathrm{T}$ cells) and antibody-producing B lymphocytes (or B cells), among other cells and mechanisms, enter into action (15).

Many pathogens exhibit glycoproteins and glycolipids on their surface, named pathogen-associated molecular patterns or PAMPS, that enable some innate cells like monocytes, macrophages and dendritic cells to recognize them as foreign. Pattern recognition receptors (PRRs) located inside and outside the cell, like toll-like receptors (TLRs like intracellular TLR7 involved in detecting SARS-CoV-2) bind to the PAMPs, and start processing the exogenous microorganism. Consequent activation of downstream transcription factors like interferon regulator factors (IRFs) and nuclear factor $\kappa \mathrm{B}(\mathrm{NF}-\kappa \mathrm{B})$ occur, inducing type I and III interferons (IFN-I and IFN-III) and IFN-stimulated genes (ISGs) activity, as well as chemokine secretion to recruit leukocytes (16) such as macrophages and dendritic cells, that bridge both the innate and adaptive systems, and release cytokines that enroll other macrophages and dendritic cells to destroy the microbes through the inflammatory response (Figure 1). T cells and B cells from the adaptive system can also be activated (17) (18). IFNs are one of the main weapons the innate immune system raises, warning the neighboring cells of the presence of the pathogen in order to stop their own protein synthesis, and therefore the virion (the complete extracellular infectious viral particle) replication. IFNs signal through the JAK-STAT pathway and induce the transcription of ISGs, which generate antiviral functions and reinforce the immune system by further inducing IFNs or ISGs, however some genes may facilitate viral 
replication. Type I (IFN- $\alpha / \beta)$ and type III (IL-28A, IL-28B, IL-29) IFNs are antiviral, though type II IFN $($ IFN- $\gamma$ ) has antiviral properties too. Each IFN induces a unique set of ISGs (19).

\section{Innate Immunity}

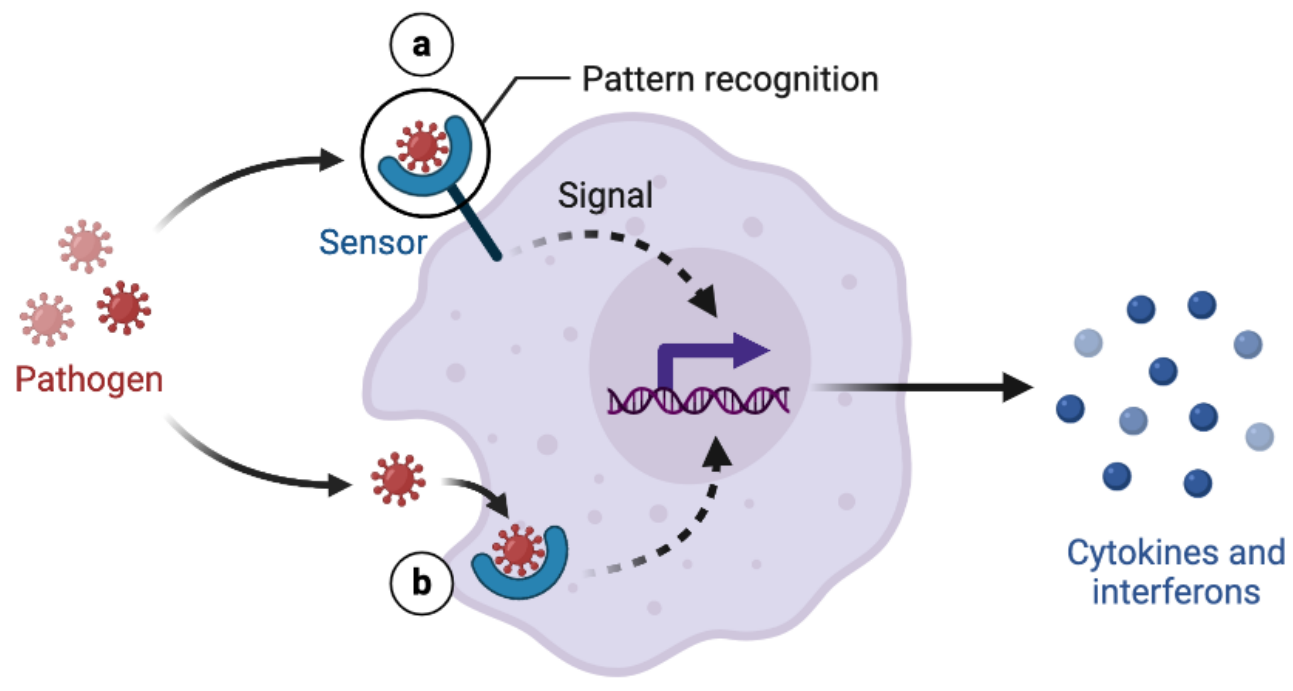

Figure 1. In innate immunity, sensors outside and inside a cell detect unusual molecules (e.g. from pathogens like viruses) through pattern recognition receptors (PRR), triggering immediate alarm through the secretion of cytokines and interferons. (Reprinted from "Innate Immunity", by BioRender, June 2020, retrieved from https://app.biorender.com/biorender-templates/Copyright 2021 by BioRender).

Cells from the immune system communicate with each other and coordinate by releasing cytokines (20) (18) (21) (22), chemical substances that are captured by specific surface cell receptors. Cytokines are small signaling proteins or glycoproteins that modulate both innate and adaptive immune responses, inflammation, and hematopoietic cell proliferation and differentiation. The two principal producers of cytokines are a kind of $\mathrm{T}$ cells (helper $\mathrm{T}$ cells) and macrophages, although any nucleated cell may act as secretor. Cytokines can be proinflammatory or anti-inflammatory. Proinflammatory cytokines induce fever and inflammation responding to infection or tissue injury, examples include interleukins (IL) 1, 6, 8, 12, and 18; interferons (INF); and tumor necrosis factor (TNF). Anti-inflammatory cytokines such as IL-4, $10,-11$, and -13; and transforming growth factor-beta (TGF- $\beta$ ) suppress the immune system. Receptor engagement triggers intracellular signaling cascades that alter gene expression in the target cell, causing biological effects like differentiation, proliferation or activation.

SARS-CoV-2 has the ability to escape the host immune surveillance, avoiding initial recognition by PRRs, dysregulating IFN responses by some IFN-antagonizing non-structural proteins (nsps, components of the viral replication /transcription complex, expressed in infected cells but not conforming the virion particle), or directly activating the NF- $\kappa \mathrm{B}$ pathway by the $\mathrm{N}$ protein. Very low amounts of IFNs have been found in the peripheral blood or lungs of severe COVID-19 patients, though IFN activity has been found in alveoli of some patients (23).

Therefore, IFN administration has been proposed for antiviral treatment, also against SARS-CoV-2. Some studies point to ACE2 as a human ISG, suggesting that SARS-CoV-2 could exploit species-specific IFN- $\alpha$-driven upregulation of ACE2 in human upper airway epithelial cells (IFN- $\gamma$ would be responsible in the case of enterocytes in the gastrointestinal mucosa), that induces tissue protection during lung injury, to enhance infection (24) (25). However, recent research shows that IFN I, II and III actually induce a short transcript of ACE2, an isoform -proteins encoded by the same gene that may exert different biological roles- unable to bind SARS-CoV-2 spike protein that might have an antiviral effects. In that respect, cytokines could be responsible of long ACE2 induction (26).

In this respect, therapies administering IFN should consider the correct dose and time of infection, as well as the specific patient features, to avoid any unwanted outcome. On the other side, severe and critical patients show a unique phenotype consisting of absence of IFN- $\beta$ and few IFN- $\alpha$ with low activity, along with a lingering blood viral load and a disproportionate inflammatory response, to some extent lead by the transcriptional factor NF- $\kappa$ B and characterized by augmented TNF- $\alpha$ and IL- 6 production and signaling (27). Also, and strikingly, high titers of neutralizing autoantibodies against type I IFN have been discovered in around 10\% of severe COVID-19 pneumonia patients, mostly aged men (28). Type III IFNs signal through a receptor complex whose expression is limited to epithelial cells and a group of immune cells like

(C) 2021 by the Author. Distributed under a CC-BY 4.0 International license. 
neutrophils, so a therapy relying on type III IFN administration would induce ISGs restricted to epithelial cells, thus lowering side effects and inflammation linked with the systemic action of type I IFNs (29).

It is worth mentioning the possible neutrophils role in COVID-19. These innate immune cells kill pathogens by oxidative burst, phagocytosis and NETs (Neutrophil Extracellular Traps), complexes of DNA and proteins forming a web released by the neutrophil. Under a cytokine storm where inflammation factors are widely present, NETs may induce macrophages to secrete IL-1 $\beta$, which in turn enhances NET formation, forming a noxious loop that might promote microthrombi and aberrant immune responses (30).

\section{ii. $\quad$ Cellular virus entry blockade}

Our complex immune system includes B cells that produce antibodies which target antigens present in pathogens like viruses. An epitope is a fragment of an antigen (a foreign or mutated self- protein able to induce an immune response) that is bound by antibodies or B/T cells receptors. Many of the designed vaccines against SARS-CoV-2 are focused on stimulating the immune system to generate neutralizing antibodies that bind epitopes present in the receptor-binding domain (RBD) of the virus spike protein, therefore avoiding the spike binding to the ACE2 receptor. However, among the SARS-CoV-2 strategies trying to evade the immune system monitoring, RBD hiding or folding is found, in a way that RBD stochastically swings upwards to offer the ACE2 binding site (31). Also, preactivation of the spike via the furin enzyme enhances SARS-CoV-2 entry the host cell. Additionally, cell surface protease TMPRSS2 and lysosomal cathepsins activate SARS-CoV-2 entry and they both help furin in gaining access to the cell (32). Therefore, drugs capable of blocking furin, the ACE2 receptor, the TMPRSS2 or the lysosomal cathepsins should be contemplated (33) (34) (35) (36), always with caution since these host cell elements may be essential for other activities. For example, ACE2, present in cells of many organs such as the lungs, heart, kidney, testis, large conduit arteries or intestines (37), is critical in lowering blood pressure by reducing the amount of angiotensin-II (vasoconstrictor) and increasing angiotensin (1-7) (vasodilator). Besides, patients suffering from diabetes or hypertension have ACE2 expression increased, and they are treated with angiotensin converting enzyme (ACE) inhibitors and angiotensin II type-I receptor blockers (ARBs) that increase ACE2 expression and therefore maybe also virus infection, however further research on this possibility is required (38) (39) (40) (41). The same is applicable to the host cell factor TMPRSS2, associated with physiological and pathological processes including digestion, tissue remodeling, fertility, blood coagulation, inflammatory responses, tumor cell invasion and apoptosis.

Despite the virus entry through the ACE2 receptor is undoubted, it is worth mentioning that other receptors might be helping SARS-CoV-2 entering the host cell. On the one hand, the expression pattern of ACE2 does not exactly match tissue tropism of SARS-CoV-2. On the other hand, there exist numerous human neutralizing antibodies that bind the spike but not the RBD. A recent study suggests that the tyrosineprotein kinase receptor UFO (encoded by AXL gene) is essential in facilitating the respiratory system infection, what would point to other potential treatments against SARS-CoV-2 (42).

Potential treatments against virus entry (33) (34) (35) (36) (43) include hrsACE2, a recombinant (genetically modified) soluble form of ACE2, and arbidol targeting ACE2; camostat mesilate, type 1 plasminogen activator inhibitor (PAI1) and nafamostat, serine protease inhibitors, and bromhexine hydrochloride, a mucolytic drug, targeting TMPRSS2; and monoclonal and recombinant antibodies targeting furin protease (44). Arbidol, in fact, may interact with several steps of the virus life cycle (45), showing a broad-spectrum efficacy (46) (47) (45). Also worth mentioning, hrsACE2 is able to neutralize the SARS-CoV-2 by binding the spike protein mimicking ACE2, but also to reduce noxious angiotensin II concentrations (48).

\section{iii. $\quad$ Antibodies and aptamers}

An antibody is a type of immunoglobulin, a protein made by B cells (49). When an antigen binds to the B-cell surface, the B cell, with the help of a type of T cell (helper T cell) undergo clonal proliferation and differentiation. The differentiated B plasma cells secrete millions of antibodies into the bloodstream and lymphatic system, where they may permeate the other body fluids, and bind to and only to the specific antigen that stimulated their production. With this binding, the antibody helps destroying the antigen, either directly (neutralizing antibody) or indirectly, marking the antigen to help other white blood cells and activate the complement system (a circulating proteins complex that act in cascade and help in eliminating pathogens).

Regarding antibodies response to SARS-CoV-2 there are still many open issues. Some studies have shown that antibody responses seem to wane after infection with some coronaviruses including SARS$\mathrm{CoV}-2$, though latest studies suggest long-lasting antibody immunity (50) (51) (52). Concretely, it has been proven that over $90 \%$ of more than 30,000 mild COVID-19 patients develop robust immunoglobulin G ( $\mathrm{IgG}$ ) antibodies against the spike protein (neutralizing antibodies), that last for at least five months (53). Also, mucosal IgA show potent neutralizing activity in early stages of the infection (54).

(C) 2021 by the Author. Distributed under a CC-BY 4.0 International license. 
Besides, it has been demonstrated that in mild convalescent COVID-19 patients, serum IgG antibodies against the spike exhibit a falling slope that smooths from month four to eleven after infection, when these IgG are still detected. This is compatible with antibodies being initial and profusely generated by shortlived plasmablasts, and subsequently by long-lived bone marrow plasma cells (BMPCs). BMPCs together with memory B-cells (MBCs), that quickly differentiate into antibody-secreting cells and form new germinal centers if second exposure to antigen occurs, then contribute to the humoral immune response against SARS-CoV-2. However, the neutralizing profile of the measured antibodies in this study is not known (55).

In symptomatic and, to a slightly lesser extent, asymptomatic COVID-19 patients, antibodies exhibit not only neutralizing capabilities, hindering the SARS-CoV-2 entrance in the host cells, but are also able to activate complement through the complement-dependent cytotoxicity (CDC), and kill infected cells via the antibody-dependent cellular cytotoxicity (ADCC) that turn on natural killer (NK) cells. It is possible that asymptomatic patients exert a quick IgA response to control the virus that, in turn, impacts a posterior lower antibody response (56).

\section{a) Monoclonal antibodies}

Monoclonal antibodies (mAb) are identical immunoglobulins, generated from a single B-cell clone (57). These antibodies recognize and bind unique epitopes on a single antigen. The epitope is a specific part of the antigen (which has several different epitopes) recognized by antibodies and T cells. Therefore, we can think of identifying the main epitopes of the antigens present in the virus (the spike and the nucleocapsid are the most immunogenic proteins in SARS-CoV-2 (58)), and develop monoclonal antibodies against them.

Many tools currently exist for predicting B cell and T cell epitopes (59) (60). For example, EpiVax has computational tools to predict epitopes, then manufactures synthetic amino acid peptides that mimic the epitopes of the virus, and finally tests the reactivity of these synthetic peptides in blood samples from COVID-19 recovered patients, since their blood -especially if recently recovered- most likely contains immune cells and antibodies that recognize the antigenic epitopes of the virus (61). Also, some neutralizing monoclonal antibodies binding to specific epitopes have already been identified, such as 47D11 that binds a conserved epitope on the spike RBD, and therefore is able to cross-neutralize both SARS-CoV and SARSCoV-2 (62). Or (the double discovery of) two human mAbs cloned from RBD-specific memory B cells isolated from recovered COVID-19 patients, that are able to block the interaction between SARS-CoV-2 RBD and ACE2 receptor, therefore neutralizing SARS-CoV-2 infection (63) (64). Also, the AstraZeneca's AZD7442 that is under trial (65), or Lilly's LY-CoV555 mAb (a.k.a. bamlanivimab) alone or in combination with LY-CoV016 mAb, which bind different epitopes in the SARS-CoV-2 spike. A trial is testing the ability of this antibody cocktail to reduce the number of patients with persistently high viral load and the hospitalizations (66), and recently bamlanivimab has been authorized by the FDA as treatment for COVID-19 (67). Also in late phase the trials for the Regeneron REGN-COV2, a combination of two neutralizing mAbs (REGN10933 and REGN10987) that bind non-competitively to the RBD of the virus' spike protein, decreasing the probability that mutant viruses or spike variants evade treatment. With the commercial names of casirivimab and imdevimab, both mAbs together have already been authorized by the FDA as treatment for COVID-19 (68). Eli Lilly and AbCellera Biologics have developed LY-CoV1404 (or LY3853113) monoclonal antibody, that has demonstrated resistance to new variants since it binds to a region in the RBD little susceptible to mutations (a reasonably conserved epitope) (69).

Besides monoclonal antibodies, broadly neutralizing antibodies (bnAbs) that target several coronavirus types (also known as cross-neutralizing antibodies) can be synthesized to overcome their low binding affinity. The engineered bnAb ADG-2 is able to approach a highly conserved epitope in the RBD with a different angle, effectively neutralizing SARS-CoV-2 (70).

The Antibody Society offers data from anti-SARS-CoV-2 antibodies in clinical studies (71).

\section{b) Aptamers}

Aptamers are synthetic short, stable single-stranded DNA or RNA oligonucleotides that bind to specific targets including toxins, non-immunogenic targets, metabolites or live cells. Their tertiary structure (3D folding) is responsible for the aptamers' high affinity binding properties. Unlike antibodies, aptamers' smaller size allows for tissue penetration, they are non-immunogenic (do not elicit an immune response, as non-human antibodies do), and they can be more easily stored, produced and delivered (72). A DNA aptamer has shown to inhibit viral infection differently from antibodies, without binding the spike RBD but once the virus has bound the host cell. However, the exact mechanism by which this inhibition is performed is still undiscovered (73). 


\section{iv. $\quad$ Nasal cavity: virus entry, ACE2 presence and nasal administration}

Since the virus penetrates the organism through our respiratory tract, we can easily think of a drug administered with the help of a nasal inhaler. An early blockade of the virus is a crucial strategy since it avoids the invasion of the lower respiratory tract, the spread of the virus throughout the organism and the potentially fatal consequences in the lungs and other organs.

Aptamers and monoclonal antibodies could be potential candidates for a nasal administered treatment; however the latter are large and not very stable, therefore not convenient for an intranasal application. Computer-designed miniproteins, which are easier to produce, more stable and avoid the need for refrigeration, have shown to block SARS-CoV-2 infection as well as monoclonal antibodies. These highaffinity miniproteins compete with ACE2 in binding the SARS-CoV-2 spike RBD, showing potent neutralization of SARS-Cov-2 (74). A similar alternative is bivalent $\mathrm{V}_{\mathrm{H}}-\mathrm{Fc} \mathrm{Ab}$, that binds to the three $\mathrm{S}$ protomers competing with ACE2 and potently neutralizes SARS-CoV-2 (75). Ty1, a single domain antibody fragment derived from an animal binds the RBD with high affinity, avoiding spike to ACE2 attachment (76). Other solutions include the nasal administration of the naturally occurring protein with antiviral properties INF- $\beta$, that may protect the virus infected lung cells. A study administering an inhaled nebulized recombinant INF- $\beta$-1a (SNG001) to COVID-19 hospitalized patients showed greater than one odds ratio and faster recovery (77). Also, stable lipopeptide membrane fusion inhibitors that are inhaled daily have shown fully effective prophylactic properties in ferrets cohabiting with infected individuals, avoiding SARS-CoV-2 transmission (78). Currently, Taffix nasal spray is available on the market, and offers a simpler solution based on a muco-adhesive gel (hydroxypropyl methyl cellulose) that covers the epithelial cells and avoids the virus binding to cell receptors, also creating an acidic microenvironment of pH 3.5 on the nasal mucosa that hinder respiratory viruses, including SARS-CoV-2, from infecting cells. Taffix achieves an odds ratio of 0.22 for SARS-CoV-2 infection (79). Besides, the well-known anticoagulant heparin and its variants exhibit exceptional binding affinity to the spike protein and show promising antiviral activity and low cytotoxicity (80). Of note, it is proven that heparin can also act in dismantling NETs (81).

Though vaccines are out of the scope of this article, there are also projects proposing intranasal administration, such as the single-dose Codagenix COVI-VAC, currently under trial. This vaccine is based on a live attenuated version of SARS-CoV-2, and as such would induce a robust and long-lasting immune response. This interesting approach processes the SARS-CoV-2 genome and inserts silent mutations in order to use codon pairs underrepresented in human cells (but keeping the aminoacids), and as a result the protein translation is deoptimized and slowed down, yielding a great decrease of pathogenesis (82).

We should not forget the mouth cavity as a means of spreading the virus when exhaling air, talking or singing. Oral mouthwashes exhibit antiviral properties against influenza and several coronaviruses such as SARS-CoV-2 (83) (84) (85), and their usual constituent CetylPyridinium Chloride (CPC) has demonstrated its ability to block viral entry, hence decreasing SARS-CoV-2 infectivity (86).

ACE2 is particularly expressed in nasal epithelial cells, besides alveolar epithelial type II cells in the parenchyma (87). Moreover, the majority of ACE2 is localized in the olfactory neuroepithelium (but not present in olfactory neurons), which may explain the anosmia suffered by COVID-19 patients. This picture may also justify nasal administered therapies (88). Neuropilins (NRP) are essential cell surface receptors involved in multiple cellular signaling cascades, also related to many pathological processes, that are profusely expressed in the respiratory and olfactory epithelium, showing highest expression in endothelial cells and in the epithelial cells of the nasal cavity. Besides, NRP-1 give assistance to carrying their binding molecules inside the cell and among cells, penetrating tissues. It has been found that the SARS-CoV-2 spike binds NRP-1, remarkably potentiating SARS-CoV-2 infectivity (89). This would explain the enhanced spreading of SARS-CoV-2 and its infection in cells with low ACE2 expression (in fact, the majority), and could also clarify the COVID-19 anosmia symptom, since both the $\mathrm{S}$ protein and the vascular endothelial growth factor-A (VEGF-A, a pro-nociceptive and angiogenic factor) bind NRP-1, therefore the spike is able to block the VEGF-A-triggered sensory neuronal firing and so silences pain (90). Interestingly, therapies for blocking NRP-1 currently exist (91).

Also, SARS-CoV-2 genetic material and proteins have been found in different parts of the nasopharynx and brain, what would support virus entry via the neural-mucosal interface in olfactory mucosa previous to a possible transport through the olfactory tract towards the central nervous system. In fact, it has been proven that the spike protein S1 subunit is able to cross the blood-brain barrier in mice (92). Moreover, virus found in the cerebellum and the brainstem would suggest additional virus ingress ways, and the latter location could further impact disturbance of the cardiovascular and respiratory systems (93). 


\section{TREATING THE DISEASE}

A. Third line of defense: inside the human host cell

\section{i. $\quad$ SARS-CoV-2 structure and life cycle}

SARS-CoV-2 is an enveloped, positive-sense, single-stranded RNA virus with a large genome comprising 31.3 kilobases, protected by a lipid membrane containing the spike (S), envelope (E) and membrane $(\mathrm{M})$ proteins. The nucleocapsid $(\mathrm{N})$ protein tightly coils and coats the virus genetic code (RNA) (94).

The virus enters the host cell through endocytosis by binding the Receptor Binding Domain (RBD) of its S protein to the Angiotensin-Converting Enzyme 2 (ACE2) receptor, which is present on the surface of several types of human cells such as the membrane of secretory and ciliated cells in nasal mucosa, bronchus, kidney, intestinal tract, pancreas or gallbladder, and in endothelial cells and pericytes in many tissues (95).

Once inside the cell, uncoating undergoes and the genetic code of the virus is released. The cell's translation machinery (the ribosomes) confuses the virus RNA with own messenger RNA (mRNA) and begins translating the main gene of the genome, the replicase, that contains the open reading frames (ORFs) $1 \mathrm{a}$ and $1 \mathrm{~b}$, which express polyproteins ppla and pplab. The polyproteins are proteolytically cleaved and give rise to sixteen non-structural proteins (nsp1-16) needed for viral replication and transcription, starting from the autocleaved main protease Mpro (nsp5, also known as 3CLpro). Some relevant nsps include the papain-like proteinase PLpro (nsp3), the RNA-dependent RNA polymerase RdRp (nsp12) or the helicase (nsp13), that also have other relevant functions to evade the immune system (96). These nsps form the replication-transcription complex that will synthesize a negative RNA strand, from which more positive RNA will be replicated to conform the genetic code of the new synthesized virions, and subgenomic positive mRNAs will be generated and then translated into the new virion proteins. Budding and assembly of the new virions occur at the rough endoplasmic reticulum and the Golgi, and the virions finally exit the cell via exocytosis (97) (Figure 2) (Figure 3).

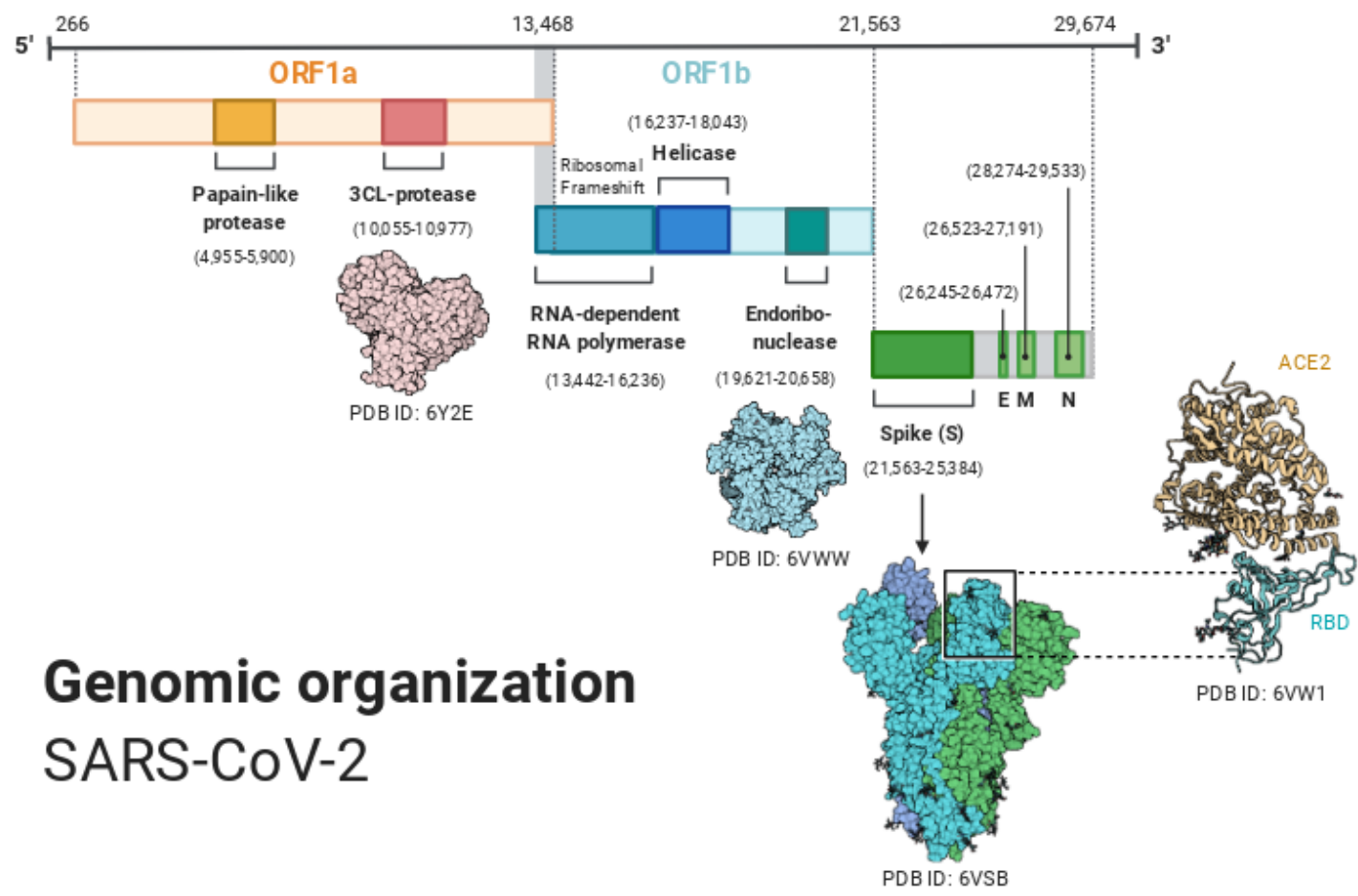

Figure 2 SARS-CoV-2 genome including ORF1a (orange), ORF1b (blue); spike (S), envelope (E), membrane (M), and nucleocapsid ( $N$ ) proteins (green). ORF1ab, the largest gene, includes overlapping ORFs that encode polyproteins ppla and pplab. Non-structural proteins (nsp) PLpro, 3CLpro, endoribonuclease, helicase, and RdRp are shown together with the structural proteins and some 3D protein structures. (Reprinted from "Genomic Organization of SARSCoV-2", by BioRender, March 2020, retrieved from https://app.biorender.com/biorender-templates/Copyright 2021 by BioRender).

(C) 2021 by the Author. Distributed under a CC-BY 4.0 International license. 


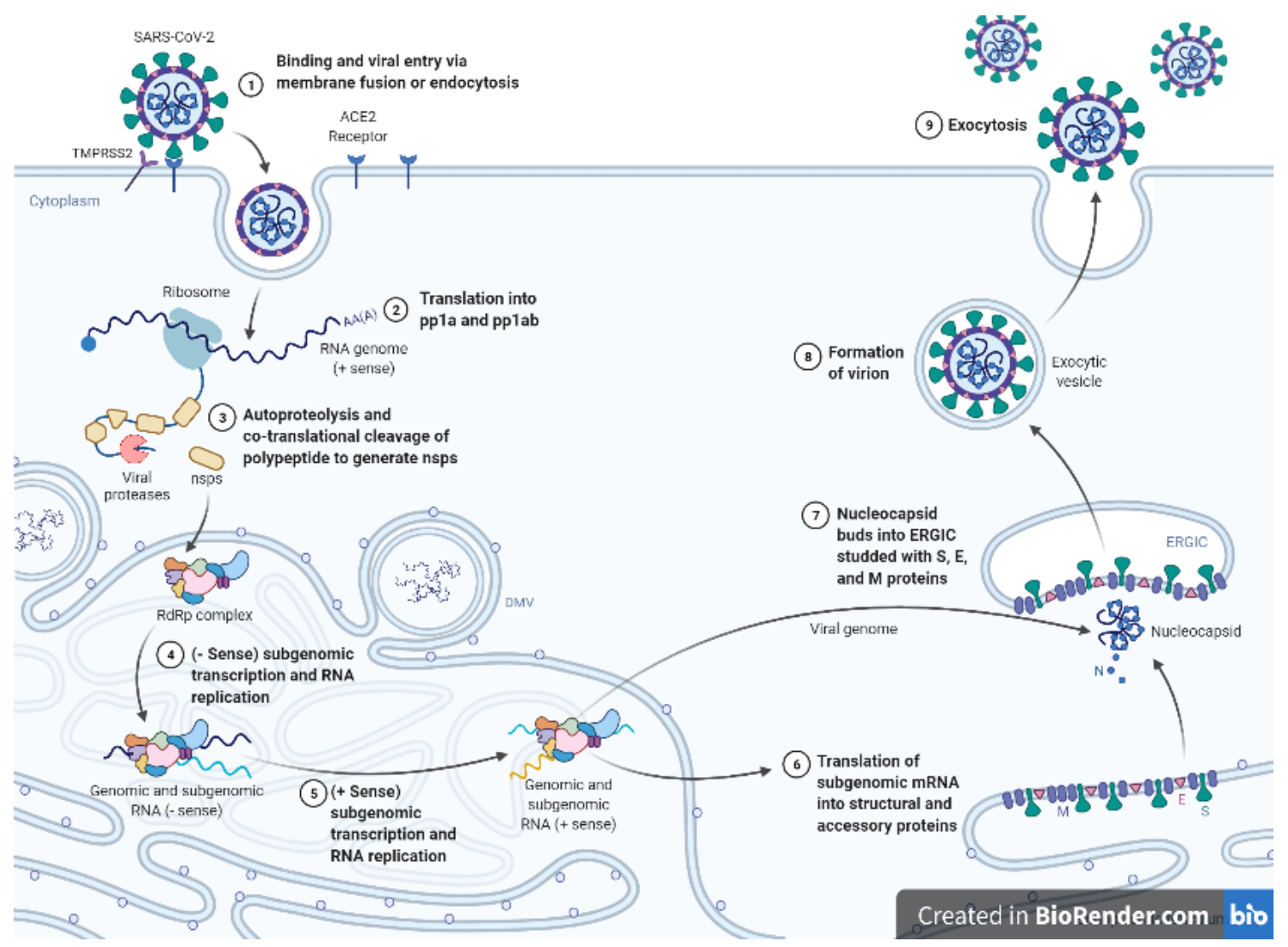

Figure 3 SARS-CoV-2 life cycle (Adapted from "Life Cycle of Coronavirus", by BioRender, August 2020, retrieved from https://app.biorender.com/biorender-templates/ Copyright 2021 by BioRender).

\section{ii. Antivirals}

All the proteins and processes involved in the virion replication process constitute potential drug targets by (antivirals) disrupting the SARS-CoV-2 life cycle, being the most relevant the proteins Mpro and RdRp. Among these direct-acting antiviral candidate drugs we can find (hydroxi)chloroquine and arbidol against endocytosis; lopinavir/ritonavir (also together with INF- $\beta$ ), darunavir/covicistat, ASC09F/oseltamivir, $\alpha$ ketoamide or disulfiram against Mpro; and remdesivir (the only drug approved by the FDA against COVID19 up to January 2021), ribavirin, favipiravir or tenofovir disoproxil against RdRp (98) (33) (34) (35) (36).

SARS-CoV-2 employs a smart triple strategy to obstruct the infected host cell gene expression process. First, it reduces the cell's translation capacity; it also degrades host mRNA; and, finally, it inhibits the translation of the cell's mRNA by avoiding its nuclear export. Altogether, these facts could lie behind the IFN response deletion appeared in some COVID-19 patients (99).

The identification of 332 human proteins that interact with SARS-CoV-2's has helped in uncovering druggable host targets (100). Besides, some of the proposed treatments against COVID-19 have already been tested in patients formerly affected from SARS and MERS (101). Drug repurposing or reuse of medicines from other diseases like cancer (aplidin), HIV (lopinavir, ritonavir), rheumatoid arthritis (baricitinib), hepatitis C HCV (ribavirin), ebola (remdesivir) or even gastric ulcer (famotidine) is being investigated in many studies (102) (103) (104) (105) (106) (107). Artificial intelligence is playing a pivotal role in repurposing and discovery of new drugs with platforms like Broad Institute's Clue drug repurposing hub (108) (109) or the IBM Functional Genomics Platform (110). A tracing of COVID-19 treatments, drugs and vaccines can be found at (111) (112).

It is worth remarking the high error rates that affect the replication process of positive-sense RNA virus genomes, generating viral clouds of mutants able to adapt to the environment and eventually evade antivirus treatments or vaccines. But the proofreading mechanism exerted by the non-structural protein nsp14 of large genome coronaviruses possibly including SARS-CoV-2, is capable to increase replication fidelity. New generation nucleotide /nucleoside analogue inhibitors (NIs) may overcome this correction barrier. Administered as prodrugs, they are metabolized and activated inside the cell, and their mis-incorporation or mispairing with natural nucleotides in the replication process may lead to chain termination or mutations that reduce replication fidelity and end in lethal mutagenesis. Remdesivir, ribavirin and favipiravir, and anti- HCV drugs daclatasvir and sofosbuvir are examples of common antiviral nucleoside analogues, but

(C) 2021 by the Author. Distributed under a CC-BY 4.0 International license. 
unfortunately have not been able to show clinical benefits up to now maybe due to the action of nsp14 (113) (114) (115), though studies continue and they still cannot be definitely discarded (116) (117). Molnupiravir, an oral pro-drug of the nucleoside analogue N4-hydroxycytidine (NHC) also known as MK-4482 or EIDD2801, and initially purposed to treat influenza, has shown therapeutic and prophylactic success from inhibiting SARS-CoV-2 replication in vivo (118). Updated information about COVID-19 antiviral therapies can be found in (119). On the other hand, antimicrobials such as azithromycin (120) (121) and antiparasitics like ivermictin (a nuclear transport inhibitor) (122) (123) (124) have shown antiviral effects in COVID-19 cases. In fact, macrolide bacteriostatic antibiotics like azithromycin, and to a higher extent clarithromycin and lexithromycin, are able to in vitro inhibit SARS-CoV-2 viral entry and could be applied to fight COVID-19 early infection (125).

We can also think of inhibiting the de novo biosynthesis of pyrimidine-based nucleotides, which basically compose the RNA and DNA, facilitated by the human dihydroorotate dehydrogenase enzyme (DHODH). Inhibition of DHODH induces pyrimidine nucleosides depletion that essentially affects RNA virus replication, moreover the decrease of pyrimidine pools triggers host antiviral genes expression and promotes innate immune responses (126) (127). PTC Therapeutics oral small molecule PTC299 trial for inhibition of DHODH activity is underway (128). Or the blocking of the eukaryotic translation elongation factor 1 alpha (EEF1A), responsible for the enzymatic delivery of aminoacyl tRNAs to the ribosome (129). PharmaMar's bet Aplidin (plitidepsin), an anticancer agent of marine origin with ongoing trials, exerts its action by effectively blocking EEF1A, already successfully tested in vivo (130) (131). Targeting hosts factors avoids the potential immune response evasion occasioned by virus mutations.

However, prophylactic oral drugs are still missing, that would be an essential weapon against SARSCoV-2 and its complex set of variants. Viruses depend on host metabolism pathways to replicate, so these could become new early targets. It has been shown that SARS-CoV-2 infected cells suffer from exhausted stores of glucose and folate, which are supposed to be deviated to viral biosynthesis. Of interest, inhibitors of folate metabolism like methotrexate are already employed to treat inflammatory types of arthritis (132). Another option comes from the well-known anti-leprosy drug clofazimine, that exerts its antiviral activity by inhibiting the viral membrane fusion and the helicase nsp action, minimizing the viral load and the subsequent inflammation. For hospitalized COVID-19 patients, clofazimine could be combined with remdesivir or with interferon beta-1b. Clinical trials are underway. Above all, this inexpensive oral drug also exhibits pan-coronavirus activity (133). Pfizer is also running trials for its oral (pan-coronavirus) antiviral drug PF-07321332, a 3CLpro protease inhibitor intended to fight the initial infection. For COVID19 hospitalized patients, another protease inhibitor intravenously administered, PF-07304814, is under clinical trial (134).

\section{iii. Epigenomics}

Epigenomics refers to epigenetic modifications involving external factors that impact gene activity (the degree of expression or even turning genes on/off) without changing the underlying DNA sequence. DNA methylation (DNAm), histone -proteins that pack the DNA- modifications (acetylation, citrullination or phosphorylation) and nucleosome remodeling, or regulation by non-coding RNAs such as miRNAs (microRNAs, short RNAs that repress target gene expression's mRNA after transcription) and siRNAs (small interfering RNAs that cleaves target mRNA and avoids translation) are typical epigenetic mechanisms. Regarding COVID-19, viral entry and immune responses like NETosis and TGF- $\beta$ pathway seem to be associated to epigenetic regulation. Also, DNAm could be related to higher susceptibility of the lung tissue to the disease (135).

On the one hand, SARS-CoV-2 is able to use epigenetic-regulated mechanisms during host-pathogen interaction in order to interfere with innate and adaptive immunity and inflammatory response. For example, by downregulating the MDA5 gene, involved in the antigen presentation, or by handling host miRNA machinery for its own benefit. Some drugs may try to counteract these epigenetic manipulations of the virus, for example heparin can avoid histone-induced platelet aggregation, curcumin (a histone deacetylase inhibitor) is a possible inhibitor of Mpro and might lower proinflammatory cytokines and expression of the NF-kB gene in macrophages, and tocilizumab, the IL-6 antagonist monoclonal antibody, may impact two epigenetic-sensitive mechanisms: the reduction of NETosis (neutrophil death after NET extrusion) and the upregulation of miRNA-23, miRNA-146 and miRNA-223 -related to coronary and immune diseases- serum levels (81). Also, drugs like vafidemstat, a lysine-specific histone demethylase 1A (KDM1A) inhibitor, are already being tested (136).

On the other hand, we can think of targeting the virus mRNA, especially in highly conserved regions of the genome, with the help of siRNAs, a powerful and recent tool whose side effects would still need a deep evaluation. Previous studies applying siRNA over SARS and MERS have been published (137) (138). The open reading frames (ORFs) themselves, the genes encoding the structural proteins and the non-structural proteins (nsps) are evident targets, but also others like the untranslated region $5^{\prime}$ UTR, involved in post- 
transcriptional regulation of gene expression (139). Current studies are being developed regarding siRNAs (140) (141) (142). Nasal administration is a natural option for potential siRNA drugs.

\section{B. Fourth line of defense: the war: the adaptive immune system}

\section{i. $\quad$ The human adaptive immune system}

Adaptive immunity is activated when a pathogen manages to evade the innate immune system. An antigen-presenting cell (APC), such as a dendritic cell or macrophage, phagocytoses the antigen and presents it through its major histocompatibility complex (MHC) class II to immature helper T cells. Then helper T cells maturate and proliferate into several types of helper T cells, which either produce cytokines to guide cytotoxic $\mathrm{T}$ cells to pathogens and activate macrophages, or present antigens to B cells. Infected cells present antigens through their MHC class I to activated cytotoxic T cells, that secrete toxins to destroy the cell (Figure 4). Finally, memory $\mathrm{T}$ cells remember the antigen and might evolve to either helper or cytotoxic $\mathrm{T}$ cells if the antigen reappears. Other $\mathrm{T}$ cells, so called suppressor $\mathrm{T}$ cells, have immunosuppressive capacities.

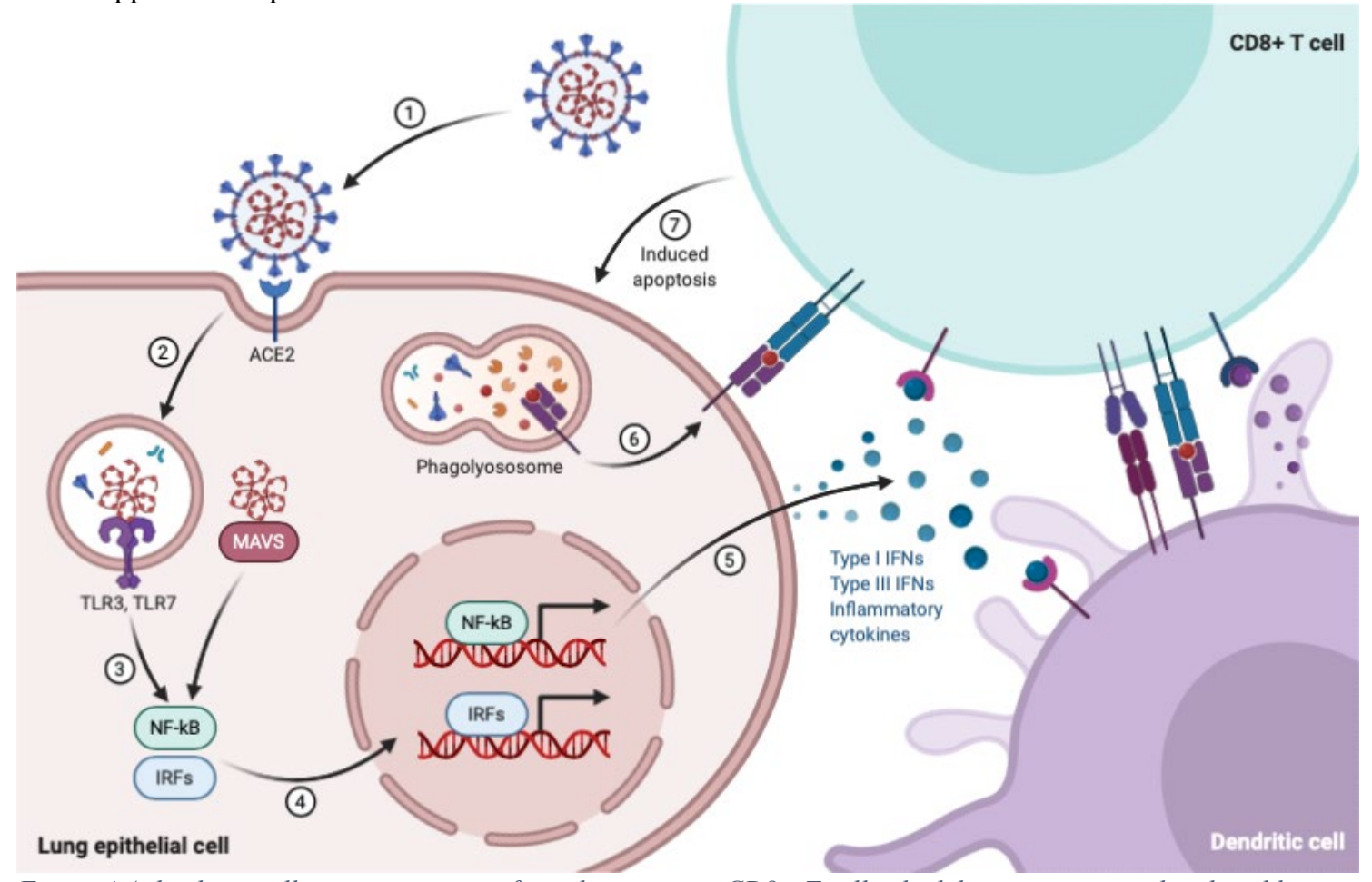

Figure 4 A dendritic cell presents antigens from the virus to a CD8+T cell, which becomes activated and is able to recognize the same antigen on the surface of an infected cell, releasing perforin and granzymes that destroy the infected cell (Reprinted from "Acute Immune Responses to Coronaviruses", by BioRender, August 2020, retrieved from https://app.biorender.com/biorender-templates/Copyright 2021 by BioRender).

The mature helper T cells activate naïve B cells that have previously recognised the antigen. These B cells then proliferate and differentiate into: plasma cells, which generate antibodies; plasmablasts, shortlived produced early in the infection that also produce (weaker) antibodies; B reg immunosuppresive cells; and memory B cells, that remember the antigen and quickly secrete antigen-specific antibodies if the antigen is newly detected (Figure 5). Both B and T memory cells are formed when the infection ends (143). 


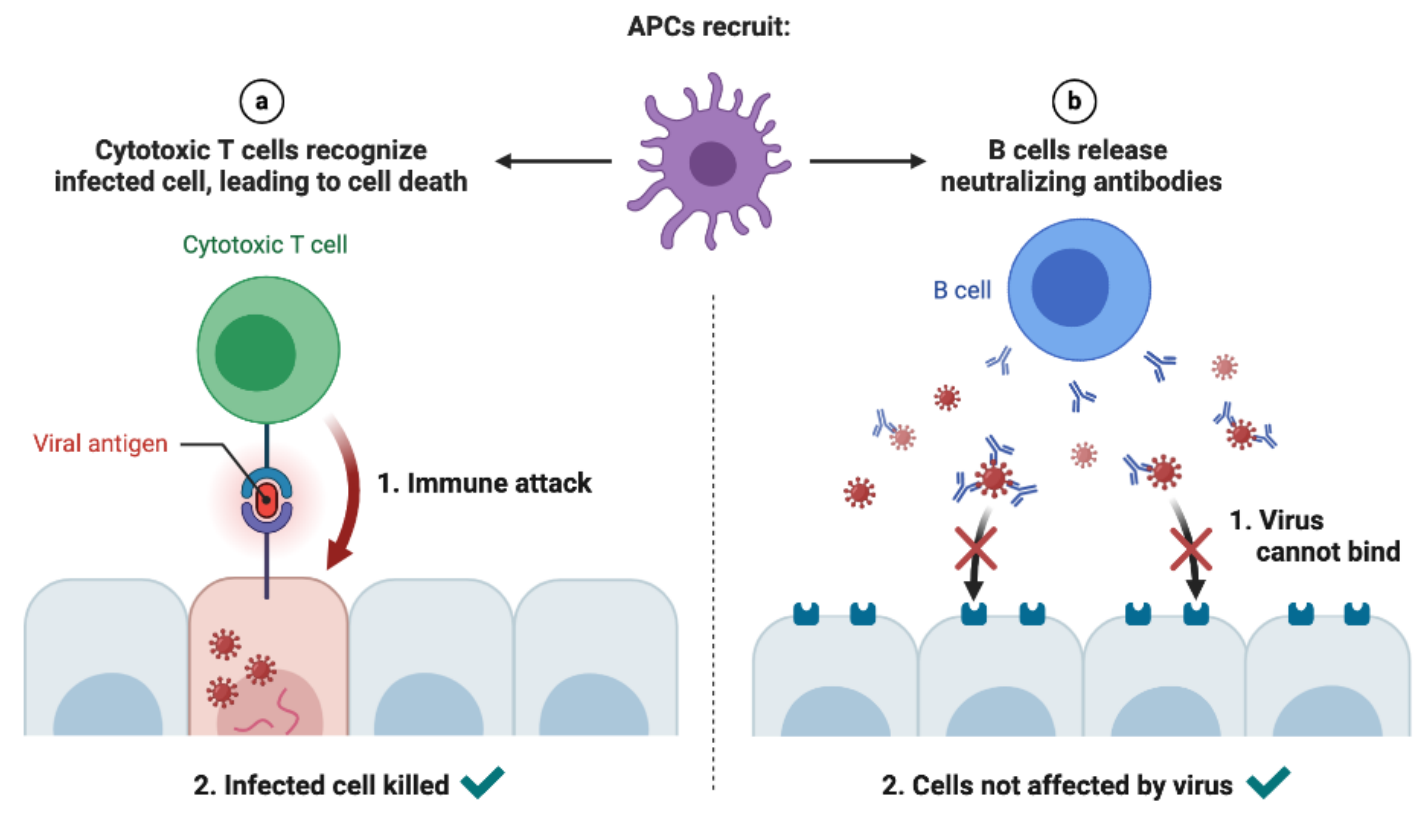

Figure 5 (Left) Once they reach the target tissue, cytotoxic $T$ cells detect antigens of the virus on the surface of infected cells and destroy them, eliminating virus factories. (Right) Antibodies secreted by B cells bind to the surface of the virus and block host entry (neutralizing antibodies). (Reprinted from "Recruitment of $T$ and B Cells by Antigenpresenting Cells (APCS)", by BioRender, August 2020, retrieved from https://app.biorender.com/biorender-templates/ Copyright 2021 by BioRender).

Ideally, the complex network that conforms our immune system and involves immune cells and the cytokines that communicate them, should be enough for blocking virus infections (144). However, strange things like trans-infection may happen. C-type Lectin Receptors (CLRs), PRRs present in APCs could help in transporting infectious SARS-CoV-2 virions to target cells, specifically DC/L-SIGN CLRs. Interestingly, glycomimetic antagonists of DC-SIGN like PM26 are capable of inhibiting the interaction of the viral spike protein with the CLR and therefore prevent the SARS-CoV-2 trans-infection process (145).

Besides, studies carried out on SARS-CoV-2 affected patients show impairments of the immune system performance, and also responses differ among individuals depending on age, sex, comorbidities, possible cross-reactivities, genetic alterations and other factors. A following section will delve into these facts.

\section{ii. $\quad$ The cytokine storm}

When fighting the virus, the immune system makes use of inflammation and fever. However, overreaction might occur, and if signals to lower inflammation are lost, prolonged cell-to-cell (involving both innate and adaptive immune cells) interactions and amplification of a pro-inflammatory cytokine cascade may lead to a cytokine storm (146) (147) (30). It is still unsure what triggers and propagates the cytokine storm. One possible factor could be the aberrant activation of neutrophils, the most abundant leukocyte in peripheral blood, and the expelling of NETs. Exorbitant NETs may precipitate inflammatory reactions that damages nearby tissues, promotes micro thrombosis, and results in permanent organ damage in lungs, kidneys and cardiovascular system. In fact, neutrophilia is a predictor of poor outcomes in COVID19 patients. Related to this, host DNA damage promoted by SARS-CoV-2, and the virus components themselves can bind several cytosolic PRRs ending in pyroptosis, which causes cytokine and DAMP release. As a consequence, dendritic cells, macrophages, natural killer cells, neutrophils, and B and T cells may be damaged or activated and provoke inflammation, coagulation and immunity dysfunction. In the course of it, transcription factors like NF- $\mathrm{kB}$ and IRF3 are activated, and if not quick and properly controlled may culminate in septic shock, multiple organ failure, and finally death (148).

Many cytokines are involved in the cytokine storm shown in severe COVID-19 cases, where increased plasma concentrations of IL-1 $\beta$, IL-2, IL-6, IL-7, IL-8, IL-10, IL-17, IFN- $\gamma$, IFN- $\gamma$-inducible protein 10, monocyte chemoattractant protein 1 (MCP1), G-CSF, macrophage inflammatory protein $1 \alpha$, and TNF- $\alpha$ are present. Besides general immunosuppressive therapies, novel treatments specifically targeting cytokines are being investigated to temper the cytokine storm. Among them, IL-6 has emerged as a main target for COVID-19 treatment. Many anti-IL-6 drugs are being tested, such as sarilumab, an anti-IL-6 receptor immunoglobulin G 1 (IgG1) mAb (149), baricitinib, a selective inhibitor of the JAK1/JAK2 kinases through which IL-6 signals when binding its receptor (150) (151), or tocilizumab, an anti-IL-6

(C) 2021 by the Author. Distributed under a CC-BY 4.0 International license. 
receptor Ab (IL-6 antagonist) (152) (153). Recent studies show benefit on treating severe COVID-19 patients with tocilizumab or sarilumab for both primary and secondary outcomes (154). The RECOVERY trial has demonstrated that a combined treatment of a systemic corticosteroid like dexamethasone and tocilizumab notably lessens mortality in COVID-19 patients with hypoxia and serious inflammation, with a reduction of one third for patients assisted with oxygen and of one half for those with invasive mechanical ventilation (155).

Apart from attacking the inflammatory molecules for blocking their action, other strategies can be observed, such as targeting the pathways that lead to the cytokines secretion. The nuclear factor kappalight-chain-enhancer of activated B cells (NF-kB) and the nuclear factor of activated T cells (NFAT) are families of transcription factors that influence the immune response (156) (157). Both NFAT and NF-KB may bind to promoter regions of DNA and together with other transcription factors, allow the expression of genes related to inflammation. Specifically, NF- $\kappa B$ promotes the release of cytokines and chemokines by inducing the expression of pro-inflammatory genes, intervenes in inflammasome (intracellular proteins that response to PAMPs and DAMPs, and induce the secretion of pro-inflammatory cytokines) regulation and regulates the survival, activation and differentiation of immune system cells (innate and inflammatory $\mathrm{T}$ cells). The NF- $\kappa \mathrm{B}$ pathway may be activated by responding to stimuli such as ligands of cytokine receptors, pattern-recognition receptors (PRRs) or T cell receptors (TCR) and B cell receptors (BCR). Cytokines such as tumor necrosis factor alpha (TNF- $\alpha$ ) or pathogen-associated molecular patterns (PAMPs) such as lipopolysaccharide (LPS) are examples of activators of NF- $\kappa B$. We can think of inhibiting NF- $\mathrm{kB}$ to lessen inflammation, however NF- $\mathrm{kB}$ is essential for normal immune responses and cell survival and therefore its inhibition might originate severe side effects, so the specific mechanism that triggers pathological activation of NF-kB in SARS-CoV-2 should be known for precise attack.

Moreover, the occupation of ACE2 receptors by SARS-CoV-2 and the consequent increase in Angiotensin II is able to trigger inflammation through NF- $\mathrm{kB}$ and IL-6-STAT3 activation, initiating the IL6 amplifier, a positive feedback cycle involved in the hyperactivation of NF- $\mathrm{kB}$ finally causing the cytokine storm. This inflammation pathway is strengthened with age, and IL-6 is a marker of cellular senescence (cell growth arrest due to stress factors that alter its gene expression (158)), which could explain the positive correlation between old age and COVID-19 severity, therefore the relevance of targeting the molecules contributing to the IL-6 AMP (159).

Cyclophilin A (CyPA) (160) is an intracellular protein that can also be secreted by cells in response to inflammatory stimuli. CyPA regulates protein folding and trafficking, as well as the infection and replication of several human viruses. High CyPA expression is a marker of poor outcome of patients with inflammatory diseases. Cyclosporine A (CsA) is a widely used immunosuppressant in transplantation and rheumatic drug (161). CsA together with CypA can sequester and inhibit the calcineurin phosphatase, which would prevent the nuclear translocation of NFAT and the dephosphorylation of IkB- $\alpha$, avoiding the translocation of NF-kB (162). Recent work has shown this CsA-CypA complex could reduce the hyperinflammatory phase in COVID-19 (163).

The mammalian target of rapamycin (mTOR) signaling pathway is involved in regulating the cellular growth and proliferation in response to nutrients. mTOR clinically approved inhibitors extend lifespan in model organisms and protect against a wide list of age-derived pathologies including cancer, metabolic and cardiovascular disease, for example rapamycin and derivatives are already employed for cancer treatment (164) (165). One possible cause for the cytokine storm in COVID-19 is the antibody-dependent enhancement, that would imply suboptimal antibody responses from sub-neutralizing titers of antiviral host antibodies including non-neutralizing antibodies and cross-reactive antibodies against SARS-CoV-2 produced by activated memory B cells (from a previous infection). These antibodies bind the virus inefficiently or with weak affinity, accomplishing virus entry into immune cells through phagocytosis, followed by a breakdown of the fragile bound of the complex and the consequent virus escape from immunity and replication. mTOR inhibitors may limit the proliferation of memory B cells, therefore reducing early cross-reactive antibody production and thus antibody-dependent enhancement (166) (167) (168). Clinical trials show that selective low-dose TOR complex 1 TORC1 inhibition decreases the incidence of infections of all type, improves influenza vaccination responses and up-regulates antiviral immunity in elder population, results that could be extrapolated to the COVID-19 disease (169). Also, the key tumor-suppressor p53 protein activators or microRNAs (miRNAs) that mimic p53 and can target mTOR are candidates to inhibit SARS-CoV-2 replication (168).

\section{iii. Cross-reactivity}

Antibodies serological testing is easy to perform and therefore is usually accomplished to examine the immunological state and response of an individual against SARS-CoV-2. Nevertheless, since antibodies evolution is not yet fully characterized in COVID-19, it seems clear that immunity cannot be assessed by antibodies presence or even absence. Besides, antibody-dependent enhancement of disease, that enables 
viral entry into cells bearing Fc $\gamma$ receptors and might amplify infection if the virus is not degraded but replicated inside the cell, has already been presented, and cross-reactive antibodies presence may be one cause (167).

On the other hand, some studies suggest that a relatively high proportion of SARS-CoV-2 non-exposed individuals present $\mathrm{T}$ cells that react to SARS-CoV-2, probably from seasonal coronaviruses responsible for common colds, what could confer some degree of immune protection against COVID-19 (170) (171). Specifically, mild COVID-19 convalescent patients have been found to exhibit robust memory $\mathrm{T}$ cell responses against both internal - the nucleocapsid- and surface - the membrane and the spike - virus proteins months after infection, even when no circulating SARS-CoV-2 specific antibodies are detected. Moreover, cross-reactive T cell responses against SARS-CoV-2 surface proteins appear in over one fourth of unexposed healthy blood donors (172). Also, high levels of SARS-CoV-2 responsive T cells are associated with absence of symptomatic SARS-CoV-2 disease, and the number of individuals showing high $\mathrm{T}$ cell responses is inversely proportional to age, what could relate to higher incidence and severity of COVID-19 in the elderly (173). As already introduced, T cell epitope identification is a helping tool for detecting both cross-reactive and specific SARS-CoV-2 T cell immunity (174).

Effective adaptive immunity creates immunological memory that reacts to previously exposed pathogens and interestingly can also affect the immune response and the course of infection of unassociated pathogens, leading to either protective immunity or immunopathology. This process is called heterologous immunity, and may be induced by vaccination through trained immunity by reprogramming innate cells such as natural killer cells (NK), natural killer T cells (NKT) and monocytes. Other procedures such as modulation of helper, regulatory and memory $\mathrm{T}$ cells, cytokine responses, concentration of antibodies, and even crossreactive antibodies and cross-reactive epitopes may also be considered as mechanisms originating heterologous immunity (175) (176). For example, BCG (Bacille Calmette Guerin) vaccine to prevent tuberculosis is known to confer heterologous protective immunity by inducing trained immunity (177) (178), and a correlation between BCG vaccinated population and less susceptibility to COVID-19 has been observed (179) (180). Besides, DTP (diphtheria, tetanus and pertussis) vaccine has been found to exhibit cross-reactive epitopes with SARS-CoV-2, including many cytotoxic and helper $\mathrm{T}$ cell epitopes and potentially neutralizing B cell epitopes in conserved antigenic domains of the virus spike protein. Since DTP vaccine is widely administered in children worldwide, DTP cross-reactivity could be one contributor to youngest population protection against SARS-CoV-2 (181). Also, mumps titers related to the Merck MMR II vaccine (licensed in 1979) has been found inversely associated to COVID-19 severity (182), and a high rate of pneumococcal vaccination inversely correlates with population morbidity and mortality due to COVID-19 (183).

Previous exposure to other unrelated pathogens and vaccines such as influenza are being considered as a source of cross-reactivity (184) (185) (186), for example it has been demonstrated in-vitro that the quadrivalent inactivated influenza vaccine can induce a trained immunity response positively impacting SARS-CoV-2 infection improving some cytokine responses (187).

\section{iv. Convalescent plasma}

It seems obvious to think about using hyperimmune plasma from recovered COVID-19 patients with sick individuals that may be in an acute phase of the disease, but still have not developed an effective immune response. This plasma will likely contain SARS-CoV-2 specific antibodies that would help in defeating the virus. This hypothesis is being demonstrated in a clinical essay carried out by a group of over thirty hospitals in Spain, with preliminary results showing that administering hyperimmune plasma may reduce the probability of disease progression to mechanical ventilation, ICU admission or death, for patients with less-advanced clinical presentations, but no benefit in critically-ill patients admitted to ICU (188). Another study at the Mayo Clinic with over 35,000 patients revealed that mortality rate was reduced in patients transfused within three days of COVID-19 diagnosis compared with patients transfused four or more days after diagnosis. Also, convalescent plasma with higher antibody levels was associated with reduced mortality (189). A recent study confirms that early administration of high-titer convalescent plasma is key in decreasing the disease advance in mild COVID-19 old patients (190).

In addition, it is surprising to find how long-lasting immunoglobulin $\mathrm{G}$ (IgG) antibodies against SARS$\mathrm{CoV}-2$ disappear in a relatively short time span of several months, in a proportion of recovered patients. It has been discovered an absence of germinal centers in lymphoid organs of severe COVID-19 patients, which causes that long-lived antibody secreting plasma cells and memory B cells are not being produced so a dysregulated humoral immune is presented. The abnormal absence of germinal centers correlates with an impaired follicular helper $\mathrm{T}\left(\mathrm{T}_{\mathrm{FH}}\right)$ cell differentiation and aberrant lymphoid TNF- $\alpha$ production (191). 
v. (Tests, tests, tests...)

COVID-19 asymptomatic and presymptomatic patients may be responsible for over one half of all the contagions, with all the implications this proportion presents (192) (193). Besides, presymptomatic cases are more infectious than after symptom onset (194). Genetic material of SARS-CoV-2 can be detected several weeks or even months after infection, however live virus culture has not been fruitfully achieved after nine days since symptoms onset, which marks a theoretical deadline for a patient's infectious state, with asymptomatic patients showing faster viral clearance. Therefore, quarantines or isolation periods of ten days without repeating confirmation RNA tests could be justified, though this time span could vary depending on the SARS-CoV-2 variant (195).

Diagnostic evaluations like reverse transcription polymerase chain reaction (RT-PCR) and antigen tests are carried out searching for presence of fragments of the SARS-CoV-2 RNA and specific virus proteins, respectively, usually via nasopharyngeal swabs, showing active virus infection. Besides, serology tests look for antibodies that imply past (IgG) or active (IgM) infection (Figure 6). However, observation of a viable virus, capable of replicating itself, is the most trustworthy benchmark of contagiousness.

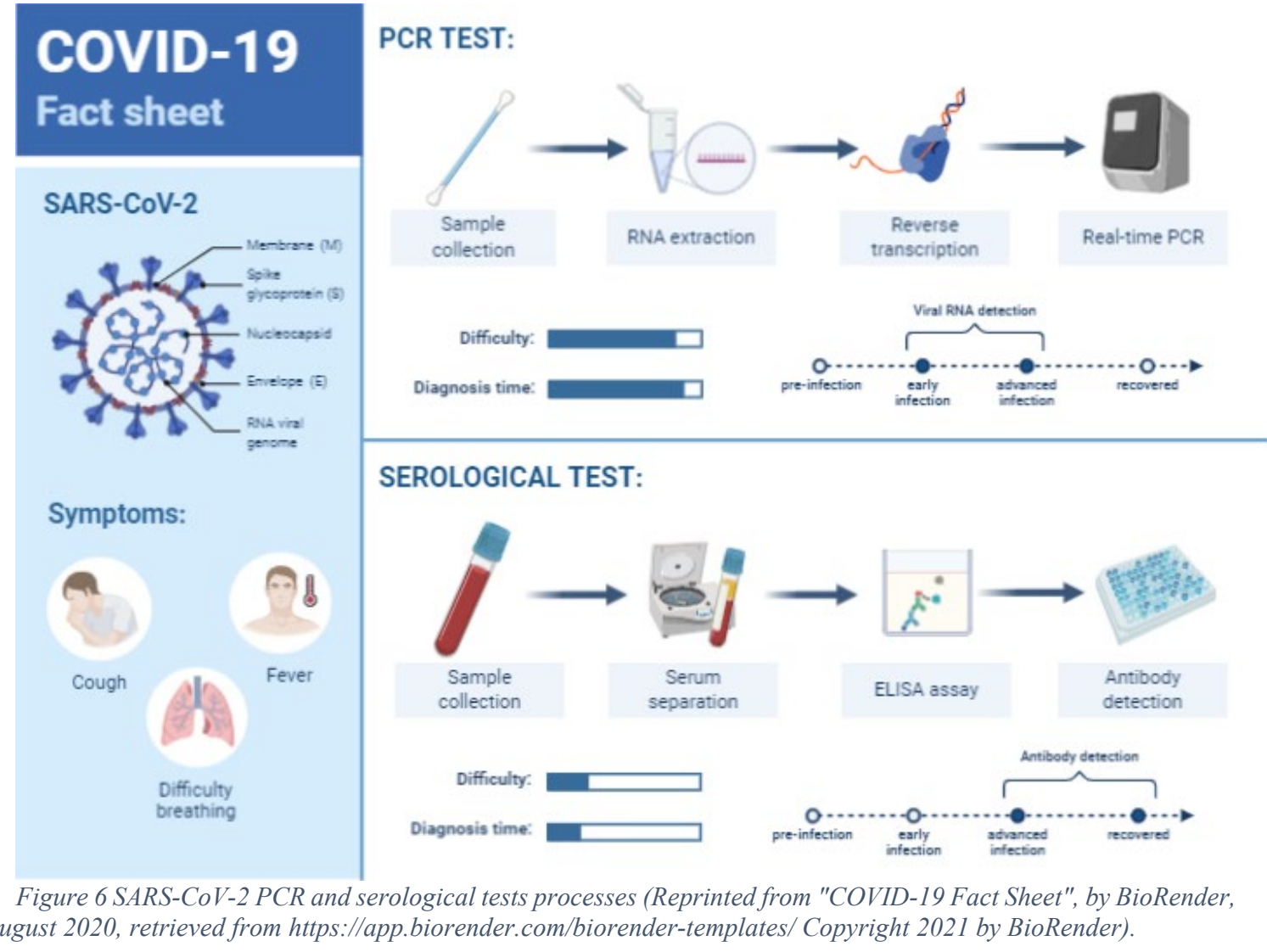

RT-PCR tests have high specificity but moderate sensitivity, and their results depend on the patient viral load, therefore the possibility of a false negative increases around the day of symptoms onset (usually about five days after infection) and when symptomatology diminishes at the final course of the infection, so a RT-PCR result initially negative might become positive after some days, and so the need for preventive quarantine of straight contacts of a COVID-19 positive, even if asymptomatic. Antigen tests are less accurate and could give false negative results due to a low or a variable viral load and the variability in the sampling process, but are faster and simpler to process. On the other side, antibodies can be detected several days or even weeks after infection and so their false negative window spans larger than PCR. Antibody tests must be designed to check for antibodies targeting specific SARS-CoV-2 antigens (avoiding crossreactivity). Though most tests detect antibodies against the spike or the nucleocapsid proteins, it is possible to point to other immunogenic proteins like Mpro, which implies cell infection and therefore might correspond with tissue damage. Also, it is interesting to detect antibodies from saliva, and include mucosal IgA that would infer protection of the upper respiratory tract (196). Serology tests should not be employed for COVID-19 diagnosis but to check whether an individual has had the infection, as well as for seroprevalence studies and to monitor the evolution of the immune response, included that from vaccination (197). Depending on the patient symptomatologic state and initial test results, both diagnostic and serology

(C) 2021 by the Author. Distributed under a CC-BY 4.0 International license. 
tests may be complementary. New faster diagnostic tests are being commercialized, which despite a somewhat higher false negative rate help to quickly isolate infected persons therefore cutting the transmission chain of the virus (198) (199). Quick, frequently performed affordable autotests like saliva tests will surely help in ending with the pandemic bad dream. Of note, saliva load has been discovered as a potential biomarker of COVID-19 severity and mortality, and a notably higher saliva viral load is detected in COVID-19 patients with risk factors (200). Also of interest, neutralizing antibodies can be detected with serology tests, being authorized by the U.S. Food and Drug Administration (FDA) for the first time in November 2020 (201).

\section{Last line of defense: fighting the consequences of the infection}

\section{i. $\quad$ Respiratory and vascular problems}

Lung damage and blood clots are one of the main severe consequences of the COVID-19. Actually, COVID-19 is recognized as a vascular disease. Consequently, the virus targets many human organs and systems and may cause heart and renal failure, cerebrovascular accident, and Acute Respiratory Distress Syndrome (ARDS) (94). Moreover, COVID-19 patients might undergo long-term sequalae affecting health beyond respiratory and cardiovascular disorders, including neurological and mental, metabolic and gastrointestinal complications, musculoskeletal pain and fatigue or anemia, in direct proportion to COVID19 severity but also reaching mildly-affected individuals (202).

ARDS implies hypoxemic respiratory failure and may be produced by a SARS-CoV-2 derived pneumonia. ARDS is one of the most common cause of death in the inflammatory phase of COVID-19, especially affecting the older and also among patients admitted to intensive care units (ICU) (Figure 7) (203).

\section{Acute Respiratory Distress Syndrome (ARDS) \\ Alveolar Changes}

Healthy alveolus

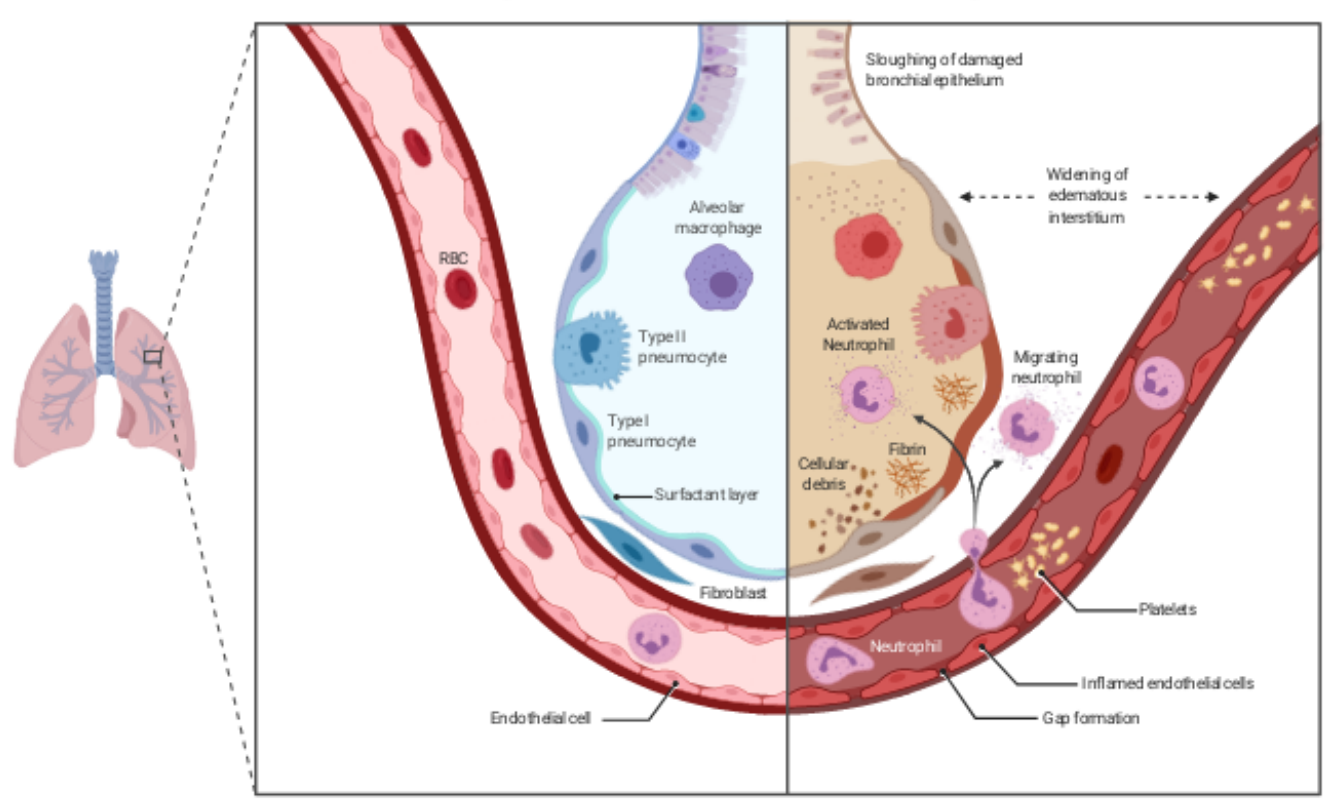

Figure 7 A healthy alveolus (left) and a damaged alveolus (right) in the acute phase of ARDS. An excess of cytokines increases the permeability of the capillaries leading to pulmonary edema (in light brown) that hinders gas exchange in the alveoli, ending in dyspnea and ARDS (Reprinted from "Acute Respiratory Distress Syndrome (ARDS)", by BioRender, July 2020, retrieved from https://app.biorender.com/biorender-templates/Copyright 2021 by BioRender.).

On the cardiovascular side, angiotensin II and angiotensin(1-7) control blood pressure. ACE2 keeps the balance between both hormones, however it seems that the way SARS-CoV-2 enters the host cell through the ACE2 receptor, provokes an imbalance with an excess of angiotensin II that makes blood more viscous, leading to clots. Heparin has already been pointed out as an effective anticoagulant drug. The TRV027 molecule, an AT1 receptor selective agonist that disrupts overactivation caused by SARS-CoV-2, presents a dual action blocking angiotensin II activity and mimicking angiotensin(1-7), and is currently under test. The type 1 angiotensin receptor AT1 is used by angiotensin II to increase blood pressure by inducing

(C) 2021 by the Author. Distributed under a CC-BY 4.0 International license. 
vasoconstriction, and to promote inflammation and fibrosis (204). Studies show that severely ill COVID19 patients exhibit an elevated risk for venous thromboembolism even when treated with prophylactic anticoagulation drugs (205).

The ACE2 receptor virus gateway is also broadly expressed in endothelial cells, that traverse multiple organs. Recruited immune cells can originate widespread endothelial dysfunction after a SARS-CoV-2 infection, implying microvascular dysfunction with vasoconstriction that cause organ ischemia, inflammation with tissue edema and a pro-coagulant state. Endothelial cells death containing viral elements, and inflammatory dead cells accumulation would suggest that SARS-CoV-2 infection induces endotheliitis in several organs, that would explain the systemic impaired microcirculatory function (Figure 8). Also, induction of apoptosis and pyroptosis could have a crucial function in endothelial cell injury in COVID-19 patients. Therapies to stabilize the endothelium while coping with viral replication seem appropriate, especially with anti-inflammatory cytokine drugs, ACE inhibitors and statins (206). In fact, statins, a common drug for decreasing blood cholesterol, are showing lower SARS-CoV-2 infection-related mortality when administered before hospitalization (207).

On the other side, presence of antiphospholipid (aPL) antibodies -able to promote a potentially fatal thrombosis- has been found in the serum of half of hospitalized COVID-19 patients within a recent study. aPL antibodies titers positively correlate with neutrophil overactivity and NETs, platelet counts and severity of respiratory disease. The existence of aPL antibodies in COVID-19 patients may have implications for instance in treatments with convalescent plasma (208).

\section{Host Tissues Known to Express ACE2}

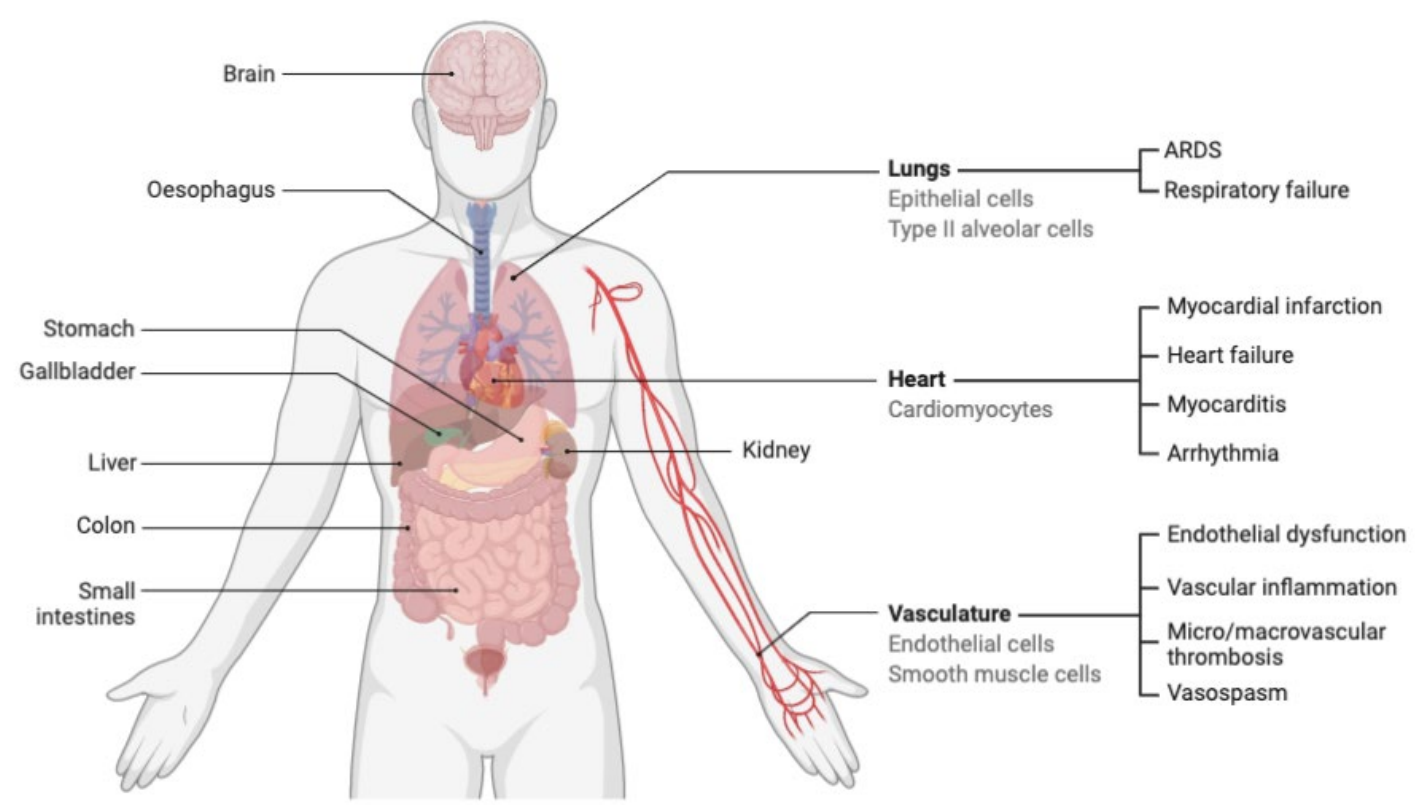

Figure 8 ACE2 receptors facilitating SARS-CoV-2 entry, causing, among others, vascular effects like endothelial dysfunction, vascular inflammation, micro and macrovascular thrombosis and vasospasm. (Reprinted from "Expression of ACE2 Receptor in Human Host Tissues", by BioRender, August 2020, retrieved from https://app.biorender.com/biorender-templates/Copyright 2021 by BioRender).

Melatonin is a bioactive molecule synthesized from tryptophan in the pineal gland, and actually in any cell since it is synthesized in mitochondria. It effectively points to an immense span of health targets ranging from sleep disorders (chronobiotic), delirium, atherosclerosis, respiratory diseases including acute respiratory stress and viral infections (as anti-inflammatory, antiapoptotic, immunomodulatory and potent antioxidant). Immune cells such as macrophages/monocytes in an inflammatory environment cannot synthesize melatonin and this could lie behind their inability to prevent the cytokine storm and neutralize free radicals inducing lung damage. Importantly, melatonin moderates the removal of the angiogenic factor VEGF in vascular endothelial cells, reducing edema and the leakage of immune cells from blood vessels contributing to the integrity of the vascular endothelial barrier, essential for immunoregulation within alveoli. Melatonin may also prevent sepsis injury and positively impact heart diseases including hypertension. Moreover, it exerts neurological protection by reducing the cerebral inflammation, cerebral edema and brain-blood barrier permeability. Melatonin synthesis sensibly decreases with age and children

(C) 2021 by the Author. Distributed under a CC-BY 4.0 International license. 
have a much higher melatonin level. All the aforementioned positive impacts on symptoms associated to COVID-19, together with its high safety profile makes melatonin an excellent candidate to be evaluated in treating the disease (209) (210) (211).

\section{ii. Inflammation}

Inflammation is a natural defensive response of the organism to infection or tissue damage, that through inflammatory mediators dilates blood vessels to boost the blood flow and permit the infiltration of lymphocytes, fluid and proteins to the site of infection. However, if this process gets out of control it may lead to a cytokine storm, related to poor clinical prognosis (212) (213). The inflammatory phase in COVID19 follows the infection and the pulmonary phases, and may culminate in a fatal prothrombotic final stage (214) (215). Intriguingly, the SARS-CoV-2 S protein by itself is able to damage the endothelium by downregulating ACE2, what would lessen the virus infectivity but also impair the renin-angiotensin system (RAS), finally resulting in endothelial injury and inflammation or endotheliitis (216). Apparently, this would not have impact on spike-producing vaccines against COVID-19, since the generated spike would be anchored to the host cell surface, unable to bind ACE2 receptors.

Corticosteroids are common drugs treating chronic inflammatory pathologies, that bind to glucocorticoid receptors and reverse histone acetylation of activated inflammatory genes, switching them off (217). Corticosteroids may modulate immune-mediated lung injury, however there is uncertainty about their effectiveness in COVID-19, which depend on the right dose, at the right time, in the right patient, despite their frequent use in syndromes related to COVID-19, such as SARS, MERS, influenza or community acquired pneumonia. Dexamethasone, a low cost, safe and widely available corticosteroid, has shown benefits in COVID-19 patients that receive oxygen by reducing mortality, especially with those at a later stage of the disease where active virus replication has given way to immunopathology, and is actually being widely used. However, no benefit arises for patients not assisted with oxygen, moreover they might suffer possible harm from the treatment (218). Recently, it has been reported the benefits of colchicine, an alkaloid used against gout, viral pericarditis and coronary diseases with anti-inflammatory properties, for orally treating non-hospitalized COVID-19 patients, in inhibiting the cytokine storm associated to SARS-CoV-2. Statistically significant results show colchicine notable impact in reducing hospitalizations by $25 \%$, mechanical ventilation need by $50 \%$, and deaths by $44 \%$ (219).

\section{iii. $\quad$ Neurological effects}

Among the wide variety of consequences on the human organism caused by the SARS-CoV-2, there is still place for fearsome neurological complications that arise with high frequency, even in the long term. Most common neurologic manifestations include myalgia, headache, encephalopathy, dizziness, dysgeusia and anosmia. Other symptoms like strokes, movement disorders, motor and sensory deficits, ataxia, and seizures may also appear but are less common. Clinical studies show that severe COVID-19 patients are in higher risk of developing neurologic manifestations, and that encephalopathy is associated with augmented morbidity and mortality, unrelated to respiratory disease severity (220). Cognitive failures like loss of memory, disorientation or concentration problems, as well as fatigue, dyspnea and sleep disorders have also been reported as a consequence of this hyperactive virus (221). EEG analyses of COVID-19 patients suffering from neurologic disorders like encephalopathy, seizures and status epilepticus have been performed, showing abnormalities like slowing, periodic discharges or epileptiform discharges, revealing localized dysfunction, nonspecific encephalopathy and cortical irritability. Interestingly, the frontal lobe, in charge of voluntary movements, and cognitive skills like language, memory and emotional expression registered the most common EEG abnormalities. In fact, EEGs may act as a useful tool to evaluate early cerebral impact in the COVID-19 disease. These neurological malfunctions might be caused by an extensive brain inflammation, by poor blood flow or by inflammation of the brain blood vessels, and /or by hypoxia, not discarding other reasons like possible virus ingress in the central nervous system as already mentioned in a former section (222) (223) (92) (93) (224). In fact, as has been mentioned previously the spike protein itself, and more specifically the S1 subunit, could lie behind endothelial damage with neurological implications, and particularly on brain endothelial cells might also provoke a proinflammatory response that negatively impact the blood-brain barrier function (225) (226). Moreover, SARS-CoV-2 infection could represent a risk factor triggering neurodegenerative disorders like Parkinson, multiple sclerosis and narcolepsy in susceptible individuals (227).

\section{COVID-19 RISK FACTORS}

Thanks to the many clinical and genetic analyses that are being carried out in the quite elevated number of COVID-19 patients, the majority of the population is already aware of the most common risk factors to SARS-CoV-2 susceptibility and severity such as age, sex (male), obesity or previous pathologies including diabetes and cardiovascular diseases, especially hypertension. In this section we will review the main

(C) 2021 by the Author. Distributed under a CC-BY 4.0 International license. 
known determinants that influence COVID-19 susceptibility, severity and prediction of the course of the disease.

\section{A. Symptoms and clinical biomarkers}

In hospitalized patients, clinical trials show that worst prognosis is associated with the isolated set of symptoms consisting of fever, cough and dyspnea (which frequently also accompanied the following other symptomatology); predominant diarrhea, vomiting and /or abdominal pain also present bad prognosis; on the contrary, ageusia and/or anosmia, followed by arthromyalgia, headache and /or sore throat symptoms seem to offer better prognosis (228).

Asymptomatic and severely affected COVID-19 patients show different immune profiles. In a cohort of 130 individuals, single-cell multi-omics analysis on almost 800,000 peripheral blood mononuclear cells (PBMC) has been performed, including single-cell sequencing, surface proteome and lymphocyte antigen receptor analyses. Asymptomatic patients show augmented levels of B cells in nasal mucosa, related to higher number of defensive IgA antibodies. B cells and helper T-cells are depleted in patients suffering severe COVID-19, in contrast to patients with mild to moderate symptoms who show raised levels of both immune cells. Finally, in hospitalized COVID-19 patients the shot up of monocytes and killer T-cells could end in lung inflammation, and also high levels of megakaryocytes, the platelet-producing cells are present (229).

Clinical analyses clearly show D-dimer, C-reactive protein (CRP), ferritin, lactate dehydrogenase (LDH), IL-6, TNF $\alpha$, IL-1 $\beta$, red cell distribution width (RDW) or procalcitonin (PCT) biomarkers of inflammation and coagulopathy associated with poor clinical outcomes, among others (230) (231) (232) (233) (234) (235) (236) (237). Predictive scores have been developed to allow for enhanced prognosis in hospitalized COVID-19 patients, comprehending factors like age, sex, dyspnea, oxygen saturation, neutrophil-to-lymphocyte ratio, and Chronic Kidney Disease Epidemiology Collaboration (CKD-EPI) equation (estimated glomerular filtration rate, related to renal failure) (238). Also, phase angle (PhA), together with standardized $\mathrm{PhA}(\mathrm{sPhA})$, a parameter that senses cell status (hydration) and is a biomarker for malnutrition and inflammation, is an accurate predictor of mortality risk in COVID-19 patients (239). Hyperglycemia is a strong predictor of mortality in non-critical and even non-diabetic hospitalized patients. It may be directly induced by the SARS-CoV-2 that infects the pancreas cells through their ACE2 receptors, originating a transient diabetes, and by stress hyperglycemia. Patients suffering from diabetes or obesity present high levels of glucose in their blood that may impact the normal macrophages and monocytes behavior. Hence patient hyperglycemia should be monitored and controlled since it stimulates the infection and may worsen the inflammatory response (240). Even periodontitis, related to systemic inflammation, has been associated with poor disease outcomes including death in COVID-19 patients (241). Inflammatory mitochondrial DNA (mtDNA) is released by injured organs, and circulating mtDNA has also been found a potential biomarker of poor COVID-19 outcomes ranging from ICU admission and intubation to mortality (242). Eosinophil count is a prognostic biomarker too, as well as lymphopenia (243) (244). Artificial intelligence techniques may help in predicting the COVID-19 phases and even the so called long-haul COVID so as to more efficiently adopt treatments (245).

Obesity is characterized by an excessive fat accumulation that may negatively impact metabolism, the respiratory and the renal systems, also inducing a chronic low-inflammatory state that stimulates the development of cardiovascular diseases like coagulation or atherosclerosis, and diabetes mellitus or cancer. A dysregulated immune response may arise in individuals with obesity. Studies show an increased mortality rate of obese COVID-19 patients, that present augmented values of parameters like blood lymphocytes, IL6 , CRP, triglycerides (heart and metabolic function), cystatin C (renal function), alanine aminotransferase (ALT, liver function), and erythrocyte sedimentation rate (ESR, inflammation) (246) (247). Also related to an individual physical condition, muscular strength lies behind the physical exercise's preservative effect against COVID-19 in older people (248).

Additional risk factors such as sociodemographic issues, comorbid conditions and symptoms are also being studied (249).

\section{B. Patient's sex and age}

\section{i. $\quad$ Males vs females}

It is well known that general infectious disease incidence is often male-biased (250), COVID-19 is not an exception and men suffer from higher COVID-19 severity and lethality than women, though their infection rate is similar (251) (252). Apart from lifestyle and comorbidities that affect men to a greater extent, other factors underlay this imbalance. Men with heart failure show more elevated plasma concentrations of ACE2 than women, what could extrapolate to a higher expression of ACE2 that would enhance SARS-CoV-2 cell entry (253). Also, there seems to be a clear difference in the construction of the

(C) 2021 by the Author. Distributed under a CC-BY 4.0 International license. 
immune response between men and women, with factors like the X-linked essence of many immune genes (genes on the X chromosome), such as the toll-like receptor 7 TLR7 -the endosomal innate immune sensor that detects single-stranded RNA as SARS-CoV-2's and induces type I interferon and inflammatory cytokine production-, and the feminine reproductive hormones estrogen and progesterone and its metabolite allopregnanolone, that have anti-inflammatory effects, improve the performance of immune cells, stimulate antibody production and reinforce respiratory epithelial cells (254) (255).

A study involving patients with moderate COVID-19 show men having higher plasma levels of innate immune cytokines like IL-8 and IL-18, together with a stronger induction of non-classical monocytes, and women with more robust CD8 $\mathrm{T}$ cell activation. Interestingly, a poor $\mathrm{T}$ cell response was associated with worse disease outcome in men, but not in women, and higher levels of innate immune cytokines like TNF SuperFamily member 10 (TNFSF10) and IL-15 were associated with worse disease progression in women, but not in men (256). Also, as already mentioned autoantibodies against type I interferons were found in around a $10 \%$ of patients with severe COVID-19, and these patients were almost all men (257). Another study examining host response gene expression show higher expression of B cell transcripts in females (since women present higher levels of B cells, and also tend to an increased inflammation responding to viral infections), and reduced B cell-specific and NK cell-specific transcripts and increased inhibitors of $\mathrm{NF}-\kappa \mathrm{B}$ signaling in males, perhaps not adequately lowering antiviral responses trying to reduce deleterious inflammation (258). Besides, the National Health Service in England has found among plasma donors that men produce higher levels of COVID-19 plasma antibodies than women (259).

Testosterone seems to play a pivotal role in this male COVID-biased affection. Male COVID-19 patients show very low levels of circulating testosterone at hospitalization -compatible with secondary hypogonadism- which inversely correlate with poorer clinical outcomes, including ICU admission and death. Probably, as a consequence of the absence of the testosterone anti-inflammatory activity (260) (261). Moreover, genetic polymorphism in the androgen receptor diminishing the receptor functionality would also have a relevant influence, in fact, normal testosterone levels could mask a low androgenicity problem. Severe COVID-19 patients with defective androgen signaling together with reduced levels of circulating androgens could potentially benefit from testosterone as adjuvant therapy (262). Additionally, an altered lipid metabolism reflected in triglycerides depletion, along with high estradiol levels (shared with females), positively associated with IFN- $\gamma$ (in charge of macrophage activation), negatively impact male COVID-19 patients' prognosis (263).

\section{ii. $\quad$ Children and older people}

Fortunately, children and young adults mostly suffer a milder version of COVID-19 compared to adults, although they are exposed to develop a life-threatening multisystem inflammatory syndrome (MIS-C) (264) (265). Much has been speculated about the reasons, including heterologous immunity from past exposures to similar or even unrelated pathogens and from vaccination, and lower affinity of ACE2 receptors for SARS-CoV-2 binding (266) (267). Another explanation implies a strong response from the innate immunity, involving interferon release and macrophages that may be delayed in adults. Studies carried out with pediatric COVID-19 patients show different antibody responses compared to adults, who present IgG, IgM and IgA antibodies against spike (S) protein, and IgG antibody against nucleocapsid (N) protein. By contrast, children generate IgG antibodies against the $\mathrm{S}$ protein but not for the $\mathrm{N}$, a protein only visible for the immune system after cells are infected, what would suggest a limited propagation of the infection. Also, serum concentrations of interleukin-17A and interferon- $\gamma$ appear inversely related to age, but not TNF- $\alpha$ or IL-6. Moreover, children present reduced neutralizing activity, what is compatible with a powerful innate response and a consequent quick virus elimination (268) (269). Innate cell profile in patients with mild infection show an augmented activation of neutrophils and a declined circulation of all monocyte types, dendritic cells and natural killer cells in children, while adults only exhibit depletion in the non-classical monocyte type (270). A study involving a family infected with COVID, formed by the parents and three children gave intriguing results, with the youngsters presenting SARS-CoV-2 antibodies and even undergoing mild symptoms but repeatedly testing negative for RT-PCR. This would suggest a very effective immune response in children able to halt virus replication before it reached the swab diagnostic test detection threshold, also with implications in the detection strategies of infected children and consequent spread of the disease (271) (272). Besides, cross-reactive (non-specific) and polyreactive secretory antibodies SIgA/IgA and SIgM/IgM against SARS-CoV-2 spike protein subunits S1 and S2 and nucleocapsid protein have been abundantly detected in human milk, as well as lactoferrin antiviral proteins, what might passively protect breastfed infants (273) (183). However, as time goes by in the pandemic era, new consequences appear, and children have been found to develop neurological symptoms in the course of the disease and even once recovered (274). Also, in children -as in adults- endothelial cells of small blood vessels may be damaged by SARS-CoV-2, leading to thrombotic microangiopathy (TMA) (275). 
Results from autopsies in children with COVID-19 show the virus capacity of infecting several organs including brain and intestine, that is suggested to have a direct impact on the pathogenesis of MIS-C (276).

In any case, children do seem to get infected with a similar susceptibility than adults, and they can also act as transmitters of the infection like adults, however due to their high asymptomatic profile they are frequently undetected and therefore might constitute a relevant infection focus, which specially materializes at school when insufficient anti-COVID measures are taken (194) (277) (278) (279). The latter is also extendible to young adults and university campuses (280) (281).

On the other hand, it is natural to think that factors associated to aging relate to infectious disease severity. In the case of COVID-19 we can point to comorbidities, cardiovascular malfunction, higher density and affinity of ACE2, antibody-dependent enhancement, immunosenescence (decreased immunological competence) and inflammaging (low-grade proinflammatory state), lower levels of vitamin D and shorter telomeres length (267) (282) (283). Cellular senescence, that stands for cell proliferation arrest due to stress factors like DNA damage or dysfunctional telomeres, protects the organism from cancer but also causes loss of regenerative capacity and therefore ageing. With their gene expression altered, senescent cells secrete pro-inflammatory cytokines and chemokines, that direct and negatively influence the course of COVID-19. Immune cells senescence or immunosenescence intensify age-related immunity vanishing facing novel pathogens and vaccines. Geroprotector drugs like mTOR inhibitors, already introduced, suppress the excess of inflammation related to senescence and enhances innate immunity, contributing to revert the effects of ageing (284) (285) (169).

\section{Genetic factors}

Since the genome codes for the operation of the whole organism, it is palpable that genetic variations must be analyzed regarding response to virus infections.

Genetic analyses would show a relation between ABO blood groups and Covid-19 susceptibility, with an advantage from blood group $\mathrm{O}$ versus group A (286). With respect to coagulopathies, correlated with COVID-19 severity, altered platelet gene expression and increased platelet aggregation have been found in COVID-19 patients, which may contribute to the disease pathophysiology (287). Moreover, conventional clinical assays can be outperformed by plasma proteomic signatures, able to identify potential biomarkers differentially expressed according to the severity level of COVID-19 patients, among them inflammation modulators, complement factors, the coagulation system, and pro-inflammatory factors like IL- 6 can be found (288).

More examples, a mutation in an interferon-stimulated gene (ISG) might severely interfere in the interferon's activity (forgive the redundancy). Following this, a deficiency found on the TLR7 of some severe COVID-19 patients cause defects in the production of type I and II interferons that might lead to impaired viral clearance (289). Additionally, preexisting dementia is known to be a risk factor for COVID19 severity. The apolipoprotein E (ApoE) genotype is a genetic risk factor for dementia, Alzheimer and cardiovascular diseases (especially allele e4). It has been discovered that the ApoE e4e4 allele results on a higher risk of developing severe COVID-19, and ApoE e4 not only affects lipoprotein function related to cardiopathies but also mediates macrophage pro-inflammatory and anti-inflammatory phenotypes. Interestingly, ApoE gene is highly co-expressed in type II alveolar cells in the lungs, as well as ACE2 (290). On the other hand, telomere length in peripheral blood lymphocytes has been observed inversely associated to severity in COVID-19, which in turn usually correlates to age (282).

In another dimension, genome-wide association studies (GWAS) show that the risk for respiratory failure in SARS-CoV-2 is increased in people carrying a genetic variant on chromosome three, inherited from Neanderthals, associated with an odds ratio for needing hospitalization of 1.6. This risk locus has an irregular geographical distribution, being carried by about half people in south Asia, one of six people in Europe, absent in east Asia and South America and with low presence in North America (286) (291). Other GWAS study has discovered relevant genetic associations with severe COVID-19, such as the protective role of interferon receptor subunit IFNAR2 or the association between the TYK2 expression, a gene that codes for a JAK protein and is involved in interferon signaling, and life-threatening illness. Other genes like OAS1, DPP9 and CCR2 may also contribute to explain some severe cases (292). Furthermore, a very relevant factor, the human leukocyte antigen (HLA) system, which codes for the major histocompatibility complex (MHC) proteins that present pathogen antigens to immune B and T cells, is essential for a correct immune response. The HLA system is polymorphic, therefore genetic variability across the three MHC I genes (HLA A, B, and C) that present antigens from a virus inside the cell, may affect susceptibility to and severity of SARS-CoV-2. In silico analysis has been performed to predict the best combination of HLAs for binding SARS-CoV-2 proteins, considering that the highest proportion and the relevance of these proteins for the virus replication have an impact on immune response effectivity (293). Another GWAS study relates the DNA methylation status of several cytosine-guanine $(\mathrm{CpG})$ sites to COVID-19 severity, specifically respiratory failure. These loci are situated inside genes linked to the interferon response

(C) 2021 by the Author. Distributed under a CC-BY 4.0 International license. 
pathway, such as the Absent in Melanoma 2 (AIM2) and HLA-C genes. AIM2 detects dsDNA from both damaged host cells or pathogens, and triggers the assembly of the inflammasome complex, the caspase- 1 activation, a sharp innate immune response with release of cytokines IL-1 $\beta$ and IL-18 and finally pyroptosis. Both hyperactivated HLA-C and AIM2 may imply autoimmune reactions and overproduction of cytokines, with a consequent aggravated immune response (294).

\section{Autoimmunity}

Autoimmunity (previously introduced with neutralizing autoantibodies against type I interferon) also appears to intervene in the course of the COVID-19 disease. In this respect, prothrombotic antiphospholipid autoantibodies that promote NETs release have been found in serum from COVID-19 hospitalized patients (295). Also, a clinical test has detected probable de novo autoantibodies on severe COVID-19 patients, some of them associated with coagulation abnormalities. If these autoreactive antibodies happened to be long lasting they could lie behind long-haul COVID, which shows a wide and diverse bunch of symptoms (296) (297) (298). The possibility of SARS-CoV-2 RNA integration into the infected cell genome following reverse-transcription, and consequent expression as chimeric transcripts has been exposed, and might contribute to explain the viral RNA presence in COVID-19 patients weeks after initial detection of infection by PCR (299).

\section{E. Chronic airway diseases: asthma}

Apparently, there is a proportionally low number patients with asthma suffering from an acute respiratory disease like COVID-19. Some studies have suggested that treatment with high-dose inhaled corticosteroids (ICSs) might increase the risk of death among severe asthmatic patients, but low-dose ICS would have no impact on the course of the disease (300) (301) (302) (303) (304). Other studies point that allergic asthma (Th2 phenotype) could even be protective from SARS-CoV-2 infection, and this might be due to a lower expression of ACE2 because of exposure to allergens and the effect of IL-13 (305) (306) (307) (308). The complexity of chronic inflammatory airway diseases like asthma and their relation to ACE2 expression levels, drives the need of further research be conducted around asthmatic population and their real risk of contracting and suffering from severe COVID-19.

\section{i. $\quad$ Nicotine}

Nicotinic acetylcholine receptors, specifically $\alpha 7 \mathrm{nAchR}$, constitute an anti-inflammatory pathway and are profusely expressed in immune cells like B cells, T cells and macrophages. Nicotine is an exogenous $\alpha 7 \mathrm{nAchR}$ agonist already used to treat some inflammatory diseases, since it is able to inhibit proinflammatory cytokines like TNF- $\alpha$, IL-1 and IL-6, and is even employed in some neuropsychiatric and neurodegenerative disorders. Additionally, $\alpha 7 \mathrm{nAChRs}$ activation on macrophages might be involved in the stimulation of the vagus nerve, which has demonstrated to have positive impact on certain diseases associated with high levels of proinflammatory cytokines such as sepsis. Together with the fact that smokers are proportionally less likely to be hospitalized, a possible therapeutic use of nicotine to inhibit the COVID19 cytokine storm would be suggested (309) (310).

\section{F. Influence of the microbiota and relevant nutrients}

\section{i. $\quad$ Microbiota and gut-brain axis}

The evidence of the microbiome essential role in an organism state of health increases every day mainly due to its relevant impact on the host's innate and adaptive immune system, so imbalances in microbiotaimmunity may contribute to the pathogenesis of many immune-mediated disorders (311). In COVID-19 disease, it should be noted that ACE2 receptors are also expressed in the intestinal epithelial cells, that a fraction of patients experience gastrointestinal symptoms usually associated to a poorer clinical outcome, and that SARS-CoV-2 RNA is present in fecal samples of infected patients (in fact, analysis of sewage water is used to search for fragments of the virus genetic material and observe the incidence of the infection by population areas, since this presence of the virus correlates with the subsequent PCR results).

An interesting study has applied machine learning to effectively predict progression to severe COVID19 disease from expression levels of a set of known serum protein and metabolite viral infections biomarkers, including the activated acute phase proteins amyloid A-1 (SAA1), SAA2 and C-reactive protein (a factor of systemic inflammation) (312). This identified set of biomarkers could also be indicator of unbalanced host immune system among older adults. In fact, elderly with preexistent cardiovascular, pulmonary, renal, and metabolic disorders present worse COVID-19 prognostic and are also more likely to present gut microbiota dysbiosis. Recent studies suggest that COVID-19 patients exhibit gut microbiota dysbiosis, and therefore microbiota eubiosis should be pursued. Additionally, gut microbial features

(C) 2021 by the Author. Distributed under a CC-BY 4.0 International license. 
(operational taxonomic units, OTUs, groups of similar bacteria) can be particularly predictive of the blood proteomic biomarkers of COVID-19 severity among non-infected healthy individuals, since disruption of gut microbiome may induce abnormal inflammation, a key factor in COVID-19 susceptibility and severity. Moreover, a group of microbial OTUs have been found notably correlated with the host inflammatory cytokines IL-1 $\beta$, IL-2, IL-4, IL-6, IL-8, IL-10, IL-12p70, IL-13, TNF- $\alpha$ and IFN- $\gamma$ (313). Multiple studies support the microbiome direct influence on the COVID-19 course (314) (315) (316) (317).

Furthermore, both gastrointestinal and neurological symptoms related to COVID-19 lead us to the fascinating gut-(lung)-brain axis. The enteric nervous system (ENS), that belongs to the autonomic nervous system (ANS) and is also known as the second brain, regulates the complex enteric performance with independence of the central nervous system (CNS). Despite this neural independence, the gut and the brain constitute a thrilling axis that bidirectionally relates diseases among them through the vagus nerve, the interaction with short-chain fatty acids, immunoregulatory elements and tryptophan (the serotonin neurotransmitter) metabolism, and the secretion of neurotransmitters by certain microbes (Figure 9). On the one hand, neurological disorders such as autism, Parkinson or Alzheimer correlate with gastrointestinal abnormalities; also, psychotropic drugs can mold the microbiome; on the other hand, psychiatric disorders like depression or anxiety are affected by the microbiota, and inflammatory bowel disease changes in stressmediated intestinal microbiota may alter neural activity in stress-sensitive areas of the brain (318) (319) (320). Related to this, a retrospective study carried out over a cohort of patients with severe mental disorders and under antipsychotics treatment, suggests a potential role of antipsychotics on preventing both SARSCoV-2 infection and poor COVID-19 outcomes (321). Specifically, the FDA approved phenylpiperazine aripiprazole has shown to revert the expression of a bunch of genes related to the immune response and hyperinflammation that are disturbed in COVID-19 patients (322). To conclude, the gut-brain connection deserves further exploration, possibly targeting the vagus nerve, that transmits information about the microbiota metabolites to the central nervous system and is also probably able to modulate the microbiota composition. Vagus nerve stimulation achieves anti-inflammatory attributes and indirectly modulates the immune activity of the spleen, what could significantly impact the course of the COVID-19 disease (323) (324).

\section{Brain Gut}

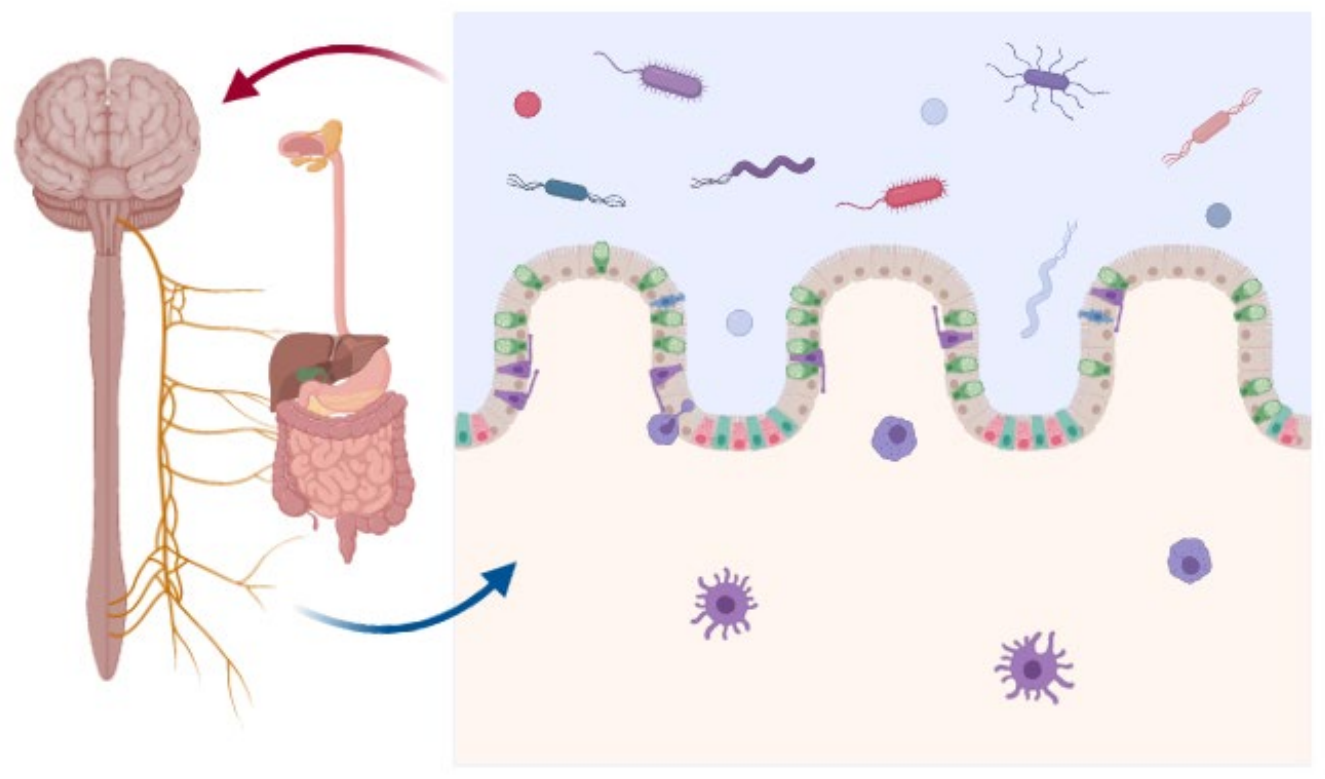

Figure 9 The gut-brain axis bidirectionally relates diseases through the vagus nerve, the interaction with shortchain fatty acids, immunoregulatory elements and tryptophan metabolism, and the secretion of neurotransmitters by certain microbes. (Reprinted from "Gut-Brain-Axis", by BioRender, October 2019, retrieved from https://app.biorender.com/biorender-templates/Copyright 2021 by BioRender).

\section{ii. Vitamin D and C}

Much has been speculated about the role of vitamin D in protecting from SARS-CoV-2 infection. Vitamin $\mathrm{D}$ is a secosteroid hormone that is mainly synthesized in the skin by the action of ultraviolet light

(C) 2021 by the Author. Distributed under a CC-BY 4.0 International license. 
radiation (vitamin D3), and can also be obtained in a lesser extent from the diet (vitamin D2 from animals, vitamin D3 from plants). By binding to vitamin D-binding protein (VDBP) in the blood flow, vitamin D reaches the liver and is metabolized into $25(\mathrm{OH})$ vitamin $\mathrm{D}$ or calcidiol, the most common circulating form of vitamin $\mathrm{D}$ in serum. $25(\mathrm{OH}) \mathrm{D}$ is then metabolized in the kidney to $1 \alpha, 25$-dihydroxyvitamin $\mathrm{D}$, $1 \alpha, 25(\mathrm{OH}) 2 \mathrm{D}$ or calcitriol, the most biologically active form of vitamin $\mathrm{D}$, that binds the vitamin $\mathrm{D}$ receptor (VDR) in the nucleus of target tissues where it takes control of regulation of calcium and phosphate metabolism. Interestingly, vitamin D also impacts regulation of the immune system: in the innate branch, it induces the secretion of antimicrobial peptides, (calcitriol) shows virus suppressive effects and reduces the release of TNF- $\alpha$ and interferon- $\gamma$ proinflammatory cytokines. In the adaptive immune branch, calcitriol stimulates T regulatory lymphocytes and suppresses cytokine release from Th1 and Th2 lymphocytes (325) (326). Importantly, some studies have shown the inverse relation between low serum levels of $25(\mathrm{OH}) \mathrm{D}$ and COVID-19 severity, with an association between COVID-19 increasing severity and 25(OH)D level decrease (327). Also, 25(OH)D level positively correlates with serum C-reactive protein (CRP) levels and negatively correlates with neutrophil and lymphocyte counts, what points to inflammation. Therefore, serum calcidiol appears as an independent predictor of COVID-19 mortality, and may constitute another factor explaining elderly outcomes since vitamin D deficiency is inversely related to age (328) (329). However, recent studies show that it is actually the active form of vitamin D (calcitriol or $1 \alpha, 25(\mathrm{OH}) 2 \mathrm{D})$ which is directly associated with bacteria that produce butyrate and improve gut microbial health, and therefore ratios of vitamin D activation and catabolism may be more accurate biomarkers than serum $25(\mathrm{OH}) \mathrm{D}(330)$. It seems evident that further research on vitamin $\mathrm{D}$, general vitamin supplementation and even impact of diet in the COVID-19 course of disease should be conducted.

Vitamin $\mathrm{C}$ or ascorbic acid is a pleiotropic stress hormone that also exerts interesting properties to fight COVID-19. As anti-inflammatory, vitamin $\mathrm{C}$ is able to interfere the NF- $\kappa \mathrm{B}$ triggering and reduce TNF $\alpha$ and IL-1 $\beta$, to suppress NETosis and also to induce cortisol production; as immunomodulator, it rises the production of type I interferons; as antioxidant, it upregulates antioxidant proteins; and as antiviral, vitamin $\mathrm{C}$ might inhibit the Mpro viral main protease. Multiple studies support vitamin $\mathrm{C}$ properties, and interestingly it has been shown that vitamin C levels are imperceptible in most COVID-19 patients suffering from acute respiratory distress syndrome (ARDS) (331) (332).

\section{iii. $\quad$ Zinc and selenium}

Zinc is a mineral present in low concentrations in cells that supports essential chemical reactions. It is involved in maintaining the respiratory epithelium barriers that help avoiding pathogens entry in the organism, in boosting the immune system, and it also shows anti-inflammatory and direct antiviral properties (inhibiting viral replication). It seems clear that zinc deficiency might negatively impact the SARS-CoV-2 infection course. A study with hospitalized COVID-19 patients shows that zinc administered together with a zinc ionophore (a fat-soluble transporter that helps zinc cross the cell membrane) correlated with a decrease of $24 \%$ in COVID-19 mortality, what evidences the need for further studies on a straightforward oral zinc supplementation against the disease (333) (334) (335). Selenium, a trace element that exist in organic and inorganic forms, is known to prevent exacerbated cytokine activation in infectious and inflammatory diseases, lessening the incidence and severity of viral infections including COVID-19. It is hypothesized that redox-active selenium compounds would be able to inhibit some SARS-CoV-2 proteases (336). Other nutrients may have positive influence on the course of COVID-19, such as folic acid, a water-soluble B vitamin that could inhibit the activity of the furin protease (337).

\section{iv. Omega-3 fatty acids}

Omega-3 are unsaturated fatty acids mainly present in fish oils, with very-long chain Eicosapentaenoic acid (EPA) and docosahexaenoic acid (DHA) being and of especial relevance. Both EPA and DHA exert a bunch of interesting anti-inflammatory properties that have shown benefit on animal models of rheumatoid arthritis, inflammatory bowel disease and asthma (337). A recent study on a small cohort of COVID-19 patients has established a strong inverse relationship between Omega-3 tissue levels measured by the Omega-3 Index (O3I) and decease, finding an odds ratio for death in patients with higher O3I levels (first quartile) of 0.25 compared to O3I less than $5.7 \%$ (339).

\section{SARS-COV-2 MUTATIONS AND VARIANTS}

Almost from the beginning of the official COVID-19 outbreak in January 2020, the SARS-CoV-2 genome is continuously being sequenced and published in repositories like the GISAID initiative, that as of June 2021 holds the official hCoV-19 reference sequence along with almost two million genetic sequences in exponential growth (340). This allows for tracking the pandemic spread and for monitoring mutations that may impact the transmissibility, pathogenicity or even the effectivity of vaccines or other treatments like therapeutic antibodies targeting the antigens' epitopes. The (evolutionary) mutation rate of

(C) 2021 by the Author. Distributed under a CC-BY 4.0 International license. 
SARS-CoV-2 is said to be relatively low, showing one mutation per two or three weeks (341), which is not incompatible with the thousands of detected mutations that can be consulted at GISAID. For example, the long time dominant D614G mutation (replacement of aspartic acid D amino acid by glycine $\mathrm{G}$ ) of the spike protein is associated to an increase in viral loads in the upper respiratory tract and a younger patient profile, and it may also suggest a selective advantage and increase in virus transmission, though in principle this should not affect the effectivity of the designed vaccines targeting the spike (342) (343) (344) (345). Mutations can affect not only the spike but also other proteins such as the immunogenic nucleocapsid $(\mathrm{N})$ (346) or the open reading frames (ORFs). Variant $\Delta 382$ presents a 382-nucleotide deletion in the strongly immunogenic ORF8, that might be involved in the virus immune evasion, so $\Delta 382$ would presumably cause a less severe infection (347) (348). Other variant called 20A.EU1 found in summer 2020 probably in Spain was spread across Europe as a consequence of the summer mobility (349).

Variants comprising many mutations may have been originated in immunosuppressed COVID-19 patients where virus replication is increased (350), or even as a consequence of reverse-zoonosis that create new animal reservoirs and can revert back to humans (351) (352). The United Kingdom has communicated in late December 2020 the new SARS-CoV-2 B.1.1.7 lineage, also known as 20I/501Y.V1 Variant of Concern (VOC) 202012/01, with surprising multiple mutations affecting the spike protein (deletion 69-70, deletion 144, N501Y, A570D, D614G, P681H, T716I, S982A, D1118H), ORF1ab, ORF8 and the nucleocapsid protein (353), with an overall figure of 14 non-synonymous mutations and 3 deletions. Some of the mutations affecting the spike are of special interest since they could exert biological effects: mutation N501Y (501 is one of six key contact residues within the receptor-binding domain (RBD)) might increase binding affinity to ACE2 (354); 69-70del might be related to evasion of the immune system; and mutation $\mathrm{P} 681 \mathrm{H}$ is adjoining to the furin cleavage site between subunits S1 and S2 (that promotes host cells viral entry) (355). Preliminary studies show higher transmissibility than other lineages and a notable increased affectation among young population, which could be caused by a longer duration of the acute infection (356) (357). An increased risk of death has been detected in this variant as compared to preceding variants, estimated at 64\% (358). However, subsequent studies contradict this and do not detect greater severity in hospitalized patients nor even an increment in the reinfection rate (359) (360).

Also, B.1.351 lineage, a.k.a. 20H/501Y.V2, detected in South Africa shows several mutations affecting the spike protein, among them K417N, E484K and N501Y (this one in common with the B.1.1.7 lineage) located in the RBD. Regarding binding affinity, both E484K and K417N mutations seem to exert a minimum effect. However, K417N and N501Y mutations, and especially E484K, could escape neutralizing antibodies binding, since the RBD is immunodominant (provokes the majority of the generated antibodies) and also the target of $90 \%$ of neutralizing antibodies (361) (362). Studies show that possible RBD escape mutations coincide in or near the contact surface between antibodies and the RBD, particularly in the epitope positioned around the 443-450 loop, precisely targeted by the Regeneron antibody cocktail REGEN-COV2 (363) (364). In fact, many monoclonal antibodies against both the RBD and the N-terminal domain (NTD) region within the spike do fail to neutralize variants carrying the E484K mutation (365). B.1.351 lineage offers a substantially increased resistance to neutralization by wild convalescent plasma and from the Pfizer/BioNTech BNT162b2 and the Moderna mRNA-1273 vaccines (365) (366). No altered neutralizing activity of antibodies generated by the Pfizer/BioNTech BNT162b2 vaccine against N501Y mutation has been found (367). Observational results from Israel, the first country to immunize its population with the Pfizer/BioNTech BNT162b2 vaccine are aligned with the clinical trial outcomes. The two-dose schedule is extremely effective in impeding symptomatic and asymptomatic SARS-CoV-2 infections in adults older than 16, including hospitalizations and death, even for the B.1.1.7 variant. COVID-19 incidence descent ignores reopening of society and directly associates with higher vaccination coverage (368) (369). Some embolic and thrombotic events affecting AstraZeneca ChAdOx1-S and COVID-19 Vaccine Janssen recipients have been reported. In the so-called vaccine induced prothrombotic immune thrombocytopenia (VIPIT) disorder, the vaccine apparently induces platelet-activating (auto)antibodies against platelet factor 4 (PF4), a cytokine released by activated platelets when aggregating, that may lead to serious thrombocytopenia and thrombotic complications at rare sites like the brain or abdomen (370). In a complementary mechanism, the DNA encoding for the spike protein in these adenovirus vaccines could suffer from undesired splicing events in the transcription process carried out in the cell nucleus, leading to shorter, soluble variants of the spike protein. These mutants, unable to be anchored to the cell membrane, may bind ACE2 expressing endothelial cells in blood vessels, and be also targeted by newly created antibodies, leading to strong inflammation and even NETs formation. The solution would imply the redesign of the spike open reading frames in DNA-based vaccines to prevent unwanted splice incidents (371). A large study comprising over 280,000 ChAdOx1-S vaccinees aged 1865 years in Norway and Denmark confirmed a higher rate of venous thromboembolic events, especially of cerebral venous thrombosis emerging in one in 40,000 individuals (372). Though arterial events were not significant in that study, several leading to ischaemic stroke have been reported in young people (373).

(C) 2021 by the Author. Distributed under a CC-BY 4.0 International license. 
P.1 lineage (a.k.a. 20J/501Y.V3) noticed in Brazil exhibit a bunch of amino acid changes and deletions, including K417T, E484K, and N501Y. A reinfection case has been reported carrying this variant (374).

Additionally, N439K mutation in the receptor-binding motif (RBM) of the spike appears in several variants, and has shown increased binding affinity to ACE2 and also evasion of several monoclonal antibodies neutralization and of polyclonal sera responses, while maintaining disease severity unaltered (375). Maps of mutations in the RBD of SARS-CoV-2 that evade antibody binding are being uncovered, with the aim of predicting potential viral escape from human sera or monoclonal antibodies in emerging variants (376) (377) (363) (378).

B.1.617 lineage, along with its three subtypes B.1.617.1, B.1.617.2 (especially this one) and B.1.617. 3 was initially identified in India. It shows an increase in transmissibility of around $50 \%$, and has quickly displaced B.1.1.7 variant in the United Kingdom. It carries mutations like L452R, T478K (B.1.617.2) and E484Q (B.1.617.1), among others, that are related to vaccine escape (379).

Centers for Disease Control and Prevention like the CDC from the U.S.A. and the European eCDC offer updated information related to SARS-CoV-2 variants of interest, variants of concern and variants of high consequence (380) (381).

Back to immunity, and importantly CD4+ and CD8+ T cell responses in both COVID-19 patients and mRNA vaccinated individuals are likely not significantly affected by mutations present in the aforementioned variants, nor are the sequences of most SARS-CoV-2 T cell epitopes (382) (383). This could be related to the polyclonal character of the $\mathrm{T}$ cell response, with $\mathrm{T}$ cell epitopes distributed along numerous regions of the spike.

New generation vaccines are to be developed in order to face novel arising variants, that usually share similarities since they are the natural consequence of the virus evolution and adaptation to the human host and the environment (e.g. antibodies presence).

Finally, genome analyses together with proteomics also shed light on the implications of the virus, for instance the non-structural proteins nsp9 and nsp10 seem to behave like virulence factors that interact with the NF-kB transcriptional repressor factor NKRF, which may contribute to the induction of IL-8 and IL-6 in lung epithelial cells and the consequent inflammatory overreaction (384). However, the SARS-CoV-2 genome remains incompletely uncovered since for example overlapping genes, able to code for proteins and /or exert other functions in the virus lifecycle, such as ORF3d are still appearing (385).

\section{SOME INNOVATIVE TREATMENTS AGAINST COVID-19}

\section{A. Cell-based therapies}

Cell-based therapies employ living cells with biological effect. Among them, Mesenchymal Stem Cells (MSCs), natural killer (NK) cells, dendritic cells and SARS-CoV2-specific T cells are being evaluated as potential COVID-19 treatments (386). For instance, a study has carried out an allogeneic adipose-tissue derived MSC (AT-MSC) treatment, that was intravenously administered to a small group of thirteen COVID-19 patients under invasive mechanical ventilation. As a result, most patients showed clinical improvement with a decrease in inflammatory parameters (CRP, IL-6, ferritin, LDH and d-dimer) as well as an increase in lymphocytes (387). A similar strategy is being developed by a Bonus BioGroup drug based on activated mesenchymal cells, leading to the fast cure of pneumonia symptoms by reducing the immune cells burden in the injured pulmonary alveoli (388). Also, SARS-CoV-2-specific memory T cells extracted from recovered patients might be infused into severe COVID-19 patients, enabling them to create their own immunological memory. A study has demonstrated the easiness of isolating SARS-CoV-2-specific T cells from selected donors conditioned to the expression of IFN- $\gamma$ and HLA (389). In this regard, a clinical trial to infuse NK cells and memory T cells to severe COVID-19 patients suffering from pneumonia and/or lymphopenia is ongoing (390).

\section{B. CRISPR}

Clustered Regularly Interspaced Short Palindromic Repeats or CRISPR, and more specifically, CRISPR/Cas9, is an eminent genome editing tool composed of a Cas9 endonuclease that cuts the DNA at a user-defined specific sequence, determined by a bound short single stranded guide RNA (gRNA), in order to add or remove DNA target nucleotide pairs. The cell itself is able to repair its damaged DNA yielding a loss-of-function mutation on the target gene. This DNA modification usually presents non-desired side effects, however CRISPR-mediated gene activation or repression without modifying the DNA can also be performed (391) (392).

New CRISPR techniques are also able to target RNA instead of DNA with novel endonucleases like Cas13, even exerting higher-level specificity than other knockdown techniques such as RNA interference (RNAi). A CRISPR system using a Cas13d protein and CRISPR-associated RNAs (crRNAs) that guide the

(C) 2021 by the Author. Distributed under a CC-BY 4.0 International license. 
Cas13d to specific RNA molecules has already been designed, to effectively target and degrade the positivesense viral genome used as template RNA and also its viral gene expression (mRNA), successfully restricting viral replication (with pan-coronavirus protection) (393). This astounding technology can also be used to perform genome-wide CRISPR loss-of-function screening to uncover host genes essential for SARS-CoV-2 to successfully infect the cells. Along with known host factors such as ACE2 receptor and the protease Cathepsin L, genes like HMGB1 and SIGMAR, and many others involved in the virus replication process, including those related to endosome regulation, have been identified (394) (395).

Also worth mentioning, CRISPR can be included as a sequence detector in tests for detecting SARSCoV-2, in two-steps methods like SHERLOCK (Specific High-sensitivity Enzymatic Reporter unLOCKing), following viral RNA extraction and amplification, showing results quicker than PCR (396).

\section{CONCLUSIONS}

The COVID-19 occurrence has affected health and economy in a worldwide scale with severe consequences on daily life of every human being. This novel disease dares our medical and biological knowledge due to its intrinsic complexity and its fast and easy spread across the globe. The wide bunch of symptoms including respiratory, digestive, neurological, cardiovascular, dermatological, inflammatory and even immunologic dysfunctions; or heterogeneous immune responses, severity profiles -including asymptomatic and long-haulers or persistent covid- and risk factors, hinder the patient prognosis and the development of an effective and personalized treatment. In fact, any (especially, non-vaccinated) person has a potential risk of developing severe COVID-19.

The resolution of the pandemic involves many factors, from simple prophylactic measures like perfectly efficient face masks to mass vaccination, going through treatments including repurposed and newly designed drugs like antivirals that block the virus replication cycle (e.g. nucleoside analogues), monoclonal antibodies and nanobodies (e.g. neutralizing antibodies targeting the receptor binding domain RBD of the spike; or IL-6 antagonists), immune modulators (e.g. convalescent hyperimmune plasma and derivates; or interferons), anti-inflammatories (e.g. dexamethasone), anticoagulants and other small molecules. Also, massive, quick, accurate and affordable tests must be frequently performed, since one of the main reasons for the success of the COVID-19 widespread has been the undetected asymptomatic but infectious individuals. Distinct biomarkers to make a precise prognosis in order to adjust treatment should be uncovered. In addition, research on alternative effective ways of neutralizing the SARS-CoV-2 capacity of infection also contributes, for instance destroying the virus lipidic membrane in the air or inside our mouth and nasal cavities. High-Efficiency Particulate Arresting HEPA mechanical filters, ozone generators, ultraviolet UV germicidal irradiation or hydrogen peroxide-based air purifiers are currently available.

Research has undoubtedly been the key. Research, and the associated funding, have made possible the historic scientific milestone of having a notable number of highly effective vaccines against COVID-19 in record time of only several months. Technology, and especially artificial intelligence has provided invaluable assistance in accelerating processes and analyzing huge amounts of data, helping with the discovery of new drugs or repurposing existing ones, with the prediction of the COVID-19 phases or the spread of the infection. However, the core work remains within the biological and medical scopes, inside the labs (research, genomic virus surveillance, genetic analyses...) and with the clinical trials, and so scientific effort and investment must keep on them their main focus. Besides, social and administrative issues have markedly impacted the development of the COVID-19 crisis. General deficiencies within the sanitary, governance, or logistic structures, not prepared for facing such a global health threat and such a disruption in the ordinary course of life, have been uncovered all over the world. The ability to implement fast and effective measures, offering accurate information to the general public, taking care and attention of elder people but also children show room for improvement. Besides, more individual responsibilities like maintaining high air quality indoors, a correct state of nutrition or physical fitness should now be of general awareness.

Many challenges and hazards are still watching. Maybe the most relevant is the appearance of SARSCoV-2 mutations that might evade or diminish the immune response from vaccinated, or the efficacy of therapies targeting parts of the virus like monoclonal antibodies and antivirals. Or the emergence of variants that increase transmissibility, susceptibility and lethality. Or new strains. Or virus recombinations with other strains or other viruses (397). Even different viruses reactivation in immunodepressed patients. Also, reverse zoonosis is a significant threat. Hence the urgency of a global, fast, flexible and massive vaccination program complemented with effective treatments (easily administered in early stages of the disease, or else for severely ill), along with a permanent tracking of vaccination immunity response, duration and possible side effects, potential reinfections and coinfections (398), population immunity and virus genome sequencing. We have unfailingly just started a new era where research and monitoring must be uninterrupted not only for ensuring the ending of the COVID-19 pandemic but also to better face foreseeable future pandemics.

(C) 2021 by the Author. Distributed under a CC-BY 4.0 International license. 


\section{Disclosure OF CONFLICTS OF INTEREST}

The author reports no conflict of interest.

\section{REFERENCES}

1. Romano, M., Ruggiero, A., Squeglia, F., Maga, G., Berisio, R. A Structural View of SARS-CoV2 RNA Replication Machinery: RNA Synthesis, Proofreading and Final Capping. Cells 2020, 9, 1267. https://doi.org/10.3390/cells9051267

2. COVID-19 Dashboard by the Center for Systems Science and Engineering (CSSE) at Johns Hopkins University (JHU). Available at https://gisanddata.maps.arcgis.com/apps/opsdashboard/ (accessed: 8 June 2021)

3. Krammer, F. SARS-CoV-2 vaccines in development. Nature 586, 516-527 (2020). https://doi.org/10.1038/s41586-020-2798-3

4. Flanagan Katie L., Best Emma, Crawford Nigel W., et al. Progress and Pitfalls in the Quest for Effective SARS-CoV-2 (COVID-19) Vaccines. Frontiers in Immunology 11 (2020). https://doi.org/10.3389/fimmu.2020.579250

5. Polack, Fernando P., Thomas, Stephen J., Kitchin, Nicholas, et al. Efficacy of the BNT162b2 mRNA Covid-19 Vaccine. New England Journal of Medicine 383. (2020). https://doi.org/10.1056/NEJMoa2034577

6. Baden, Lindsey R., El Sahly, Hana M., Essink, Brandon et al. Efficacy and Safety of the mRNA1273 SARS-CoV-2 Vaccine. New England Journal of Medicine (2020). https://doi.org/10.1056/NEJMoa2035389

7. Merryn Voysey, Sue Ann Costa Clemens, Shabir A Madhi, Lily Y Weckx, Pedro M Folegatti, Parvinder K Aley, et al. Safety and efficacy of the ChAdOx1 nCoV-19 vaccine (AZD1222) against SARS-CoV-2: an interim analysis of four randomised controlled trials in Brazil, South Africa, and the UK. The Lancet Journal 397 (2021). https://doi.org/10.1016/S0140-6736(20)32661-1

8. Novavax COVID-19 Vaccine Demonstrates 89.3\% Efficacy in UK Phase 3 Trial. January 28, 2021. Available at https://ir.novavax.com/node/15506/pdf

9. Denis Y Logunov, Inna V Dolzhikova, Dmitry V Shcheblyakov, et al. Safety and efficacy of an rAd26 and rAd5 vector-based heterologous prime-boost COVID-19 vaccine: an interim analysis of a randomised controlled phase 3 trial in Russia, The Lancet, 2021, ISSN 0140-6736, https://doi.org/10.1016/S0140-6736(21)00234-8.

10. Jerald Sadoff, Mathieu Le Gars, Georgi Shukarev, et al. Interim Results of a Phase 1-2a Trial of Ad26.COV2.S Covid-19 Vaccine. The New England Journal of Medicine. 2021. DOI: 10.1056/NEJMoa2034201

11. Coronavirus is in the air — there's too much focus on surfaces. Editorial, 02 February 2021. Nature. Available at https://www.nature.com/articles/d41586-021-00277-8

12. Scientific Brief: SARS-CoV-2 and Potential Airborne Transmission. Updated Oct. 5, 2020. Available at https://www.cdc.gov/coronavirus/2019-ncov/more/scientific-brief-sars-cov-2.html

13. Kiros, M., Andualem, H., Kiros, T. et al. COVID-19 pandemic: current knowledge about the role of pets and other animals in disease transmission. Virology Journal 17, 143 (2020). https://doi.org/10.1186/s12985-020-01416-9

14. Oude Munnink BB, Sikkema RS, Nieuwenhuijse DF, et al. Transmission of SARS-CoV-2 on mink farms between humans and mink and back to humans. Science. 2021 http://doi.org/10.1126/science.abe5901.

15. Jop de Vrieze. Can a century-old TB vaccine steel the immune system against the new coronavirus? Mar. 23, 2020. Available at https://www.sciencemag.org/news/2020/03/cancentury-old-tb-vaccine-steel-immune-system-against-new-coronavirus

16. Daniel Blanco-Melo, Benjamin E. Nilsson-Payant, et al. Imbalanced Host Response to SARSCoV-2 Drives Development of COVID-19. Cell $181 \quad$ (2020). https://doi.org/10.1016/j.cell.2020.04.026.

17. Microbiology: An Introduction. G. Tortora, B. Funke, C. Case. $13^{\text {th }}$ edition. Ed. Pearson. ISBN: 9780134709260. 2019.

18. Iwasaki, A., Medzhitov, R. Control of adaptive immunity by the innate immune system. Nature Immunology 16, 343-353 (2015). https://doi.org/10.1038/ni.3123

19. John W Schoggins, Charles M Rice. Interferon-stimulated genes and their antiviral effector functions. Current Opinion in Virology 1 (2011) https://doi.org/10.1016/j.coviro.2011.10.008.

20. Jodie Testar, Imperial College London, UK. Cytokines: Introduction. Available at: https://www.immunology.org/public-information/bitesized-immunology/receptors-andmolecules/cytokines-introduction (accessed 8 June 2021) 
21. Chapter 4 - Antiviral Immunity and Virus Vaccines. Editor(s): N. James MacLachlan, Edward J. Dubovi. Fenner's Veterinary Virology (Fifth Edition). Academic Press. (2017) https://doi.org/10.1016/B978-0-12-800946-8.00004-0.

22. McComb S., Thiriot A., Akache B., Krishnan L., Stark F. (2019) Introduction to the Immune System. In: Fulton K., Twine S. (eds) Immunoproteomics. Methods in Molecular Biology, vol 2024. Humana, New York, NY. https://doi.org/10.1007/978-1-4939-9597-4_1

23. Acharya, D., Liu, G. \& Gack, M.U. Dysregulation of type I interferon responses in COVID-19. Nature Reviews Immunology 20, 397-398 (2020). https://doi.org/10.1038/s41577-020-0346-X

24. Taylor, Brian Lin, Avinash Waghray, et al. SARS-CoV-2 Receptor ACE2 Is an InterferonStimulated Gene in Human Airway Epithelial Cells and Is Detected in Specific Cell Subsets across Tissues. Cell 181 (2020). https://doi.org/10.1016/j.cell.2020.04.035.

25. Julian Heuberger, Jakob Trimpert, Daria Vladimirova, et al. Epithelial response to IFN- $\gamma$ promotes SARS-CoV-2 infection. EMBO Molecular Medicine (2021)0:e13191, https://doi.org/10.15252/emmm.202013191

26. Blume, C., Jackson, C.L., Spalluto, C.M. et al. A novel ACE2 isoform is expressed in human respiratory epithelia and is upregulated in response to interferons and RNA respiratory virus infection. Nature Genetics (2021). https://doi.org/10.1038/s41588-020-00759-x

27. Hadjadj J, Yatim N, Barnabei L, et al. Impaired type I interferon activity and inflammatory responses in severe COVID-19 patients. Science $369 \quad$ (2020) http://doi.org/10.1126/science.abc6027.

28. Zhang Q, Bastard P, Liu Z, et al. Inborn errors of type I IFN immunity in patients with lifethreatening COVID-19. Science 370 (2020). http://doi.org/10.1126/science.abd4570.

29. Ludmila Prokunina-Olsson, Noémie Alphonse, Ruth E. Dickenson, et al. COVID-19 and emerging viral infections: The case for interferon lambda. Journal of Experimental Medicine 4 May 2020; 217 (5): e20200653. doi: https://doi.org/10.1084/jem.20200653

30. Betsy J. Barnes, Jose M. Adrover, Amelia Baxter-Stoltzfus, et al. Targeting potential drivers of COVID-19: Neutrophil extracellular traps. Journal of Experimental Medicine 1 June 2020; 217 (6): e20200652. doi: https://doi.org/10.1084/jem.20200652

31. Zhou, D., Duyvesteyn, H.M.E., Chen, CP. et al. Structural basis for the neutralization of SARSCoV-2 by an antibody from a convalescent patient. Nature Structural and Molecular Biology 27, 950-958 (2020). https://doi.org/10.1038/s41594-020-0480-y

32. Jian Shang, Yushun Wan, Chuming Luo, et al. Cell entry mechanisms of SARS-CoV-2. Proceedings of the National Academy of Sciences May 2020, 117 (21) 11727-11734; http://doi.org/10.1073/pnas.2003138117

33. Li H, Zhou Y, Zhang M, Wang H, Zhao Q, Liu J. Updated approaches against SARS-CoV-2. Antimicrobial Agents and Chemotherapy 64:e00483-20. https://doi.org/10.1128/AAC.00483-20.

34. Rehman M, Tauseef I, Aalia B, Shah SH, Junaid M, Haleem KS. Therapeutic and vaccine strategies against SARS-CoV-2: past, present and future. Future Virology. (2020); 10.2217/fvl2020-0137. http://doi.org/doi:10.2217/fvl-2020-0137

35. Jeong GU, Song H, Yoon GY, Kim D and Kwon Y-C (2020). Therapeutic Strategies Against COVID-19 and Structural Characterization of SARS-CoV-2: A Review. Frontiers in Microbiology. 11:1723. doi: 10.3389/fmicb.2020.01723

36. Jamshaid, H., Zahid, F., Din, I.u. et al. Diagnostic and Treatment Strategies for COVID-19. AAPS PharmSciTech 21, 222 (2020). https://doi.org/10.1208/s12249-020-01756-3

37. Igase, M., Kohara, K., Nagai, T. et al. Increased Expression of Angiotensin Converting Enzyme 2 in Conjunction with Reduction of Neointima by Angiotensin II Type 1 Receptor Blockade. Hypertension Research 31, 553-559 (2008). https://doi.org/10.1291/hypres.31.553

38. Lei Fang, George Karakiulakis, Michael Roth. Are patients with hypertension and diabetes mellitus at increased risk for COVID-19 infection? The Lancet Respiratory Medicine 8 (2020). https://doi.org/10.1016/S2213-2600(20)30116-8.

39. Mehrshad Sadria, Anita T. Layton. Use of Angiotensin-Converting Enzyme Inhibitors and Angiotensin II Receptor Blockers During the COVID-19 Pandemic: A Modeling Analysis. PLOS Computational Biology 16 (2020). https://doi.org/10.1371/journal.pcbi.1008235

40. Shibata, S., Arima, H., Asayama, K. et al. Hypertension and related diseases in the era of COVID19: a report from the Japanese Society of Hypertension Task Force on COVID-19. Hypertension Research 43, 1028-1046 (2020). https://doi.org/10.1038/s41440-020-0515-0

41. Gupta, R., Hussain, A. Misra, A. Diabetes and COVID-19: evidence, current status and unanswered research questions. European Journal of Clinical Nutrition 74, 864-870 (2020). https://doi.org/10.1038/s41430-020-0652-1 
42. Wang, S., Qiu, Z., Hou, Y. et al. AXL is a candidate receptor for SARS-CoV-2 that promotes infection of pulmonary and bronchial epithelial cells. Cell Research 31, 126-140 (2021). https://doi.org/10.1038/s41422-020-00460-y

43. Depfenhart M, de Villiers D, Lemperle G, Meyer M, Di Somma S. Potential new treatment strategies for COVID-19: is there a role for bromhexine as add-on therapy?. Internal and Emergency Medicine. 2020;15(5):801-812. doi:10.1007/s11739-020-02383-3

44. Gene cards. Furin gene. Available at https://www.genecards.org/cgibin/carddisp.pl?gene=FURIN (accessed 8 June 2021).

45. Julie Blaising, Stephen J. Polyak, Eve-Isabelle Pécheur. Arbidol as a broad-spectrum antiviral: An update. Antiviral Research 107. (2014) https://doi.org/10.1016/j.antiviral.2014.04.006.

46. Gao, W., Chen, S., Wang, K. et al. Clinical features and efficacy of antiviral drug, Arbidol in 220 nonemergency COVID-19 patients from East-West-Lake Shelter Hospital in Wuhan: a retrospective case series. Virology Journal 17, 162 (2020). https://doi.org/10.1186/s12985-02001428-5

47. Nojomi, M., Yassin, Z., Keyvani, H. et al. Effect of Arbidol (Umifenovir) on COVID-19: a randomized controlled trial. BMC Infectious Diseases 20, 954 (2020). https://doi.org/10.1186/s12879-020-05698-w

48. Alexander Zoufaly, Marko Poglitsch, Judith H Aberle, et al. Human recombinant soluble ACE2 in severe COVID-19. The Lancet Respiratory Medicine 8 (2020). https://doi.org/10.1016/S22132600(20)30418-5.

49. Molecular Biology of the Cell, 6th edition. Bruce Alberts, Alexander Johnson, Julian Lewis, Martin Raff, Keith Roberts, and Peter Walter. New York: Garland Science; 2015. ISBN: 978-08153-4464-3.

50. Christian Gaebler, Zijun Wang, Julio C. C. Lorenzi, et al. Evolution of Antibody Immunity to SARS-CoV-2. bioRxiv; doi: https://doi.org/10.1101/2020.11.03.367391

51. Ibarrondo, F. Javier, Fulcher, Jennifer A., Goodman-Meza, David, et al. Rapid Decay of AntiSARS-CoV-2 Antibodies in Persons with Mild Covid-19. New England Journal of Medicine 383. (2020). https://doi.org/10.1056/NEJMc2025179

52. Long, QX., Tang, XJ., Shi, QL. et al. Clinical and immunological assessment of asymptomatic SARS-CoV-2 infections. Nature Medicine 26, 1200-1204 (2020). https://doi.org/10.1038/s41591020-0965-6

53. Wajnberg A, Amanat F, Firpo A, et al. Robust neutralizing antibodies to SARS-CoV-2 infection persist for months. Science. 2020;370(6521):1227-1230. doi: 10.1126/science.abd7728.

54. Sterlin D, Mathian A, Miyara M, et al. IgA dominates the early neutralizing antibody response to SARS-CoV-2. Science Translational Medicine. 2021 Jan 20;13(577):eabd2223. doi: 10.1126/scitranslmed.abd2223. Epub 2020 Dec 7. PMID: 33288662.

55. Turner, J.S., Kim, W., Kalaidina, E. et al. SARS-CoV-2 infection induces long-lived bone marrow plasma cells in humans. Nature (2021). https://doi.org/10.1038/s41586-021-03647-4

56. Jérémy Dufloo, Ludivine Grzelak, Isabelle Staropoli, et al. Asymptomatic and symptomatic SARS-CoV-2 infections elicit polyfunctional antibodies. Cell Reports Medicine. 2021. https://doi.org/10.1016/j.xcrm.2021.100275

57. Monoclonal Antibodies Overview. Available at: https://www.genscript.com/how-to-makemonoclonal-antibodies.html (accessed: 8 June 2021)

58. Dutta NK, Mazumdar K, Gordy JT. The Nucleocapsid Protein of SARS-CoV-2: a Target for Vaccine Development. Journal of Virology. 2020;94(13):e00647-20. doi: 10.1128/JVI.00647-20.

59. Jose L. Sanchez-Trincado, Marta Gomez-Perosanz, Pedro A. Reche, "Fundamentals and Methods for T- and B-Cell Epitope Prediction", Journal of Immunology Research, vol. 2017, Article ID 2680160, 14 pages, 2017. https://doi.org/10.1155/2017/2680160

60. Immune Epitope Database (IEDB). Available at: http://www.iedb.org/ (accessed 8 June 2021)

61. Danielle Medeiros. Press Release: Generex Signs Contract with EpiVax to Develop Ii-Key Peptide Vaccines to Address the Coronavirus Pandemic. Mar 4, 2020. Available at: https://epivax.com/news/press-release-generex-signs-contract-with-epivax-to-develop-ii-keypeptide-vaccines-to-address-the-coronavirus-pandemic

62. Wang, C., Li, W., Drabek, D. et al. A human monoclonal antibody blocking SARS-CoV-2 infection. Nature Communications 11, 2251 (2020). https://doi.org/10.1038/s41467-020-16256-y

63. Chen, X., Li, R., Pan, Z. et al. Human monoclonal antibodies block the binding of SARS-CoV-2 spike protein to angiotensin converting enzyme 2 receptor. Cellular and Molecular Immunology 17, 647-649 (2020). https://doi.org/10.1038/s41423-020-0426-7 
64. Wu Y, Wang F, Shen C, et al. A noncompeting pair of human neutralizing antibodies block COVID-19 virus binding to its receptor ACE2. Science. 2020 ;368(6496):1274-1278. doi: $10.1126 /$ science.abc2241.

65. COVID-19 Long-Acting AntiBody (LAAB) combination AZD7442 rapidly advances into Phase III clinical trials. 9 October 2020. Available at: https://www.astrazeneca.com/media-centre/pressreleases/2020/covid-19-long-acting-antibody-laab-combination-azd7442-rapidly-advances-intophase-iii-clinical-trials.html

66. Lilly announces proof of concept data for neutralizing antibody LY-CoV555 in the COVID-19 outpatient setting. September 16, 2020. Available at: https://investor.lilly.com/newsreleases/news-release-details/lilly-announces-proof-concept-data-neutralizing-antibody-ly

67. Coronavirus (COVID-19) Update: FDA Authorizes Monoclonal Antibody for Treatment of COVID-19. November 09, 2020. Available at: https://www.fda.gov/news-events/pressannouncements/coronavirus-covid-19-update-fda-authorizes-monoclonal-antibody-treatmentcovid-19

68. Coronavirus (COVID-19) Update: FDA Authorizes Monoclonal Antibodies for Treatment of COVID-19. November 21, 2020. Available at: https://www.fda.gov/news-events/pressannouncements/coronavirus-covid-19-update-fda-authorizes-monoclonal-antibodies-treatmentcovid-19

69. Kathryn Westendorf, Stefanie Žentelis, Denisa Foster, et al. LY-CoV1404 potently neutralizes SARS-CoV-2 variants. bioRxiv 2021. doi: https://doi.org/10.1101/2021.04.30.442182

70. Rappazzo CG, Tse LV, Kaku CI, et al. Broad and potent activity against SARS-like viruses by an engineered human monoclonal antibody. Science. 2021 Jan 25:eabf4830. doi: 10.1126/science.abf4830. Epub ahead of print. PMID: 33495307.

71. COVID-19 Biologics Tracker. Available at: https://www.antibodysociety.org/covid-19-biologicstracker/ (accessed 8 June 2021).

72. Kalra P, Dhiman A, Cho WC, Bruno JG and Sharma TK (2018) Simple Methods and Rational Design for Enhancing Aptamer Sensitivity and Specificity. Frontiers in Molecular Biosciences. 5:41. doi: 10.3389/fmolb.2018.00041

73. Anton Schmitz, Anna Weber, Mehtap Bayin et al. A SARS-CoV-2 Spike Binding DNA Aptamer that Inhibits Pseudovirus Infection by an RBD-Independent Mechanism. Angewandte Chemie International Edition, vol. 60, 2021. https://doi.org/10.1002/anie.202100316

74. Cao L, Goreshnik I, Coventry B, et al. De novo design of picomolar SARS-CoV-2 miniprotein inhibitors. Science. 2020 Oct 23;370(6515):426-431. doi: 10.1126/science.abd9909. Epub 2020 Sep 9. PMID: 32907861.

75. Wei Li, Alexandra Schäfer, Swarali S. Kulkarni, et al. High Potency of a Bivalent Human VH Domain in SARS-CoV-2 Animal Models. Cell $183 . \quad$ (2020). https://doi.org/10.1016/j.cell.2020.09.007.

76. Hanke, L., Vidakovics Perez, L., Sheward, D.J. et al. An alpaca nanobody neutralizes SARS-CoV2 by blocking receptor interaction. Nature Communications 11, 4420 (2020). https://doi.org/10.1038/s41467-020-18174-5

77. Phillip D Monk, Richard J Marsden, Victoria J Tear, et al. Safety and efficacy of inhaled nebulised interferon beta-1a (SNG001) for treatment of SARS-CoV-2 infection: a randomised, double-blind, placebo-controlled, phase 2 trial. The Lancet Respiratory Medicine. 2020. https://doi.org/10.1016/S2213-2600(20)30511-7.

78. de Vries RD, Schmitz KS, Bovier FT, et al. Intranasal fusion inhibitory lipopeptide prevents directcontact SARS-CoV-2 transmission in ferrets. Science. 2021 Feb 17:eabf4896. doi: 10.1126/science.abf4896. Epub ahead of print. PMID: 33597220.

79. Klang Shmuel, Mann Barbara, Megiddo Dalia et al. Low pH Hypromellose (Taffix ${ }^{\mathrm{TM}}$ ) nasal powder spray reduced SARS-CoV-2 infection rate post mass-gathering event at a highly endemic community: An observational prospective open label user survey, 20 January 2021, PREPRINT (Version 2) available at Research Square https://doi.org/10.21203/rs.3.rs-100328/v2

80. Kwon, P.S., Oh, H., Kwon, SJ. et al. Sulfated polysaccharides effectively inhibit SARS-CoV-2 in vitro. Cell Discovery 6, 50 (2020). https://doi.org/10.1038/s41421-020-00192-8.

81. Ettore Crimi, Giuditta Benincasa, Neisaliz Figueroa-Marrero, Massimiliano Galdiero, Claudio Napoli. Epigenetic susceptibility to severe respiratory viral infections and its therapeutic implications: a narrative review. British Journal of Anaesthesia 125 (2020). https://doi.org/10.1016/j.bja.2020.06.060.

82. COVI-VAC for SARS-CoV-2 (COVID-19). Available at: https://codagenix.com/vaccineprograms/covid-19/ (accessed: 8 June 2021). 
83. Toni Luise Meister, Yannick Brüggemann, Daniel Todt, et al. Virucidal Efficacy of Different Oral Rinses Against Severe Acute Respiratory Syndrome Coronavirus 2, The Journal of Infectious Diseases, Volume 222, Issue 8, 15 October 2020, Pages 1289-1292, https://doi.org/10.1093/infdis/jiaa471

84. Valerie B O’Donnell, David Thomas, Richard Stanton, et al., Potential Role of Oral Rinses Targeting the Viral Lipid Envelope in SARS-CoV-2 Infection, Function, Volume 1, Issue 1, 2020, zqaa002, https://doi.org/10.1093/function/zqaa002

85. Evelina Statkute, Anzelika Rubina, Valerie B O’Donnell, et al. Brief Report: The Virucidal Efficacy of Oral Rinse Components Against SARS-CoV-2 In Vitro. bioRxiv 2020.11.13.381079; doi: https://doi.org/10.1101/2020.11.13.381079

86. Jordana Muñoz-Basagoiti, Daniel Perez-Zsolt, Rubén León, et al.Cetylpyridinium chloridecontaining mouthwashes reduce in vitro SARS-CoV-2 infectivity. bioRxiv 2020.12.21.423779; doi: https://doi.org/10.1101/2020.12.21.423779.

87. Sungnak, W., Huang, N., Bécavin, C. et al. SARS-CoV-2 entry factors are highly expressed in nasal epithelial cells together with innate immune genes. Nature Medicine 26, 681-687 (2020). https://doi.org/10.1038/s41591-020-0868-6

88. Chen M, Shen W, Rowan NR, Kulaga H, Hillel A, Ramanathan M Jr, Lane AP. Elevated ACE-2 expression in the olfactory neuroepithelium: implications for anosmia and upper respiratory SARS-CoV-2 entry and replication. European Respiratory Journal. 2020 Sep 24;56(3):2001948. doi: 10.1183/13993003.01948-2020.

89. Cantuti-Castelvetri L, Ojha R, Pedro LD, et al. Neuropilin-1 facilitates SARS-CoV-2 cell entry and infectivity. Science. 2020 Nov 13;370(6518):856-860. doi: 10.1126/science.abd2985. Epub 2020 Oct 20. PMID: 33082293.

90. Moutal, Aubina; Martin, Laurent; Boinon, Lisa; et al. SARS-CoV-2 spike protein co-opts VEGFA/neuropilin-1 receptor signaling to induce analgesia, PAIN: January 2021 - Volume 162 - Issue 1 - p 243-252. doi: 10.1097/j.pain.0000000000002097

91. Ding Y, Zhou J, Wang S, et al. Anti-neuropilin-1 monoclonal antibody suppresses the migration and invasion of human gastric cancer cells via Akt dephosphorylation. Experimental and Therapeutic Medicine. 2018;16(2):537-546. doi:10.3892/etm.2018.6234

92. Rhea, E.M., Logsdon, A.F., Hansen, K.M. et al. The S1 protein of SARS-CoV-2 crosses the bloodbrain barrier in mice. Nature Neuroscience (2020). https://doi.org/10.1038/s41593-020-00771-8

93. Meinhardt, J., Radke, J., Dittmayer, C. et al. Olfactory transmucosal SARS-CoV-2 invasion as a port of central nervous system entry in individuals with COVID-19. Nature Neuroscience (2020). https://doi.org/10.1038/s41593-020-00758-5

94. SangJoon Lee, Rudragouda Channappanavar, Thirumala-Devi Kanneganti. Coronaviruses: Innate Immunity, Inflammasome Activation, Inflammatory Cell Death, and Cytokines. Trends in Immunology 41 (2020) https://doi.org/10.1016/j.it.2020.10.005.

95. The human protein atlas. ACE2. Available at: https://www.proteinatlas.org/ENSG00000130234ACE2/tissue (accessed: 8 June 2021)

96. Canrong Wu, Yang Liu, Yueying Yang, et al. Analysis of therapeutic targets for SARS-CoV-2 and discovery of potential drugs by computational methods. Acta Pharmaceutica Sinica B 10 (2020). https://doi.org/10.1016/j.apsb.2020.02.008.

97. SK Manirul Haque, Omar Ashwaq, Abdulla Sarief, and Abdul Kalam Azad John Mohamed. A comprehensive review about SARS-CoV-2. Future Virology 2020 15:9, 625-648. https://doi.org/10.2217/fvl-2020-0124

98. Peter W Horby, Marion Mafham, Jennifer L Bell, et al. Lopinavir-ritonavir in patients admitted to hospital with COVID-19 (RECOVERY): a randomised, controlled, open-label, platform trial. The Lancet 396. 2020. https://doi.org/10.1016/S0140-6736(20)32013-4.

99. Finkel, Y., Gluck, A., Nachshon, A. et al. SARS-CoV-2 uses a multipronged strategy to impede host protein synthesis. Nature (2021). https://doi.org/10.1038/s41586-021-03610-3

100.Gordon, D.E., Jang, G.M., Bouhaddou, M. et al. A SARS-CoV-2 protein interaction map reveals targets for drug repurposing. Nature 583, 459-468 (2020). https://doi.org/10.1038/s41586-0202286-9

101.Zumla, A., Chan, J., Azhar, E. et al. Coronaviruses - drug discovery and therapeutic options. Nature Reviews Drug Discovery 15, 327-347 (2016). https://doi.org/10.1038/nrd.2015.37

102. Khalid El Bairi, Dario Trapani, Angelica Petrillo, et al. Repurposing anticancer drugs for the management of COVID-19. European Journal of Cancer 141. 2020. https://doi.org/10.1016/j.ejca.2020.09.014. 
103.Mahdi, M., Mótyán, J.A., Szojka, Z.I. et al. Analysis of the efficacy of HIV protease inhibitors against SARS-CoV-2's main protease. Virology Journal 17, 190 (2020). https://doi.org/10.1186/s12985-020-01457-0

104.Kumar S, Zhi K, Mukherji A, Gerth K. Repurposing Antiviral Protease Inhibitors Using Extracellular Vesicles for Potential Therapy of COVID-19. Viruses. 2020;12(5):486. Published 2020 Apr 26. doi:10.3390/v12050486

105.Peng Sang, Shu-Hui Tian, Zhao-Hui Meng, Li-Quan Yang. Anti-HIV drug repurposing against SARS-CoV-2. RSC Advances 27. (2020). https://doi.org/10.1039/D0RA01899F

106. Guangdi Li, Erik De Clercq. Therapeutic options for the 2019 novel coronavirus (2019-nCoV). Nature Reviews Drug Discovery 19, 149-150 (2020). https://doi.org/10.1038/d41573-020-000160

107.Janowitz T, Gablenz E, Pattinson D, et al. Famotidine use and quantitative symptom tracking for COVID-19 in non-hospitalised patients: a case series. Gut 2020;69:1592-1597. http://dx.doi.org/10.1136/gutjnl-2020-321852

108. Broad Institute. Drug repurposing hub. Available at: https://clue.io/repurposing (accessed: 8 June 2021)

109.Daisy A. Hoagland, Daniel J.B. Clarke, Rasmus Møller, et al. Modulating the transcriptional landscape of SARS-CoV-2 as an effective method for developing antiviral compounds. bioRxiv; doi: https://doi.org/10.1101/2020.07.12.199687

110.IMB. Functional genomics platform. Available at: https://s2s-omxware.ussouth.containers.appdomain.cloud/home, https://covid19-mol.mybluemix.net/ (accessed 8 June 2021)

111. ${ }^{1}$ Coronavirus Drug and Treatment Tracker. Katherine J. Wu, Carl Zimmer and Jonathan Corum. Updated Feb. 2, 2021. Available at: https://www.nytimes.com/interactive/2020/science/coronavirus-drugs-treatments.html

112. Milken Institute. COVID-19 Treatment and Vaccine Tracker. Last updated: February 2, 2021. Available at: https://covid-19tracker.milkeninstitute.org/

113.Fran Robson, Khadija Shahed Khan, Thi Khanh Le, et al. Coronavirus RNA Proofreading: Molecular Basis and Therapeutic Targeting. Molecular Cell 79. 2020. https://doi.org/10.1016/j.molcel.2020.07.027.

114.Andrea J Pruijssers, Mark R Denison. Nucleoside analogues for the treatment of coronavirus infections. Current Opinion in Virology 35. 2019. https://doi.org/10.1016/j.coviro.2019.04.002.

115.Carolina Q. Sacramento, Natalia Fintelman-Rodrigues, Jairo R. Temerozo, et al. The in vitro antiviral activity of the anti-hepatitis $\mathrm{C}$ virus (HCV) drugs daclatasvir and sofosbuvir against SARS-CoV-2. bioRxiv; doi: https://doi.org/10.1101/2020.06.15.153411

116.Buckland, M.S., Galloway, J.B., Fhogartaigh, C.N. et al. Treatment of COVID-19 with remdesivir in the absence of humoral immunity: a case report. Nature Communications 11, 6385 (2020). https://doi.org/10.1038/s41467-020-19761-2

117.Kokic, G., Hillen, H.S., Tegunov, D. et al. Mechanism of SARS-CoV-2 polymerase stalling by remdesivir. Nature Communications 12, 279 (2021). https://doi.org/10.1038/s41467-020-20542-0

118.Wahl, A., Gralinski, L.E., Johnson, C.E. et al. SARS-CoV-2 infection is effectively treated and prevented by EIDD-2801. Nature (2021). https://doi.org/10.1038/s41586-021-03312-w

119. Stanford University. SARS-COV-2 antiviral therapy. Available at: https://covdb.stanford.edu/page/covid-review/ (Accessed: 8 June 2021).

120. Catherine E Oldenburg, Thuy Doan. Azithromycin for severe COVID-19. The Lancet 396. 2020. https://doi.org/10.1016/S0140-6736(20)31863-8.

121.Juan Ignacio Morán Blanco, Judith A. Alvarenga Bonilla, Sakae Homma, Kazuo Suzuki, Philip Fremont-Smith, Karina Villar Gómez de las Heras. Antihistamines and azithromycin as a treatment for COVID-19 on primary health care - A retrospective observational study in elderly patients, Pulmonary Pharmacology \& Therapeutics, Volume 67, 2021, 101989, ISSN 1094-5539, https://doi.org/10.1016/j.pupt.2021.101989.

122.Leon Caly, Julian D. Druce, Mike G. Catton, David A. Jans, Kylie M. Wagstaff. The FDAapproved drug ivermectin inhibits the replication of SARS-CoV-2 in vitro. Antiviral Research 178. 2020. https://doi.org/10.1016/j.antiviral.2020.104787.

123.Arianna Portmann-Baracco, Mayte Bryce-Alberti, Roberto Alfonso Accinelli. Propiedades antivirales y antiinflamatorias de ivermectina y su potencial uso en COVID-19. Archivos de Bronconeumología 56. 2020. https://doi.org/10.1016/j.arbres.2020.06.011.

124. Carlos Chaccour, Aina Casellas, Andrés Blanco-Di Matteo, et al. The effect of early treatment with ivermectin on viral load, symptoms and humoral response in patients with non-severe COVID-19: A pilot, double-blind, placebo-controlled, randomized clinical trial, 
$\begin{array}{llll}\text { EClinicalMedicine, } & 2021, & \text { 100720, } & \text { ISSN }\end{array}$ https://doi.org/10.1016/j.eclinm.2020.100720.

125.Jorge Galvez, Riccardo Zanni, Maria Galvez-Llompart, Jose Maria Benlloch. Macrolides May Prevent Severe Acute Respiratory Syndrome Coronavirus 2 Entry into Cells: A Quantitative Structure Activity Relationship Study and Experimental Validation. Journal of Chemical Information and Modeling, 2021, 61 (4), ISSN 1549-9596. DOI: 10.1021/acs.jcim.0c01394

126.Xu, Y., Jiang, H. Potential treatment of COVID-19 by inhibitors of human dihydroorotate dehydrogenase. Protein Cell 11, 699-702 (2020). https://doi.org/10.1007/s13238-020-00769-9

127. Coelho, A.R. and Oliveira, P.J. (2020), Dihydroorotate dehydrogenase inhibitors in SARS-CoV2 infection. European Journal of Clinical Investigation, 50: e13366. https://doi.org/10.1111/eci.13366

128.PTC Therapeutics Announces the Initiation of a Phase 2/3 Clinical Trial to Evaluate PTC299 for the Treatment of COVID-19. June 17, 2020. Available at: https://ir.ptcbio.com/node/12966/pdf

129.NCBI Resources. Gene. EEF1A1 eukaryotic translation elongation factor 1 alpha 1. Updated on 29-Jan-2021. Available at: https://www.ncbi.nlm.nih.gov/gene/1915

130. Onco'Zine. Plitidepsin - A novel Anti-cancer Agent Possibly Active Against COVID19. Peter Hofland. March 16, 2020. Available at: https://www.oncozine.com/plitidepsin-a-novel-anticancer-agent-possibly-active-against-covid18/

131.Kris M. White, Romel Rosales, Soner Yildiz, et al. Plitidepsin has potent preclinical efficacy against SARS-CoV-2 by targeting the host protein eEF1A. Science. 2021. Doi: 10.1126/Science.Abf4058

132.Zhang, Y., Guo, R., Kim, S.H. et al. SARS-CoV-2 hijacks folate and one-carbon metabolism for viral replication. Nature Communications 12, 1676 (2021). https://doi.org/10.1038/s41467-02121903-Z

133. Yuan, S., Yin, X., Meng, X. et al. Clofazimine broadly inhibits coronaviruses including SARSCoV-2. Nature (2021). https://doi.org/10.1038/s41586-021-03431-4

134.Pfizer initiates Phase 1 study of novel oral antiviral therapeutic agent against SARS-CoV-2. Available at: https:/www.pfizer.com/news/press-release/press-release-detail/pfizer-initiatesphase-1-study-novel-oral-antiviral (accessed 8 June 2021).

135. Shirvaliloo M. Epigenomics in COVID-19; the link between DNA methylation, histone modifications and SARS-CoV-2 infection. Epigenomics. 2021;10.2217/epi-2021-0057. doi:10.2217/epi-2021-0057

136. Oryzon. Vafidemstat. Available at: https://www.oryzon.com/es/programas/vafidemstat (accessed 8 June 2021).

137.Uludağ H, Parent K, Aliabadi HM and Haddadi A (2020) Prospects for RNAi Therapy of COVID19. Frontiers in Bioengineering and Biotechnology. 8:916. doi: 10.3389/fbioe.2020.00916

138. Ghosh S, Firdous SM, Nath A. siRNA could be a potential therapy for COVID-19. EXCLI Journal. 2020;19:528-531. Published 2020 Apr 22. doi:10.17179/excli2020-1328

139. Antonella Baldassarre, Alessandro Paolini, Stefania Paola Bruno, Cristina Felli, Alberto Eugenio Tozzi, and Andrea Masotti. Potential use of noncoding RNAs and innovative therapeutic strategies to target the 5'UTR of SARS-CoV-2. Epigenomics 2020 12:15, 1349-1361. https://doi.org/10.2217/epi-2020-0162

140.Si Dingyao Zhang, Jun Lu. In Silico Design of siRNAs Targeting Existing and Future Respiratory Viruses with Virus. bioRxiv; doi: https://doi.org/10.1101/2020.08.13.250076

141. Chen, W., Feng, P., Liu, K. et al. Computational Identification of Small Interfering RNA Targets in SARS-CoV-2. Virologia Sinica. 35, 359-361 (2020). https://doi.org/10.1007/s12250-02000221-6

142. Se Hun Gu, Chi Ho Yu, Youngjo Song, et al. A Small interfering RNA lead targeting RNAdependent RNA-polymerase effectively inhibit the SARS-CoV-2 infection in Golden Syrian hamster and Rhesus macaque. bioRxiv; doi: https://doi.org/10.1101/2020.07.07.190967

143.B. Alberts, Molecular Biology of the Cell, $6^{\text {th }}$ Edition. ISBN: 978-0-8153-4432-2. Garland Science, Taylor \& Francis Group. 2020.

144.Zhang, Jun-Ming, An, Jianxiong. Cytokines, Inflammation, and Pain, International Anesthesiology Clinics: April 2007 - Volume 45 - Issue 2 - p 27-37 doi: 10.1097/AIA.0b013e318034194e

145. Thépaut M, Luczkowiak J, Vivès C, et al. DC/L-SIGN recognition of spike glycoprotein promotes SARS-CoV-2 trans-infection and can be inhibited by a glycomimetic antagonist. PLOS Pathogens 17(5): e1009576. (2021) https://doi.org/10.1371/journal.ppat.1009576 
146. Heidi Ledford. Nature. How does COVID-19 kill? Uncertainty is hampering doctors' ability to choose treatments. 9 April 2020. Available at: https://www.nature.com/articles/d41586-02001056-7

147. Crayne CB, Albeituni S, Nichols KE and Cron RQ (2019) The Immunology of Macrophage Activation Syndrome. Frontiers in Immunology. 10:119. doi: 10.3389/fimmu.2019.00119

148. Tang D, Comish P, Kang R (2020) The hallmarks of COVID-19 disease. PLoS Pathogens 16(5): e1008536. https://doi.org/10.1371/journal.ppat.1008536

149. John Hodgson. Nature Biotechnology 38, 523-532 (2020). doi: https://doi.org/10.1038/d41587020-00005-Z

150.Gutiérrez-Lorenzo M, Cuadros-Martínez CM. Baricitinib en el tratamiento de infección por SARS-CoV-2 [Baricitinib in the treatment of SARS-CoV-2 infection]. Revista Española de Quimioterapia. 2020;33(4):294-295. doi:10.37201/req/047.2020

151.Čokić VP, Mitrović-Ajtić O, Beleslin-Čokić BB, et al. Proinflammatory Cytokine IL-6 and JAKSTAT Signaling Pathway in Myeloproliferative Neoplasms. Mediators of Inflammation. 2015;2015:453020. doi:10.1155/2015/453020

152.Fridman JS, Scherle PA, Collins R, et al. Selective inhibition of JAK1 and JAK2 is efficacious in rodent models of arthritis: preclinical characterization of INCB028050. The Journal of Immunology. 2010 May 1;184(9):5298-307. doi: 10.4049/jimmunol.0902819. Epub 2010 Apr 2. PMID: 20363976.

153.José María Galván-Román, Sebastián C. Rodríguez-García, Emilia Roy-Vallejo, et al. IL-6 serum levels predict severity and response to tocilizumab in COVID-19: An observational study. Journal of Allergy and Clinical Immunology 147. 2021. https://doi.org/10.1016/j.jaci.2020.09.018.

154. Anthony C. Gordon, Paul R. Mouncey, Farah Al-Beidh, et al. Interleukin-6 Receptor Antagonists in Critically Ill Patients with Covid-19 - Preliminary report. The REMAP-CAP Investigators. medRxiv; doi: https://doi.org/10.1101/2021.01.07.21249390

155.RECOVERY Collaborative Group, Peter W Horby, Guilherme Pessoa-Amorim, et al. Tocilizumab in patients admitted to hospital with COVID-19 (RECOVERY): a randomised, controlled, open-label, platform trial. The Lancet. 2021. doi: https://doi.org/10.1016/S01406736(21)00676-0

156. Fisher WG, Yang PC, Medikonduri RK, Jafri MS. NFAT and NFkappaB activation in $T$ lymphocytes: a model of differential activation of gene expression. Annals of Biomedical Engineering. 2006;34(11):1712-1728. doi:10.1007/s10439-006-9179-4

157.Liu, T., Zhang, L., Joo, D. et al. NF-אB signaling in inflammation. Signal Transduction and Targeted Therapy, 17023 (2017). https://doi.org/10.1038/sigtrans.2017.23

158. Campisi, J., d'Adda di Fagagna, F. Cellular senescence: when bad things happen to good cells. Nature Reviews Molecular Cell Biology 8, 729-740 (2007). https://doi.org/10.1038/nrm2233

159. Toshio Hirano, Masaaki Murakami, COVID-19: A New Virus, but a Familiar Receptor and Cytokine Release Syndrome, Immunity, Volume 52. 2020. https://doi.org/10.1016/j.immuni.2020.04.003.

160.Nigro, P., Pompilio, G. Capogrossi, M. Cyclophilin A: a key player for human disease. Cell Death and Disease 4, e888 (2013). https://doi.org/10.1038/cddis.2013.410

161. Mohamed M. Osman, Dzenan Lulic, Loren Glover, et al. Cyclosporine-A as a neuroprotective agent against stroke: Its translation from laboratory research to clinical application, Neuropeptides 45, 2011, https://doi.org/10.1016/j.npep.2011.04.002.

162. Dmitry Lim, Francesca Rocchio, Lisa Mapelli, Francesco Moccia. From Pathology to Physiology of Calcineurin Signalling in Astrocytes. Opera Medica et Physiologica. Volume 2 Issue 2, pages 122-140; 2016. doi:10.20388/OMP2016.002.0029

163.Pablo Guisado-Vasco, Sofia Valderas-Ortega, Maria Maravillas Carralón-González, et al. Clinical characteristics and outcomes among hospitalized adults with severe COVID-19 admitted to a tertiary medical center and receiving antiviral, antimalarials, glucocorticoids, or immunomodulation with tocilizumab or cyclosporine: A retrospective observational study (COQUIMA cohort), EClinicalMedicine, 2020, https://doi.org/10.1016/j.eclinm.2020.100591.

164. Katherine H. Schreiber, Monique N. O’Leary, Brian K. Kennedy, Chapter 2 - The mTOR Pathway and Aging, Editor(s): Matt R. Kaeberlein, George M. Martin, Handbook of the Biology of Aging (Eighth Edition), Academic Press, 2016, https://doi.org/10.1016/B978-0-12-411596-5.00002-2.

165.Johnson SC, Rabinovitch PS, Kaeberlein M. mTOR is a key modulator of ageing and age-related disease. Nature. 2013;493(7432):338-345. doi:10.1038/nature11861 
166.Zheng, Y, Li, R, Liu, S. Immunoregulation with mTOR inhibitors to prevent COVID-19 severity: A novel intervention strategy beyond vaccines and specific antiviral medicines. Journal of Medical Virology. 2020; 92: 1495- 1500. https://doi.org/10.1002/jmv.26009

167.Arvin, A.M., Fink, K., Schmid, M.A. et al. A perspective on potential antibody-dependent enhancement of SARS-CoV-2. Nature 584, 353-363 (2020). https://doi.org/10.1038/s41586-0202538-8

168. Mekala Janaki Ramaiah, mTOR inhibition and p53 activation, microRNAs: The possible therapy against pandemic COVID-19, Gene Reports, 20, 2020, https://doi.org/10.1016/j.genrep.2020.100765.

169. Mannick JB, Morris M, Hockey HP, et al. TORC1 inhibition enhances immune function and reduces infections in the elderly. Science Translational Medicine. 2018 Jul 11;10(449):eaaq1564. doi: 10.1126/scitranslmed.aaq1564. PMID: 29997249.

170. Alba Grifoni, Daniela Weiskopf, Sydney I. Ramirez, et al. Targets of T Cell Responses to SARSCoV-2 Coronavirus in Humans with COVID-19 Disease and Unexposed Individuals, Cell 181, 2020, https://doi.org/10.1016/j.cell.2020.05.015.

171. Manish Sagar, Katherine Reifler, Michael Rossi, Nancy S. Miller, Pranay Sinha, Laura F. White, Joseph P. Mizgerd. Recent endemic coronavirus infection is associated with less-severe COVID19. The Journal of Clinical Investigation. 2021;131(1):e143380. https://doi.org/10.1172/JCI143380.

172. Takuya Sekine, André Perez-Potti, Olga Rivera-Ballesteros, et al. Robust T Cell Immunity in Convalescent Individuals with Asymptomatic or Mild COVID-19, Cell 183, 2020, https://doi.org/10.1016/j.cell.2020.08.017.

173.David Wyllie, Ranya Mulchandani, Hayley E Jones, et al. SARS-CoV-2 responsive T cell numbers are associated with protection. from COVID-19: A prospective cohort study in keyworkers. medRxiv; doi: https://doi.org/10.1101/2020.11.02.20222778

174. Annika Nelde, Tatjana Bilich, Jonas S. Heitmann et al. SARS-CoV-2 T-cell epitopes define heterologous and COVID-19-induced T-cell recognition, 16 June 2020, PREPRINT available at Research Square. https://doi.org/10.21203/rs.3.rs-35331/v1

175. Sharma, S. and Thomas, P.G. (2014), The two faces of heterologous immunity: protection or immunopathology. Journal of Leukocyte Biology, 95: 405-416. https://doi.org/10.1189/jlb.0713386

176. Agrawal B. (2019). Heterologous Immunity: Role in Natural and Vaccine-Induced Resistance to Infections. Frontiers in Immunology. 10:2631. doi: 10.3389/fimmu.2019.02631

177.S.J.C.F.M. Moorlag, R.J.W. Arts, R. van Crevel, M.G. Netea. Non-specific effects of BCG vaccine on viral infections, Clinical Microbiology and Infection 25, 2019, https://doi.org/10.1016/j.cmi.2019.04.020.

178. Rob J.W. Arts, Agostinho Carvalho, Claudia La Rocca, et al. Immunometabolic Pathways in BCG-Induced Trained Immunity, Cell Reports 17, 2016, https://doi.org/10.1016/j.celrep.2016.11.011.

179.O'Neill, L.A.J., Netea, M.G. BCG-induced trained immunity: can it offer protection against COVID-19? Nature Reviews Immunology 20, 335-337 (2020). https://doi.org/10.1038/s41577020-0337-y

180.Nigel Curtis, Annie Sparrow, Tedros A Ghebreyesus, Mihai G Netea, Considering BCG vaccination to reduce the impact of COVID-19, The Lancet 395, 2020, https://doi.org/10.1016/S0140-6736(20)31025-4.

181. Reche PA (2020). Potential Cross-Reactive Immunity to SARS-CoV-2 From Common Human Pathogens and Vaccines. Frontiers in Immunology. 11:586984. doi: 10.3389/fimmu.2020.586984

182.Jeffrey E. Gold, William H. Baumgartl, et al. Analysis of Measles-Mumps-Rubella (MMR) Titers of Recovered COVID-19 Patients. mBio. Nov 2020, 11 (6) e02628-20; DOI: 10.1128/mBio.02628-20

183. Root-Bernstein, R. Age and Location in Severity of COVID-19 Pathology: Do Lactoferrin and Pneumococcal Vaccination Explain Low Infant Mortality and Regional Differences?. BioEssays 2020, 42, 2000076. https://doi.org/10.1002/bies.202000076

184. Mohamed Labib Salem, Dina El-Hennawy, The possible beneficial adjuvant effect of influenza vaccine to minimize the severity of COVID-19, Medical Hypotheses 140, 2020, https://doi.org/10.1016/j.mehy.2020.109752.

185.Marín-Hernández, D., Schwartz, R.E. and Nixon, D.F. (2021), Epidemiological evidence for association between higher influenza vaccine uptake in the elderly and lower COVID-19 deaths in Italy. Journal of Medical Virology, 93: 64-65. https://doi.org/10.1002/jmv.26120 
186. Claudio Zanettini, Mohamed Omar, Wikum Dinalankara, et al. I nfluenza Vaccination and COVID-19 Mortality in the USA: An Ecological Study. Vaccines. 9(5), 427. 2021. doi: https://doi.org/10.3390/vaccines9050427.

187.Priya A. Debisarun, Patrick Struycken, Jorge Domínguez-Andrés, et al The effect of influenza vaccination on trained immunity: impact on COVID-19. medRxiv; doi: https://doi.org/10.1101/2020.10.14.20212498

188. Cristina Avendano-Sola, Antonio Ramos-Martinez, Elena Munez-Rubio, et al. Convalescent Plasma for COVID-19: A multicenter, randomized clinical trial. medRxiv; doi: https://doi.org/10.1101/2020.08.26.20182444

189. Michael J Joyner, Jonathon W Senefeld, et al. Effect of Convalescent Plasma on Mortality among Hospitalized Patients with COVID-19: Initial Three-Month Experience. medRxiv; doi: https://doi.org/10.1101/2020.08.12.20169359

190. Romina Libster, Gonzalo Pérez Marc, Diego Wappner, et al. Early High-Titer Plasma Therapy to Prevent Severe Covid-19 in Older Adults. The New England Journal of Medicine, 2021, DOI: 10.1056/NEJMoa2033700

191.Naoki Kaneko, Hsiao-Hsuan Kuo, Julie Boucau, et al. Loss of Bcl-6-Expressing T Follicular Helper Cells and Germinal Centers in COVID-19, Cell 183, 2020, https://doi.org/10.1016/j.cell.2020.08.025.

192. Seyed M. Moghadas, Meagan C. Fitzpatrick, Pratha Sah, et al. The implications of silent transmission for the control of COVID-19 outbreaks. Proceedings of the National Academy of Sciences Jul 2020, 117 (30) 17513-17515; DOI: 10.1073/pnas.2008373117

193.Johansson MA, Quandelacy TM, Kada S, et al. SARS-CoV-2 Transmission From People Without COVID-19 Symptoms. JAMA Network Open. 2021;4(1):e2035057. doi:10.1001/jamanetworkopen.2020.35057

194.Fang Li, Yuan-Yuan Li, Ming-Jin Liu, et al. Household transmission of SARS-CoV-2 and risk factors for susceptibility and infectivity in Wuhan: a retrospective observational study, The Lancet Infectious Diseases, 2021, https://doi.org/10.1016/S1473-3099(20)30981-6.

195. Muge Cevik, Matthew Tate, Ollie Lloyd, et al. SARS-CoV-2, SARS-CoV, and MERS-CoV viral load dynamics, duration of viral shedding, and infectiousness: a systematic review and metaanalysis, The Lancet Microbe 2, 2021, https://doi.org/10.1016/S2666-5247(20)30172-5.

196.Pedro Martínez-Fleta, Arantzazu Alfranca, Isidoro González-Álvaro, et al. SARS-CoV-2 Cysteine-like Protease Antibodies Can Be Detected in Serum and Saliva of COVID-19Seropositive Individuals. The Journal of Immunology December 1, 2020, 205 (11) 3130-3140; DOI: $10.4049 /$ jimmunol.2000842

197. Watson Jessica, Richter Alex, Deeks Jonathan. Testing for SARS-CoV-2 antibodies BMJ 2020; 370 :m3325. https://doi.org/10.1136/bmj.m3325

198. Antonio La Marca, Martina Capuzzo, Tiziana Paglia, Laura Roli, Tommaso Trenti, Scott M. Nelson, Testing for SARS-CoV-2 (COVID-19): a systematic review and clinical guide to molecular and serological in-vitro diagnostic assays, Reproductive BioMedicine Online 41, 2020, https://doi.org/10.1016/j.rbmo.2020.06.001.

199. Andrea Alemany, Bàrbara Baró, Dan Ouchi, et al. Analytical and clinical performance of the panbio COVID-19 antigen-detecting rapid diagnostic test. Journal of Infection, 2021, https://doi.org/10.1016/j.jinf.2020.12.033.

200.Julio Silva, Carolina Lucas, Maria Sundaram, et al. Saliva viral load is a dynamic unifying correlate of COVID-19 severity and mortality. medRxiv; doi: https://doi.org/10.1101/2021.01.04.21249236

201. Coronavirus (COVID-19) Update: FDA Authorizes First Test that Detects Neutralizing Antibodies from Recent or Prior SARS-CoV-2 Infection. November 06, 2020. Available at: https://www.fda.gov/news-events/press-announcements/coronavirus-covid-19-update-fdaauthorizes-first-test-detects-neutralizing-antibodies-recent-or

202.Al-Aly, Z., Xie, Y. \& Bowe, B. High-dimensional characterization of post-acute sequalae of COVID-19. Nature (2021). https://doi.org/10.1038/s41586-021-03553-9

203. Torres Acosta MA, Singer BD. Pathogenesis of COVID-19-induced ARDS: implications for an ageing population. European Respiratory Journal. 2020 Sep 24;56(3):2002049. doi: 10.1183/13993003.02049-2020. PMID: 32747391; PMCID: PMC7397945.

204.London researchers to test promising coronavirus treatment. Julia Bakker. 15 June 2020. https://www.bhf.org.uk/what-we-do/news-from-the-bhf/news-archive/2020/june/londonresearchers-to-test-promising-coronavirus-treatment 
205. Sergi Bellmunt, Claudia Riera, Daniel Gil, et al. COVID-19 Infection in Critically Ill Patients Carries a High Risk for Venous Thromboembolism, European Journal of Vascular and Endovascular Surgery, 2020, https://doi.org/10.1016/j.ejvs.2020.12.015.

206.Zsuzsanna Varga, Andreas J Flammer, Peter Steiger, et al. Endothelial cell infection and endotheliitis in COVID-19, The Lancet 395, 2020, https://doi.org/10.1016/S0140-6736(20)309375.

207.Lluís Masana, Eudald Correig, Cèlia Rodríguez-Borjabad, et al. On Behalf of the STACOVXULA Research Group. Effect of statin therapy on SARS-CoV-2 infection-related mortality in hospitalized patients, European Heart Journal - Cardiovascular Pharmacotherapy, pvaa128, https://doi.org/10.1093/ehjcvp/pvaa128

208. Yu Zuo, Shanea K. Estes, Ramadan A. Ali, et al. Prothrombotic autoantibodies in serum from patients hospitalized with COVID-19. Science Translational Medicine 18. Nov 2020. Vol. 12, Issue 570, eabd3876. DOI: 10.1126/scitranslmed.abd3876

209. Reiter RJ, Abreu-Gonzalez P, Marik PE, Dominguez-Rodriguez A (2020) Therapeutic Algorithm for Use of Melatonin in Patients With COVID-19. Frontiers in Medicine. 7:226. doi: $10.3389 /$ fmed.2020.00226

210.Zhang R, Wang X, Ni L, et al. COVID-19: Melatonin as a potential adjuvant treatment. Life Sciences. 2020;250:117583. doi:10.1016/j.lfs.2020.117583

211.Reiter RJ, Sharma R, Ma Q, Dominquez-Rodriguez A, Marik PE, Abreu-Gonzalez P. Melatonin Inhibits COVID-19-induced Cytokine Storm by Reversing Aerobic Glycolysis in Immune Cells: A Mechanistic Analysis. Medicine in Drug Discovery. 2020;6:100044. doi:10.1016/j.medidd.2020.100044

212.Pamukçu B. Inflammation and thrombosis in patients with COVID-19: A prothrombotic and inflammatory disease caused by SARS coronavirus-2. The Anatolian Journal of Cardiology. 2020;24(4):224-234. doi:10.14744/AnatolJCardiol.2020.56727

213. Mahmudpour M, Roozbeh J, Keshavarz M, Farrokhi S, Nabipour I. COVID-19 cytokine storm: The anger of inflammation. Cytokine. 2020 Sep;133:155151. doi: 10.1016/j.cyto.2020.155151. Epub 2020 May 30. PMID: 32544563; PMCID: PMC7260598.

214. Taboada M, Caruezo V, Naveira A, Atanassoff PG. Corticosteroids and the hyper-inflammatory phase of the COVID-19 disease. Journal of Clinical Anesthesia. 2020;66:109926. doi:10.1016/j.jclinane.2020.109926

215.Lee, C., Choi, W.J. Overview of COVID-19 inflammatory pathogenesis from the therapeutic perspective. Archives of Pharmacal Research. 44, 99-116 (2021). https://doi.org/10.1007/s12272020-01301-7

216. Yuyang Lei, Jiao Zhang, Cara R. Schiavon, et al. SARS-CoV-2 Spike Protein Impairs Endothelial Function via Downregulation of ACE2. bioRxiv. 2020. https://doi.org/10.1101/2020.12.04.409144

217.Barnes PJ. How corticosteroids control inflammation: Quintiles Prize Lecture 2005. British Journal of Pharmacology. 2006;148(3):245-254. doi:10.1038/sj.bjp.0706736

218.Peter Horby, Wei Shen Lim, Jonathan Emberson, et al. RECOVERY Collaborative Group. Dexamethasone in Hospitalized Patients with Covid-19. The New England Journal of Medicine. 2021. 384:693-704. doi: 10.1056/NEJMoa2021436.

219.Jean-Claude Tardif, Nadia Bouabdallaoui, Philippe L L'Allier, et al. Efficacy of Colchicine in Non-Hospitalized Patients with COVID-19. medRxiv; doi: https://doi.org/10.1101/2021.01.26.21250494

220.Liotta, E.M., Batra, A., Clark, J.R., et al. (2020), Frequent neurologic manifestations and encephalopathy-associated morbidity in Covid-19 patients. Annals of Clinical and Translational Neurology, 7: 2221-2230. https://doi.org/10.1002/acn3.51210

221. Garrigues E, Janvier P, Kherabi Y, et al. Post-discharge persistent symptoms and health-related quality of life after hospitalization for COVID-19. Journal of Infection. 2020;81(6):e4-e6. doi:10.1016/j.jinf.2020.08.029

222. Arun Raj Antony, Zulfi Haneef, Systematic review of EEG findings in 617 patients diagnosed with COVID-19, Seizure 83, 2020, https://doi.org/10.1016/j.seizure.2020.10.014.

223. Cecchetti, G., Vabanesi, M., Chieffo, R. et al. Cerebral involvement in COVID-19 is associated with metabolic and coagulation derangements: an EEG study. Journal of Neurology 267, 31303134 (2020). https://doi.org/10.1007/s00415-020-09958-2

224.Eric Song, Ce Zhang, Benjamin Israelow, et al. Neuroinvasion of SARS-CoV-2 in human and mouse brain. Journal of Experimental Medicine 1 March 2021; 218 (3): e20202135. doi: https://doi.org/10.1084/jem.20202135 
225. Gerard J. Nuovo, Cynthia Magro, Toni Shaffer, et al. Endothelial cell damage is the central part of COVID-19 and a mouse model induced by injection of the S1 subunit of the spike protein, Annals of Diagnostic Pathology, Volume 51, 2021, 151682, ISSN 1092-9134, https://doi.org/10.1016/j.anndiagpath.2020.151682.

226. Tetyana P. Buzhdygan, Brandon J. DeOre, Abigail Baldwin-Leclair, et al. The SARS-CoV-2 spike protein alters barrier function in 2D static and 3D microfluidic in-vitro models of the human blood-brain barrier, Neurobiology of Disease, Volume 146, 2020, 105131, ISSN 0969-9961, https://doi.org/10.1016/j.nbd.2020.105131.

227. Schirinzi, T., Landi, D., Liguori, C. COVID-19: dealing with a potential risk factor for chronic neurological disorders. Journal of Neurology (2020). https://doi.org/10.1007/s00415-020-10131$\mathrm{y}$

228.Rubio-Rivas, M.; Corbella, X.; Mora-Luján, J.M.; et al. Predicting Clinical Outcome with Phenotypic Clusters in COVID-19 Pneumonia: An Analysis of 12,066 Hospitalized Patients from the Spanish Registry SEMI-COVID-19. Journal of Clinical Medicine. 2020, 9, 3488. https://doi.org/10.3390/jcm9113488

229. Stephenson, E., Reynolds, G., Botting, R.A. et al. Single-cell multi-omics analysis of the immune response in COVID-19. Nat Med (2021). https://doi.org/10.1038/s41591-021-01329-2

230. Shant Ayanian, Juan Reyes, Lei Lynn, Karolyn Teufel. The association between biomarkers and clinical outcomes in novel coronavirus pneumonia in a US cohort. Biomarkers in Medicine. 2020 14:12, 1091-1097. https://doi.org/10.2217/bmm-2020-0309

231. Foy BH, Carlson JCT, Reinertsen E, et al. Association of Red Blood Cell Distribution Width With Mortality Risk in Hospitalized Adults With SARS-CoV-2 Infection. JAMA Network Open. 2020;3(9):e2022058. doi:10.1001/jamanetworkopen.2020.22058

232.Lippi, G., \& Plebani, M. (2020). Laboratory abnormalities in patients with COVID-2019 infection, Clinical Chemistry and Laboratory Medicine (CCLM), 58(7), 1131-1134. doi: https://doi.org/10.1515/cclm-2020-0198

233. Rui Hu, Chaofei Han, Shiyao Pei, Mingzhu Yin, Xiang Chen, Procalcitonin levels in COVID-19 patients, International Journal of Antimicrobial Agents 56, 2020, https://doi.org/10.1016/j.ijantimicag.2020.106051.

234.Fei Zhou, Ting Yu, Ronghui Du, et al. Clinical course and risk factors for mortality of adult inpatients with COVID-19 in Wuhan, China: a retrospective cohort study, The Lancet 395, 2020, https://doi.org/10.1016/S0140-6736(20)30566-3.

235. Chaolin Huang, Yeming Wang, Xingwang Li, et al. Clinical features of patients infected with 2019 novel coronavirus in Wuhan, China, The Lancet 395, 2020, https://doi.org/10.1016/S01406736(20)30183-5.

236. Tang, N, Li, D, Wang, X, Sun, Z. Abnormal coagulation parameters are associated with poor prognosis in patients with novel coronavirus pneumonia. Journal of Thrombosis and Haemostasis. 2020; 18: 844- 847. https://doi.org/10.1111/jth.14768

237. Michael S. Abers, Ottavia M. Delmonte, Emily E. Ricotta, et al. An immune-based biomarker signature is associated with mortality in COVID-19 patients. JCI Insight. 2021;6(1):e144455. https://doi.org/10.1172/jci.insight.144455.

238. Berenguer J, Borobia AM, Ryan P, et al. Development and validation of a prediction model for 30-day mortality in hospitalised patients with COVID-19: the COVID-19 SEIMC score. Thorax. 2021. doi: 10.1136/thoraxjnl-2020-216001.

239.Isabel Cornejo-Pareja, Isabel M. Vegas-Aguilar, Jose Manuel García-Almeida, et al.Phase angle and standardized phase angle from bioelectrical impedance measurements as a prognostic factor for mortality at 90 days in patients with COVID-19: A longitudinal cohort study, Clinical Nutrition, 2021, ISSN 0261-5614, https://doi.org/10.1016/j.clnu.2021.02.017.

240.Francisco Javier Carrasco-Sánchez, Ma Dolores López-Carmona, Francisco Javier MartínezMarcos, et al. for the SEMI-COVID-19 Network (2021) Admission hyperglycemia as a predictor of mortality in patients hospitalized with COVID-19 regardless of diabetes status: data from the Spanish SEMI-COVID-19 Registry, Annals of Medicine, 53:1, 103-116, DOI: 10.1080/07853890.2020.1836566

241.Marouf, N., Cai, W., Said, K.N., et al. (2021), Association between periodontitis and severity of COVID-19 infection: a case-control study. Journal of Clinical Periodontology. Accepted Author Manuscript. https://doi.org/10.1111/jcpe.13435

242. Davide Scozzi, Marlene Cano, Lina Ma, et al. Circulating mitochondrial DNA is an early indicator of severe illness and mortality from COVID-19. JCI Insight. 2021. https://doi.org/10.1172/jci.insight.143299. 
243.Fang Liu, Aifang Xu, Yan Zhang, et al. Patients of COVID-19 may benefit from sustained Lopinavir-combined regimen and the increase of Eosinophil may predict the outcome of COVID19 progression, International Journal of Infectious Diseases 95, 2020, https://doi.org/10.1016/j.ijid.2020.03.013.

244.Tan, L., Wang, Q., Zhang, D. et al. Lymphopenia predicts disease severity of COVID-19: a descriptive and predictive study. Signal Transduction and Targeted Therapy 5, 33 (2020). https://doi.org/10.1038/s41392-020-0148-4

245. Bruce K Patterson, Jose Guevara-Coto, Ram Yogendra, et al. Immune-Based Prediction of COVID-19 Severity and Chronicity Decoded Using Machine Learning. bioRxiv; doi: https://doi.org/10.1101/2020.12.16.423122

246.Kang, Z., Luo, S., Gui, Y. et al. Obesity is a potential risk factor contributing to clinical manifestations of COVID-19. International Journal of Obesity 44, 2479-2485 (2020). https://doi.org/10.1038/s41366-020-00677-2

247. See Kwok, Safwaan Adam, Jan Hoong Ho, et al. Obesity: A critical risk factor in the COVID-19 pandemic. Clinical Obesity. Vol. 10. 2020 https://doi.org/10.1111/cob.12403

248. Silvio Maltagliati, Stephen Sieber, Philippe Sarrazin, et al. Muscle Strength Explains the Protective Effect of Physical Activity against COVID-19 Hospitalization among Adults aged 50 Years and Older. medRxiv. 2021.02.25.21252451; doi: https://doi.org/10.1101/2021.02.25.21252451

249. Ioannou GN, Locke E, Green P, et al. Risk Factors for Hospitalization, Mechanical Ventilation, or Death Among 10131 US Veterans With SARS-CoV-2 Infection. JAMA Network Open. 2020;3(9):e2022310. doi:10.1001/jamanetworkopen.2020.22310

250.Felipe Guerra-Silveira, Fernando Abad-Franch. Sex Bias in Infectious Disease Epidemiology: Patterns and Processes. PLoS ONE 8 (2013). https://doi.org/10.1371/journal.pone.0062390

251.Peckham, H., de Gruijter, N.M., Raine, C. et al. Male sex identified by global COVID-19 metaanalysis as a risk factor for death and ITU admission. Nature Communications 11, 6317 (2020). https://doi.org/10.1038/s41467-020-19741-6

252. The COVID-19 Sex-Disaggregated Data Tracker. Available at: https://globalhealth5050.org/thesex-gender-and-covid-19-project/ (accessed: 8 June 2021).

253.Iziah E Sama, Alice Ravera, Bernadet T Santema, et al. Circulating plasma concentrations of angiotensin-converting enzyme 2 in men and women with heart failure and effects of reninangiotensin-aldosterone inhibitors, European Heart Journal, Volume 41, Issue 19, 14 May 2020, Pages 1810-1817, https://doi.org/10.1093/eurheartj/ehaa373

254.Klein, S., Flanagan, K. Sex differences in immune responses. Nature Reviews Immunology 16, 626-638 (2016). https://doi.org/10.1038/nri.2016.90

255.Graziano Pinna. Sex and COVID-19: A Protective Role for Reproductive Steroids, Trends in Endocrinology \& Metabolism 32, 2021, https://doi.org/10.1016/j.tem.2020.11.004.

256. Takahashi, T., Ellingson, M.K., Wong, P. et al. Sex differences in immune responses that underlie COVID-19 disease outcomes. Nature 588, 315-320 (2020). https://doi.org/10.1038/s41586-0202700-3

257. Bastard P, Rosen LB, Zhang Q, et al. Autoantibodies against type I IFNs in patients with lifethreatening COVID-19. Science. 2020 370(6515):eabd4585. doi: 10.1126/science.abd4585.

258.Lieberman NAP, Peddu V, Xie H, Shrestha L, Huang ML, et al. (2020) In vivo antiviral host transcriptional response to SARS-CoV-2 by viral load, sex, and age. PLOS Biology 18(9): e3000849. https://doi.org/10.1371/journal.pbio.3000849

259. NHS. Men make more coronavirus antibodies than women, making them better plasma donors. 23 June 2020. Available at: https://www.nhsbt.nhs.uk/news/men-make-more-coronavirusantibodies-than-women/

260. Salonia A, Pontillo M, Capogrosso P, et al. Severely low testosterone in males with COVID-19: A case-control study. Andrology. 2021 Feb 26. doi: 10.1111/andr.12993.

261. Selahittin Çayan, Mustafa Uğuz, Barış Saylam, Erdem Akbay. Effect of serum total testosterone and its relationship with other laboratory parameters on the prognosis of coronavirus disease 2019 (COVID-19) in SARS-CoV-2 infected male patients: a cohort study, The Aging Male, 2020, DOI: $10.1080 / 13685538.2020 .1807930$

262. Margherita Baldassarri, Nicola Picchiotti, Francesca Fava, et al. Shorter androgen receptor polyQ alleles protect against life-threatening COVID-19 disease in European males. EBioMedicine. Vol. 65. 2021. DOI: https://doi.org/10.1016/j.ebiom.2021.103246

263. Maria Schroeder, Berfin Schaumburg, Zacharias Müller, et al. Sex hormone and metabolic dysregulations are associated with critical illness in male Covid-19 patients. medRxiv 2020.05.07.20073817; doi: https://doi.org/10.1101/2020.05.07.20073817

(C) 2021 by the Author. Distributed under a CC-BY 4.0 International license. 
264.Leora R. Feldstein, Erica B. Rose, Steven M. Horwitz, et al. Multisystem Inflammatory Syndrome in U.S. Children and Adolescents. The New England Journal of Medicine 2020; 383:334-346, 2020, DOI: 10.1056/NEJMoa2021680

265. Mubbasheer Ahmed, Shailesh Advani, Axel Moreira, et al. Multisystem inflammatory syndrome in children: A systematic review, EClinicalMedicine 26, 2020, https://doi.org/10.1016/j.eclinm.2020.100527.

266. How kids' immune systems can evade COVID, Bianca Nogrady, Nature 588, 382 (2020), doi: https://doi.org/10.1038/d41586-020-03496-7

267.Zimmermann P, Curtis N. Why is COVID-19 less severe in children? A review of the proposed mechanisms underlying the age-related difference in severity of SARS-CoV-2 infections. Archives of Disease in Childhood. 2020. doi: 10.1136/archdischild-2020-320338

268. Weisberg, S.P., Connors, T.J., Zhu, Y. et al. Distinct antibody responses to SARS-CoV-2 in children and adults across the COVID-19 clinical spectrum. Nature Immunology 22, 25-31 (2021). https://doi.org/10.1038/s41590-020-00826-9

269.Pierce CA, Preston-Hurlburt P, Dai Y, et al. Immune responses to SARS-CoV-2 infection in hospitalized pediatric and adult patients. Science Translational Medicine. 2020 Oct 7;12(564):eabd5487. doi: 10.1126/scitranslmed.abd5487. Epub 2020 Sep 21. PMID: 32958614; PMCID: PMC7658796.

270.Neeland, M.R., Bannister, S., Clifford, V. et al. Innate cell profiles during the acute and convalescent phase of SARS-CoV-2 infection in children. Nature Communications 12, 1084 (2021). https://doi.org/10.1038/s41467-021-21414-x

271. Tosif, S., Neeland, M.R., Sutton, P. et al. Immune responses to SARS-CoV-2 in three children of parents with symptomatic COVID-19. Nature Communications 11, 5703 (2020). https://doi.org/10.1038/s41467-020-19545-8

272. Markus Hippich, Philipp Sifft, Jose Zapardiel-Gonzalo, et al. A Public Health Antibody Screening Indicates a Marked Increase of SARS-CoV-2 Exposure Rate in Children during the Second Wave, Med, 2021, ISSN 2666-6340, https://doi.org/10.1016/j.medj.2021.03.019.

273.Demers-Mathieu, V., Do, D.M., Mathijssen, G.B. et al. Difference in levels of SARS-CoV-2 S1 and S2 subunits- and nucleocapsid protein-reactive SIgM/IgM, IgG and SIgA/IgA antibodies in human milk. Journal of Perinatology (2020). https://doi.org/10.1038/s41372-020-00805-w

274. Camilla E Lindan, Kshitij Mankad, Dipak Ram, et al. Neuroimaging manifestations in children with SARS-CoV-2 infection: a multinational, multicentre collaborative study, The Lancet Child \& Adolescent Health, 2020, https://doi.org/10.1016/S2352-4642(20)30362-X.

275. Caroline Diorio, Kevin O. McNerney, Michele Lambert, et al. Evidence of thrombotic microangiopathy in children with SARS-CoV-2 across the spectrum of clinical presentations. Blood Advances 2020; 4 (23): 6051-6063. https://doi.org/10.1182/bloodadvances.2020003471

276. Amaro Nunes Duarte-Neto, Elia Garcia Caldini, Michele Soares Gomes-Gouvêa, et al. An autopsy study of the spectrum of severe COVID-19 in children: From SARS to different phenotypes of MIS-C, EClinicalMedicine, Volume 35, 2021, ISSN 2589-5370, https://doi.org/10.1016/j.eclinm.2021.100850.

277.Markus Hippich, Lisa Holthaus, Robin Assfalg, et al. A Public Health Antibody Screening Indicates a 6-Fold Higher SARS-CoV-2 Exposure Rate than Reported Cases in Children, Med, 2020, https://doi.org/10.1016/j.medj.2020.10.003.

278.Pedro C Hallal, Fernando P Hartwig, Bernardo L Horta, et al. SARS-CoV-2 antibody prevalence in Brazil: results from two successive nationwide serological household surveys, The Lancet Global Health, 8, 2020, https://doi.org/10.1016/S2214-109X(20)30387-9.

279. Laxminarayan R, Wahl B, Dudala SR, et al. Epidemiology and transmission dynamics of COVID19 in two Indian states. Science. 2020 Nov 6;370(6517):691-697. doi: 10.1126/science.abd7672. Epub 2020 Sep 30. PMID: 33154136.

280.Hannah Lu, Cortney Weintz, Joseph Pace, Dhiraj Indana, Kevin Linka \& Ellen Kuhl (2021) Are college campuses superspreaders? A data-driven modeling study, Computer Methods in Biomechanics and Biomedical Engineering, DOI: 10.1080/10255842.2020.1869221

281.Elena Losina, Valia Leifer, Lucia Millham, et al. College Campuses and COVID-19 Mitigation: Clinical and Economic Value. Annals of Internal Medicine. [Epub ahead of print 21 December 2020]. doi:10.7326/M20-6558

282.Sanchez-Vazquez R, Guio-Carrion A, Zapatero-Gaviria A, Martinez P, Blasco MA. Shorter telomere lengths in patients with severe COVID-19 disease. Aging (Albany NY). 2021; 13:1-15. https://doi.org/10.18632/aging.202463 
283.Pietrobon AJ, Teixeira FME and Sato MN (2020). Immunosenescence and Inflammaging: Risk Factors of Severe COVID-19 in Older People. Frontiers in Immunology. 11:579220. doi: 10.3389/fimmu.2020.579220

284.Di Micco, R., Krizhanovsky, V., Baker, D. et al. Cellular senescence in ageing: from mechanisms to therapeutic opportunities. Nature Reviews Molecular Cell Biology 22, 75-95 (2021). https://doi.org/10.1038/s41580-020-00314-w

285.Lynne S Cox, Ilaria Bellantuono, Janet M Lord, et al. Tackling immunosenescence to improve COVID-19 outcomes and vaccine response in older adults, The Lancet Healthy Longevity, Volume 1, Issue 2, 2020, https://doi.org/10.1016/S2666-7568(20)30011-8.

286. The Severe Covid-19 GWAS Group. Genomewide Association Study of Severe Covid-19 with Respiratory Failure. 2020, The New England Journal of Medicine 2020; 383:1522-1534, DOI: 10.1056/NEJMoa2020283

287. Bhanu Kanth Manne, Frederik Denorme, Elizabeth A. Middleton, et al. Platelet gene expression and function in patients with COVID-19. Blood 2020; 136 (11): 1317-1329. doi: https://doi.org/10.1182/blood.2020007214

288. Christoph B. Messner, Vadim Demichev, Daniel Wendisch, et al. Ultra-High-Throughput Clinical Proteomics Reveals Classifiers of COVID-19 Infection, Cell Systems 11, 2020, https://doi.org/10.1016/j.cels.2020.05.012.

289.van der Made CI, Simons A, Schuurs-Hoeijmakers J, et al. Presence of Genetic Variants Among Young Men With Severe COVID-19. JAMA. 2020;324(7):663-673. doi:10.1001/jama.2020.13719

290.Chia-Ling Kuo, Luke C Pilling, Janice L Atkins, et al. APOE e4 Genotype Predicts Severe COVID-19 in the UK Biobank Community Cohort, The Journals of Gerontology: Series A, Volume 75, Issue 11, November 2020, Pages 2231-2232, https://oi.org/10.1093/gerona/glaa131

291.Zeberg, H., Pääbo, S. The major genetic risk factor for severe COVID-19 is inherited from Neanderthals. Nature 587, 610-612 (2020). https://doi.org/10.1038/s41586-020-2818-3

292.Pairo-Castineira, E., Clohisey, S., Klaric, L. et al. Genetic mechanisms of critical illness in Covid19. Nature (2020). https://doi.org/10.1038/s41586-020-03065-y

293. Austin Nguyen, Julianne K. David, Sean K. Maden, et al. Human Leukocyte Antigen Susceptibility Map for Severe Acute Respiratory Syndrome Coronavirus 2. Journal of Virology Jun 2020, 94 (13) e00510-20; DOI: 10.1128/JVI.00510-20

294. Manuel Castro de Moura, Veronica Davalos, Laura Planas-Serra, et al. Epigenome-wide association study of COVID-19 severity with respiratory failure, EBioMedicine, 2021, 103339, ISSN 2352-3964, https://doi.org/10.1016/j.ebiom.2021.103339.

295.Zuo Y, Estes SK, Ali RA, et al. Prothrombotic autoantibodies in serum from patients hospitalized with COVID-19. Science Translational Medicine. 2020 Nov 18;12(570):eabd3876. doi: 10.1126/scitranslmed.abd3876. Epub 2020 Nov 2. PMID: 33139519; PMCID: PMC7724273.

296. Matthew C. Woodruff, Richard P. Ramonell, F. Eun-Hyung Lee, Ignacio Sanz. Clinically identifiable autoreactivity is common in severe SARS-CoV-2 Infection. medRxiv; doi: https://doi.org/10.1101/2020.10.21.20216192

297.Woodruff, M.C., Ramonell, R.P., Nguyen, D.C. et al. Extrafollicular B cell responses correlate with neutralizing antibodies and morbidity in COVID-19. Nature Immunology 21, 1506-1516 (2020). https://doi.org/10.1038/s41590-020-00814-Z

298. Chaolin Huang, Lixue Huang, Yeming Wang, et al. 6-month consequences of COVID-19 in patients discharged from hospital: a cohort study, The Lancet, Volume 397, Issue 10270, 2021, https://doi.org/10.1016/S0140-6736(20)32656-8.

299.Zhang L, Richards A, Barrasa MI, et al. Reverse-transcribed SARS-CoV-2 RNA can integrate into the genome of cultured human cells and can be expressed in patient-derived tissues. Proceedings of the National Academy of Sciences of the U.S.A, PNAS. 2021 May 25;118(21):e2105968118. doi: 10.1073/pnas.2105968118. PMID: 33958444.

300. Anna Schultze, Alex J Walker, Brian MacKenna, et al. Risk of COVID-19-related death among patients with chronic obstructive pulmonary disease or asthma prescribed inhaled corticosteroids: an observational cohort study using the OpenSAFELY platform, The Lancet Respiratory Medicine, Volume 8, Issue 11, 2020, https://doi.org/10.1016/S2213-2600(20)30415-X.

301.Kow, C.S., Capstick, T. and Hasan, S.S. (2021), Are severe asthma patients at higher risk of developing severe outcomes from COVID-19? Allergy. https://doi.org/10.1111/all.14589

302.Heffler, E., Detoraki, A., Contoli, et al. (2021), COVID-19 in Severe Asthma Network in Italy (SANI) patients: Clinical features, impact of comorbidities and treatments. Allergy. https://doi.org/10.1111/all.14532 
303.Junqing Yue, Lu Qin, Cong Zhang, Min Xie, Reply, Journal of Allergy and Clinical Immunology, Volume 146, 2020, https://doi.org/10.1016/j.jaci.2020.06.002.

304. Smith SJ, Busby J, Heaney LG, et al. The impact of the first COVID19 surge on Severe Asthma Patients in the UK. Which is worse: The virus or the lockdown?. ERJ Open Research 2020; https://doi.org/10.1183/23120541.00768-2020.

305. Muñoz X, Pilia F, Ojanguren I, et al. Is asthma a risk factor for COVID-19? Are phenotypes important? ERJ Open Research 2020; https://doi.org/10.1183/23120541.00216-2020.

306.Peter AB Wark, Prabuddha S. Pathinayake, Gerard Kaiko, et al. ACE2 Expression is elevated in Airway Epithelial Cells from aged and male donors but reduced in asthma. medRxiv; doi: https://doi.org/10.1101/2020.07.26.20162248

307. Branco ACCC, Sato MN, Alberca RW. (2020). The Possible Dual Role of the ACE2 Receptor in Asthma and Coronavirus (SARS-CoV2) Infection. Frontiers in Cellular and Infection Microbiology. 10:550571. doi: 10.3389/fcimb.2020.550571

308. Yao, Y, Wang, H, Liu, Z. Expression of ACE2 in airways: Implication for COVID-19 risk and disease management in patients with chronic inflammatory respiratory diseases. Clinical and Experimental Allergy. 2020; 50: 1313- 1324. https://doi.org/10.1111/cea.13746

309. Tizabi, Y., Getachew, B., Copeland, R.L. and Aschner, M. (2020), Nicotine and the nicotinic cholinergic system in COVID-19. The FEBS Journal, 287: 3656-3663. https://doi.org/10.1111/febs.15521

310. Gonzalez-Rubio J, Navarro-Lopez C, Lopez-Najera E, et al. (2020) Cytokine Release Syndrome (CRS) and Nicotine in COVID-19 Patients: Trying to Calm the Storm. Frontiers in Immunology. 11:1359. doi: 10.3389/fimmu.2020.01359

311.Zheng, D., Liwinski, T., Elinav, E. Interaction between microbiota and immunity in health and disease. Cell Research 30, 492-506 (2020). https://doi.org/10.1038/s41422-020-0332-7

312. Bo Shen, Xiao Yi, Yaoting Sun, et al. Proteomic and Metabolomic Characterization of COVID19 Patient Sera, Cell, Volume 182, Issue 1, 2020, https://doi.org/10.1016/j.cell.2020.05.032.

313. Wanglong Gou, Yuanqing Fu, Liang Yue, et al. Gut microbiota may underlie the predisposition of healthy individuals to COVID-19. medRxiv; doi: https://doi.org/10.1101/2020.04.22.20076091

314. Silan Gu, Yanfei Chen, Zhengjie Wu, et al. Alterations of the Gut Microbiota in Patients With Coronavirus Disease 2019 or H1N1 Influenza, Clinical Infectious Diseases, Volume 71, Issue 10, 15 November 2020, Pages 2669-2678, https://doi.org/10.1093/cid/ciaa709

315.Zuo T, Liu Q, Zhang F, et al. Depicting SARS-CoV-2 faecal viral activity in association with gut microbiota composition in patients with COVID-19. Gut 2021;70:276-284. DOI: 10.1136/gutjnl2020-322294

316. Tao Zuo, Hui Zhan, Fen Zhang, et al. Alterations in Fecal Fungal Microbiome of Patients With COVID-19 During Time of Hospitalization until Discharge, Gastroenterology, Volume 159, Issue 4, 2020, https://doi.org/10.1053/j.gastro.2020.06.048.

317.Ferreira, C.; Viana, S.D.; Reis, F. Gut Microbiota Dysbiosis-Immune HyperresponseInflammation Triad in Coronavirus Disease 2019 (COVID-19): Impact of Pharmacological and $\begin{array}{lllll}\text { Nutraceutical } & \text { Approaches. } & \text { Microorganisms } & 2020, & 8,\end{array}$ https://doi.org/10.3390/microorganisms8101514

318.Rao, M., Gershon, M. The bowel and beyond: the enteric nervous system in neurological disorders. Nature Reviews Gastroenterology \& Hepatology 13, 517-528 (2016). https://doi.org/10.1038/nrgastro.2016.107

319. Thomaz F S Bastiaanssen, Caitlin S M Cowan, Marcus J Claesson, Timothy G Dinan, John F Cryan, Making Sense of ... the Microbiome in Psychiatry, International Journal of Neuropsychopharmacology, Volume 22, Issue 1, January 2019, Pages 37-52, https://doi.org/10.1093/ijnp/pyy067

320. Sinagra E, Utzeri E, Morreale GC, Fabbri C, Pace F, Anderloni A. Microbiota-gut-brain axis and its affect inflammatory bowel disease: Pathophysiological concepts and insights for clinicians. World Journal of Clinical Cases 2020; 8(6): 1013-1025. doi: 10.12998/wjcc.v8.i6.1013

321.M. Canal-Rivero, R. Catalán-Barragán, A. Rubio-García, et al. Lower risk of SARS-CoV2 infection in individuals with severe mental disorders on antipsychotic treatment: A retrospective epidemiological study in a representative Spanish population. Schizophrenia Research. Volume 229, 2021, Pages 53-54, ISSN 0920-9964, https://doi.org/10.1016/j.schres.2021.02.002.

322. Crespo-Facorro B, Ruiz-Veguilla M, Vázquez-Bourgon J, et al. Aripiprazole as a Candidate Treatment of COVID-19 Identified Through Genomic Analysis. Frontiers in Pharmacology. 12:646701. (2021). doi: 10.3389/fphar.2021.646701 
323. Breit S, Kupferberg A, Rogler G, Hasler G (2018) Vagus Nerve as Modulator of the Brain-Gut Axis in Psychiatric and Inflammatory Disorders. Frontiers in Psychiatry 9:44. doi: $10.3389 /$ fpsyt.2018.00044

324. Bonaz B, Bazin T and Pellissier S (2018) The Vagus Nerve at the Interface of the Microbiota-GutBrain Axis. Frontiers in Neuroscience. 12:49. doi: 10.3389/fnins.2018.00049

325.Jeon, SM., Shin, EA. Exploring vitamin D metabolism and function in cancer. Experimental \& Molecular Medicine 50, 20 (2018). https://doi.org/10.1038/s12276-018-0038-9

326. Charoenngam, N.; Holick, M.F. Immunologic Effects of Vitamin D on Human Health and Disease. Nutrients 2020, 12, 2097. https://doi.org/10.3390/nu12072097

327.Merzon, E., Tworowski, D., Gorohovski, A., et al. Low plasma $25(\mathrm{OH})$ vitamin D level is associated with increased risk of COVID-19 infection: an Israeli population-based study. The FEBS Journal, 287: 3693-3702. (2020). https://doi.org/10.1111/febs.15495

328. Karahan, S., Katkat, F. Impact of Serum 25(OH) Vitamin D Level on Mortality in Patients with COVID-19 in Turkey. The journal of nutrition, health \& aging (2020). https://doi.org/10.1007/s12603-020-1479-0

329.Kaufman HW, Niles JK, Kroll MH, Bi C, Holick MF (2020). SARS-CoV-2 positivity rates associated with circulating 25-hydroxyvitamin D levels. PLOS ONE 15(9): e0239252. https://doi.org/10.1371/journal.pone.0239252

330. Thomas, R.L., Jiang, L., Adams, J.S. et al. Vitamin D metabolites and the gut microbiome in older men. Nature Communications 11, 5997 (2020). https://doi.org/10.1038/s41467-020-19793-8

331.Holford, P.; Carr, A.C.; Jovic, T.H.; et al. Vitamin C-An Adjunctive Therapy for Respiratory Infection, Sepsis and COVID-19. Nutrients 2020, 12, 3760. https://doi.org/10.3390/nu12123760

332. Chiscano-Camón, L., Ruiz-Rodriguez, J., Ruiz-Sanmartin, A. et al. Vitamin C levels in patients with SARS-CoV-2-associated acute respiratory distress syndrome. Critical Care 24, 522 (2020). https://doi.org/10.1186/s13054-020-03249-y

333. Wessels I, Rolles B and Rink L (2020) The Potential Impact of Zinc Supplementation on COVID19 Pathogenesis. Frontiers in Immunology. 11:1712. doi: 10.3389/fimmu.2020.01712

334.Rahman, M.T., Idid, S.Z. Can Zn Be a Critical Element in COVID-19 Treatment? Biological Trace Element Research 199, 550-558 (2021). https://doi.org/10.1007/s12011-020-02194-9

335.Jennifer A. frontera, Joseph O. Rahimian, Shadi Yaghi et al. Treatment with Zinc is Associated with Reduced In-Hospital Mortality Among COVID-19 Patients: A Multi-Center Cohort Study, 26 October 2020, PREPRINT (Version 1) available at Research Square [https://doi.org/10.21203/rs.3.rs-94509/v1]

336. Jinsong Zhang, Ramy Saad, Ethan Will Taylor, Margaret P. Rayman, Selenium and selenoproteins in viral infection with potential relevance to COVID-19, Redox Biology, Volume 37, 2020, 101715, ISSN 2213-2317, https://doi.org/10.1016/j.redox.2020.101715.

337. Sheybani Z, Dokoohaki MH, Negahdaripour M, et al. The Role of Folic Acid in the Management of Respiratory Disease Caused by COVID-19. ChemRxiv; 2020. DOI: 10.26434/chemrxiv.12034980.v1

338. Calder PC. Marine omega-3 fatty acids and inflammatory processes: Effects, mechanisms and clinical relevance. Biochimica et Biophysica Acta (BBA) - Molecular and Cell Biology of Lipids. 2015 Apr;1851(4):469-84. doi: 10.1016/j.bbalip.2014.08.010. Epub 2014 Aug 20. PMID: 25149823.

339. Arash Asher, Nathan L. Tintle, Michael Myers, Laura Lockshon, Heribert Bacareza, William S. Harris. Blood omega-3 fatty acids and death from COVID-19: A pilot study. Prostaglandins, Leukotrienes and Essential Fatty Acids. Volume 166, 2021, 102250, https://doi.org/10.1016/j.plefa.2021.102250.

340.GISAID. Available at: https://www.gisaid.org/ (accessed: 8 June 2021)

341.Jason W. Rausch, Adam A. Capoferri, Mary Grace Katusiime, Sean C. Patro, Mary F. Kearney. Low genetic diversity may be an Achilles heel of SARS-CoV-2. Proceedings of the National Academy of Sciences Oct 2020, 117 (40) 24614-24616; DOI: 10.1073/pnas.2017726117

342.Plante, J.A., Liu, Y., Liu, J. et al. Spike mutation D614G alters SARS-CoV-2 fitness. Nature (2020). https://doi.org/10.1038/s41586-020-2895-3

343.S. Wesley Long, Randall J. Olsen, Paul A. Christensen, et al. Molecular Architecture of Early Dissemination and Massive Second Wave of the SARS-CoV-2 Virus in a Major Metropolitan Area. mBio. Oct 2020, 11 (6) e02707-20; DOI: 10.1128/mBio.02707-20

344. Bette Korber, Will M. Fischer, Sandrasegaram Gnanakaran, et al. Tracking Changes in SARSCoV-2 Spike: Evidence that D614G Increases Infectivity of the COVID-19 Virus, Cell, Volume 182, Issue 4, 2020, Pages 812-827.e19, ISSN 0092-8674, https://doi.org/10.1016/j.cell.2020.06.043. 
345.Erik Volz, Verity Hill, John T. McCrone, et al. Evaluating the Effects of SARS-CoV-2 Spike Mutation D614G on Transmissibility and Pathogenicity, Cell, Volume 184, Issue 1, 2021, Pages 64-75.e11, ISSN 0092-8674, https://doi.org/10.1016/j.cell.2020.11.020.

346. Tomaszewski T, DeVries RS, Dong M, Bhatia G, Norsworthy MD, Zheng X, Caetano-Anollés G. New Pathways of Mutational Change in SARS-CoV-2 Proteomes Involve Regions of Intrinsic Disorder Important for Virus Replication and Release. Evolutionary Bioinformatics Online. 2020 Oct 23;16:1176934320965149. doi: 10.1177/1176934320965149. PMID: 33149541; PMCID: PMC7586267.

347. Yiwen Zhang, Junsong Zhang, Yingshi Chen, et al. The ORF8 Protein of SARS-CoV-2 Mediates Immune Evasion through Potently Downregulating MHC-I. bioRxiv. 2020.05.24.111823; doi: https://doi.org/10.1101/2020.05.24.111823

348. Barnaby E Young, Siew-Wai Fong, Yi-Hao Chan, et al. Effects of a major deletion in the SARSCoV-2 genome on the severity of infection and the inflammatory response: an observational cohort study, The Lancet, Volume 396, Issue 10251, 2020, Pages 603-611, ISSN 0140-6736, https://doi.org/10.1016/S0140-6736(20)31757-8.

349.Emma B. Hodcroft, Moira Zuber, Sarah Nadeau, et al. Emergence and spread of a SARS-CoV-2 variant through Europe in the summer of 2020. SeqCOVID-SPAIN consortium, Tanja Stadler, Richard A. Neher. medRxiv. 2020.10.25.20219063; doi: https://doi.org/10.1101/2020.10.25.20219063

350.Kemp, S.A., Collier, D.A., Datir, R.P. et al. SARS-CoV-2 evolution during treatment of chronic infection. Nature (2021). https://doi.org/10.1038/s41586-021-03291-y

351. Teresa Aydillo, Ana S. Gonzalez-Reiche, Sadaf Aslam, et al. Shedding of Viable SARS-CoV-2 after Immunosuppressive Therapy for Cancer. The New England Journal of Medicine 2020; 383:2586-2588. DOI: 10.1056/NEJMc2031670

352.Bazykin GA, Stanevich O, Danilenko D, et al. Emergence of Y453F and $\Delta 69-70 \mathrm{HV}$ mutations in a lymphoma patient with long-term COVID-19. Virological. Available at: https:/virological.org/t/emergence-of-y453f-and-69-70hv-mutations-in-a-lymphoma-patientwith-long-term-covid-19/580 (accessed: 8 June 2021)

353.European Centre for Disease Prevention and Control. Threat Assessment Brief: Rapid increase of a SARS-CoV-2 variant with multiple spike protein mutations observed in the United Kingdom. 20 Dec 2020. Available at: https://www.ecdc.europa.eu/en/publications-data/threat-assessmentbrief-rapid-increase-sars-cov-2-variant-united-kingdom

354.Jadson C. Santos, Geraldo A. Passos. The high infectivity of SARS-CoV-2 B.1.1.7 is associated with increased interaction force between Spike-ACE2 caused by the viral N501Y mutation. bioRxiv; doi: https://doi.org/10.1101/2020.12.29.424708

355. Andrew Rambaut, Nick Loman, Oliver Pybus, et al. on behalf of COVID-19 Genomics Consortium UK (CoG-UK). Preliminary genomic characterisation of an emergent SARS-CoV-2 lineage in the UK defined by a novel set of spike mutations. Virological. Available at: https://virological.org/t/preliminary-genomic-characterisation-of-an-emergent-sars-cov-2lineage-in-the-uk-defined-by-a-novel-set-of-spike-mutations/563 (accessed: 8 June 2021)

356.Kissler, Stephen, Joseph R. Fauver, Christina Mack, Caroline G. Tai, Mallery I. Breban, et al. "Densely sampled viral trajectories suggest longer duration of acute infection with B.1.1.7 variant relative to non-B.1.1.7 SARS-CoV-2." Preprint, 2021. Available at https://nrs.harvard.edu/URN3:HUL.INSTREPOS:37366884

357.Erik Volz, Swapnil Mishra, Meera Chand, et al. The COVID-19 Genomics UK (COG-UK) consortium, Seth Flaxman, Oliver Ratmann, Samir Bhatt, Susan Hopkins, Axel Gandy, Andrew Rambaut, Neil M Ferguson. medRxiv; doi: https://doi.org/10.1101/2020.12.30.20249034

358. Challen R, Brooks-Pollock E, Read J M, et al. Risk of mortality in patients infected with SARSCoV-2 variant of concern 202012/1: matched cohort study. BMJ 2021; 372:n579 doi:10.1136/bmj.n579

359. Dan Frampton, Tommy Rampling, Aidan Cross, et al. Genomic characteristics and clinical effect of the emergent SARS-CoV-2 B.1.1.7 lineage in London, UK: a whole-genome sequencing and hospital-based cohort study, The Lancet Infectious Diseases, 2021, ISSN 1473-3099, https://doi.org/10.1016/S1473-3099(21)00170-5.

360. Mark S Graham, Carole H Sudre, Anna May, et al. Changes in symptomatology, reinfection, and transmissibility associated with the SARS-CoV-2 variant B.1.1.7: an ecological study, The Lancet Public Health, 2021, ISSN 2468-2667, https://doi.org/10.1016/S2468-2667(21)00055-4.

361.Houriiyah Tegally, Eduan Wilkinson, Marta Giovanetti, et al. Emergence and rapid spread of a new severe acute respiratory syndrome-related coronavirus 2 (SARS-CoV-2) lineage with 
multiple spike mutations in South Africa. medRxiv. doi: https://doi.org/10.1101/2020.12.21.20248640

362.Luca Piccoli, Young-Jun Park, M. Alejandra Tortorici, et al. Mapping Neutralizing and Immunodominant Sites on the SARS-CoV-2 Spike Receptor-Binding Domain by StructureGuided High-Resolution Serology, Cell, Volume 183, Issue 4, 2020, Pages 1024-1042.e21, ISSN 0092-8674, https://doi.org/10.1016/j.cell.2020.09.037.

363. Allison J. Greaney, Andrea N. Loes, Katharine H.D. Crawford, et al. Comprehensive mapping of mutations to the SARS-CoV-2 receptor-binding domain that affect recognition by polyclonal human serum antibodies. bioRxiv. doi: https://doi.org/10.1101/2020.12.31.425021

364. Allison J. Greaney, Tyler N. Starr, Pavlo Gilchuk, et al. Comprehensive mapping of mutations in the SARS-CoV-2 receptor-binding domain that affect recognition by polyclonal human plasma antibodies. Cell Host \& Microbe. 2021. Vol. 29, issue 3, P463-476.E6. doi: https://doi.org/10.1016/j.chom.2021.02.003

365.Wang, P., Nair, M.S., Liu, L. et al. Antibody resistance of SARS-CoV-2 variants B.1.351 and B.1.1.7. Nature (2021). https://doi.org/10.1038/s41586-021-03398-2

366. Yang Liu, Jianying Liu, Hongjie Xia, et al. Neutralizing Activity of BNT162b2-Elicited Serum Preliminary Report. The New England Journal of Medicine. 2021. DOI: 10.1056/NEJMc2102017

367. Xuping Xie, Jing Zou, Camila R. Fontes-Garfias, et al. Neutralization of N501Y mutant SARSCoV-2 by BNT162b2 vaccine-elicited sera. bioRxiv. doi: https://doi.org/10.1101/2021.01.07.425740

368.Eric J Haas, Frederick J Angulo, John M McLaughlin, et al. Impact and effectiveness of mRNA BNT162b2 vaccine against SARS-CoV-2 infections and COVID-19 cases, hospitalisations, and deaths following a nationwide vaccination campaign in Israel: an observational study using national surveillance data, The Lancet, 2021, ISSN 0140-6736, https://doi.org/10.1016/S01406736(21)00947-8.

369. Noa Dagan, Noam Barda, Eldad Kepten, et al. BNT162b2 mRNA Covid-19 Vaccine in a Nationwide Mass Vaccination Setting. New England Journal of Medicine, 2021; 384:1412-1423. DOI: 10.1056/NEJMoa2101765

370.Andreas Greinacher, M.D., Thomas Thiele, M.D., Theodore E. Warkentin, et al. Thrombotic Thrombocytopenia after ChAdOx1 nCov-19 Vaccination. The New England Journal of Medicine. 2021. DOI: 10.1056/NEJMoa2104840

371.Eric Kowarz, Lea Krutzke, Jenny Reis et al. "Vaccine-Induced Covid-19 Mimicry" Syndrome: Splice reactions within the SARS-CoV-2 Spike open reading frame result in Spike protein variants that may cause thromboembolic events in patients immunized with vector-based vaccines, 26 May 2021, PREPRINT (Version 1) available at Research Square, https://doi.org/10.21203/rs.3.rs$558954 / \mathrm{v} 1$

372. Anton Pottegård, Lars Christian Lund, Øystein Karlstad, et al. Arterial events, venous thromboembolism, thrombocytopenia, and bleeding after vaccination with Oxford-AstraZeneca ChAdOx1-S in Denmark and Norway: population based cohort study. BMJ. 2021; 373:n1114 doi:10.1136/bmj.n1114

373.Al-Mayhani T, Saber S, Stubbs MJ, et al. Ischaemic stroke as a presenting feature of ChAdOx1 nCoV-19 vaccine-induced immune thrombotic thrombocytopaenia. Journal of Neurology, Neurosurgery \& Psychiatry. 2021. doi: 10.1136/jnnp-2021-326984

374.Paola Cristina Resende, João Felipe Bezerra, Romero Henrique Teixeira de Vasconcelos, et al. Spike E484K mutation in the first SARS-CoV-2 reinfection case confirmed in Brazil. Virological. Available at: https://virological.org/t/spike-e484k-mutation-in-the-first-sars-cov-2-reinfectioncase-confirmed-in-brazil-2020/584 (accessed: 8 June 2021).

375.Emma C. Thomson, Laura E. Rosen, James G. Shepherd, et al. Circulating SARS-CoV-2 spike N439K variants maintain fitness while evading antibody-mediated immunity, Cell, 2021, ISSN 0092-8674, https://doi.org/10.1016/j.cell.2021.01.037.

376. Allison J. Greaney, Tyler N. Starr, Pavlo Gilchuk, et al. Complete Mapping of Mutations to the SARS-CoV-2 Spike Receptor-Binding Domain that Escape Antibody Recognition, Cell Host \& Microbe, Volume 29, Issue 1, 2021, Pages 44-57.e9, ISSN 1931-3128, https://doi.org/10.1016/j.chom.2020.11.007.

377. Starr TN, Greaney AJ, Addetia A, Hannon WW, Choudhary MC, Dingens AS, Li JZ, Bloom JD. Prospective mapping of viral mutations that escape antibodies used to treat COVID-19. Science. 2021 Jan 25:eabf9302. doi: 10.1126/science.abf9302. Epub ahead of print. PMID: 33495308.

378. Hie B, Zhong ED, Berger B, Bryson B. Learning the language of viral evolution and escape. Science. 2021 Jan 15;371(6526):284-288. doi: 10.1126/science.abd7331. PMID: 33446556. 
379.David Adam. What scientists know about new, fast-spreading coronavirus variants. Nature. 2021. https://doi.org/10.1038/d41586-021-01390-4

380.SARS-CoV-2 Variant Classifications and Definitions. Center for Disease Control and Prevention, CDC. Available at: https:/www.cdc.gov/coronavirus/2019-ncov/variants/variant-info.html (accessed: 8 June 2021).

381.SARS-CoV-2 variants dashboard. European Center for Disease Prevention and Control, eCDC. Available at: https://www.ecdc.europa.eu/en/covid-19/situation-updates/variants-dashboard (accessed: 8 June 2021)

382. Alison Tarke, John Sidney, Conner K. Kidd, et al. Comprehensive analysis of $\mathrm{T}$ cell immunodominance and immunoprevalence of SARS-CoV-2 epitopes in COVID-19 cases, Cell Reports Medicine, Volume 2, Issue 2, 2021, ISSN 2666-3791, https://doi.org/10.1016/j.xcrm.2021.100204.

383. Alison Tarke, John Sidney, Nils Methot, et al. Negligible impact of SARS-CoV-2 variants on CD4+ and CD8+ $\mathrm{T}$ cell reactivity in COVID-19 exposed donors and vaccinees. bioRxiv 2021.02.27.433180; doi: https://doi.org/10.1101/2021.02.27.433180

384.Jingjiao Li, Mingquan Guo, Xiaoxu Tian, et al. Virus-Host Interactome and Proteomic Survey Reveal Potential Virulence Factors Influencing SARS-CoV-2 Pathogenesis. Med. Vol. 2, issue 1, P99-112.E7. 2021. doi: https://doi.org/10.1016/j.medj.2020.07.002

385. Chase W Nelson, Zachary Ardern, Tony L Goldberg, et al. Dynamically evolving novel overlapping gene as a factor in the SARS-CoV-2 pandemic. eLife 2020;9:e59633 DOI: 10.7554/eLife.59633

386. Golchin, A. Cell-Based Therapy for Severe COVID-19 Patients: Clinical Trials and Cost-Utility. Stem Cell Reviews and Reports (2020). https://doi.org/10.1007/s12015-020-10046-1

387.Fermín Sánchez-Guijo, Mariano García-Arranz, Miriam López-Parra, et al. Adipose-derived mesenchymal stromal cells for the treatment of patients with severe SARS-CoV-2 pneumonia requiring mechanical ventilation. A proof of concept study, EClinicalMedicine, Volume 25, 2020, 100454, ISSN 2589-5370, https://doi.org/10.1016/j.eclinm.2020.100454.

388. Safety and the Efficacy of MesenCure for the Treatment of Pulmonary Manifestations of COVID19. ClinicalTrials.gov Identifier: NCT04716998. Last Update Posted: January 22, 2021. Available at: https://clinicaltrials.gov/ct2/show/NCT04716998

389.C Ferreras, B Pascual-Miguel, C Mestre-Durán, et al. SARS-CoV-2 specific memory T lymphocytes from COVID-19 convalescent donors: identification, biobanking and large-scale production for Adoptive Cell Therapy. Frontiers in Cell and Developmental Biology. 9:620730. 2021. doi: https://doi.org/10.3389/fcell.2021.620730

390. Safety Infusion of NatuRal KillEr celLs or MEmory T Cells as Adoptive Therapy in COVID-19 pnEumonia or Lymphopenia (RELEASE). ClinicalTrials.gov Identifier: NCT04578210. Last Update Posted: October 19, 2020. Available at: https:/clinicaltrials.gov/ct2/show/NCT04578210

391.Dance A. Core Concept: CRISPR gene editing. Proceedings of the National Academy of Sciences of the United States of America. 2015 May 19;112(20):6245-6. doi: 10.1073/pnas.1503840112. PMID: 25991847; PMCID: PMC4443382.

392. Joel McDade. Genome-wide Screening Using CRISPR. Updated on Aug 20, 2020. Available at: https://blog.addgene.org/genome-wide-screening-using-crispr/cas9

393. Timothy R. Abbott, Girija Dhamdhere, Yanxia Liu, et al. Development of CRISPR as an Antiviral Strategy to Combat SARS-CoV-2 and Influenza, Cell, Volume 181, Issue 4, 2020, Pages 865876.e12, ISSN 0092-8674, https://doi.org/10.1016/j.cell.2020.04.020.

394.Jin Wei, Mia Madel Alfajaro, Peter C. DeWeirdt, et al. Genome-wide CRISPR Screens Reveal Host Factors Critical for SARS-CoV-2 Infection, Cell, Volume 184, Issue 1, 2021, Pages 7691.e13, ISSN 0092-8674, https://doi.org/10.1016/j.cell.2020.10.028.

395.Zharko Daniloski, Tristan X. Jordan, Hans-Hermann Wessels, et al. Identification of Required Host Factors for SARS-CoV-2 Infection in Human Cells, Cell, Volume 184, Issue 1, 2021, Pages 92-105.e16, ISSN 0092-8674, https://doi.org/10.1016/j.cell.2020.10.030.

396. Julia Joung, Alim Ladha, Makoto Saito, et al. Detection of SARS-CoV-2 with SHERLOCK OnePot Testing. The New England Journal of Medicine 2020; 383:1492-1494. DOI: 10.1056/NEJMc2026172

397.Gribble, J., Stevens, L. J., Agostini, M.L., et al. The coronavirus proofreading exoribonuclease mediates extensive viral recombination. PLOS Pathogens 17(1). 2021. https://doi.org/10.1371/journal.ppat.1009226

398.Ester C Sabino, Lewis F Buss, Maria P S Carvalho, et al. Resurgence of COVID-19 in Manaus, Brazil, despite high seroprevalence, The Lancet, 2021, ISSN 0140-6736, https://doi.org/10.1016/S0140-6736(21)00183-5. 